\title{
Critical Causes of Degradation in Integrated Laboratory Scale Cells During High-Temperature Electrolysis
}

M. S. Sohal

J. E. O'Brien

C. M. Stoots

J. S. Herring

J. J. Hartvigsen

D. Larsen

S. Elangovan

J. D. Carter

V. I. Sharma

B. Yildiz

May 2009

The INL is a U.S. Department of Energy National Laboratory operated by Battelle Energy Alliance

Idaho National Laboratory 
INL/EXT-09-16004

\title{
Critical Causes of Degradation in Integrated Laboratory Scale Cells During High-Temperature Electrolysis
}

\author{
M. S. Sohal \\ J. E. O'Brien \\ C. M. Stoots \\ J. S. Herring \\ J. J. Hartvigsen ${ }^{1}$ \\ D. Larsen ${ }^{1}$ \\ S. Elangovan ${ }^{1}$ \\ J. D. Carter ${ }^{2}$ \\ V. I. Sharma ${ }^{3}$ \\ B. Yildiz ${ }^{3}$ \\ ${ }^{1}$ Ceramatec, Inc. \\ ${ }^{2}$ Argonne National Laboratory \\ ${ }^{3}$ MIT \\ May 2009 \\ Idaho National Laboratory \\ Idaho Falls, Idaho 83415 \\ http://www.inl.gov \\ Prepared for the \\ U.S. Department of Energy \\ Office of Nuclear Energy \\ Under DOE Idaho Operations Office \\ Contract DE-AC07-05ID14517
}




\section{DISCLAIMER}

This information was prepared as an account of work sponsored by an agency of the U.S. Government. Neither the U.S. Government nor any agency thereof, nor any of their employees, makes any warranty, expressed or implied, or assumes any legal liability or responsibility for the accuracy, completeness, or usefulness, of any information, apparatus, product, or process disclosed, or represents that its use would not infringe privately owned rights. References herein to any specific commercial product, process, or service by trade name, trade mark, manufacturer, or otherwise, does not necessarily constitute or imply its endorsement, recommendation, or favoring by the U.S. Government or any agency thereof. The views and opinions of authors expressed herein do not necessarily state or reflect those of the U.S. Government or any agency thereof. 



\section{ABSTRACT}

An ongoing project at Idaho National Laboratory involves generating hydrogen from steam using solid oxide electrolysis cells (SOEC). This report describes background information about SOECs, the Integrated Laboratory Scale (ILS) testing of solid-oxide electrolysis stacks, ILS performance degradation, and post-test examination of SOECs by various researchers. The ILS test was a 720cell, three-module test comprised of 12 stacks of 60 cells each. A peak $\mathrm{H}_{2}$ production rate of $5.7 \mathrm{Nm}^{3} / \mathrm{hr}$ was achieved. Module area-specific resistance ranged from $1.25 \Omega \mathrm{cm}^{2}$ to just over $2 \Omega \mathrm{cm}^{2}$. Total $\mathrm{H}_{2}$ production rate decreased from $5.7 \mathrm{Nm}^{3} / \mathrm{hr}$ to a steady state value of $0.7 \mathrm{Nm}^{3} / \mathrm{hr}$. The decrease was primarily due to cell degradation.

Post test examination by Ceramatec showed that the hydrogen electrode appeared to be in good condition. The oxygen evolution electrode does show delamination in operation and an apparent foreign layer deposited at the electrolyte interface. Post test examination by Argonne National Laboratory showed that the $\mathrm{O}_{2}$-electrode delaminated from the electrolyte near the edge. One possible reason for this delamination is excessive pressure buildup with high $\mathrm{O}_{2}$ flow in the over-sintered region. According to a Massachusetts Institute of Technology post test examination, the electrochemical reactions have been recognized as one of the prevalent causes of their degradation. Specifically, two important degradation mechanisms were examined: (1) transport of $\mathrm{Cr}-$ containing species from steel interconnects into the oxygen electrode and lanthanum strontium chromite bond layers in SOECs, and (2) cation segregation and phase separation in the bond layer.

INL conducted a workshop to discuss possible causes of degradation in a SOEC stack. Generally, it was agreed that the following are major degradation issues relating to SOECs:

- Delamination of the $\mathrm{O}_{2}$-electrode and bond layer on the steam $/ \mathrm{O}_{2}$-electrode side

- Contaminants ( $\mathrm{Ni}, \mathrm{Cr}, \mathrm{Si}$, etc.) on reaction sites (triple phase boundary)

- Loss of electrical/ionic conductivity of electrolyte. 


\section{CONTENTS}

ABSTRACT

ACRONYMS ix

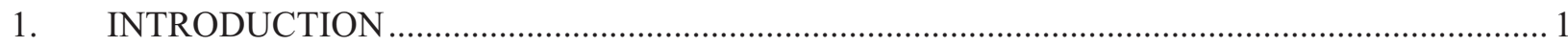

2. INL'S HIGH-TEMPERATURE ELECTROLYSIS PROJECT …................................................ 3

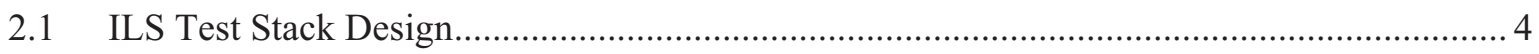

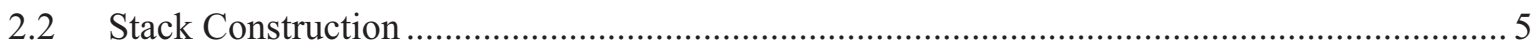

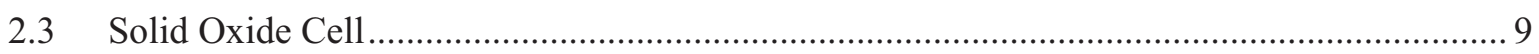

3. POLARIZATION LOSSES (DEGRADATION) IN A SOLID OXIDE CELL............................. 12

4. DEGRADATION PHENOMENA IN SOLID OXIDE ELECTROLYSIS CELLS ....................... 15

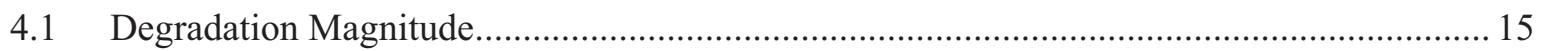

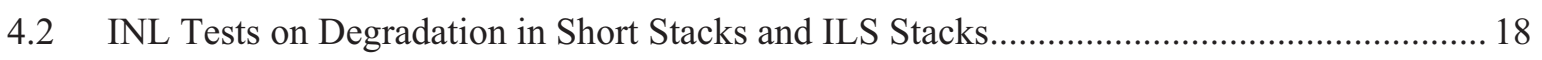

4.3 Discussion on Some Aspects of ILS Test Results............................................................. 22

5. POST-TEST EXAMINATION OF SOLID OXIDE ELECTROLYSIS CELLS...........................25

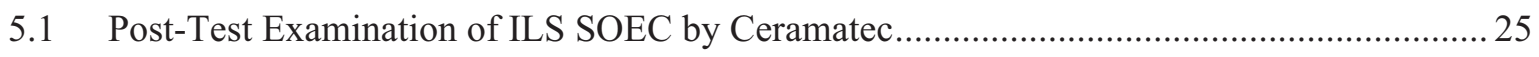

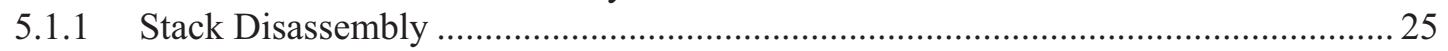

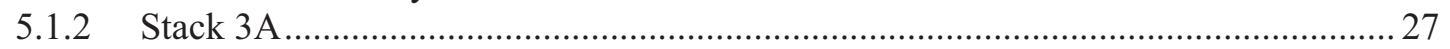

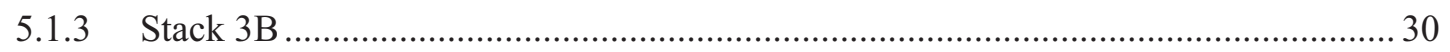

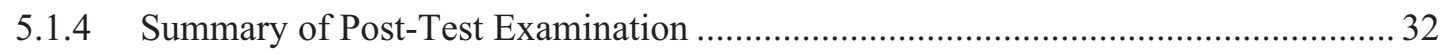

5.2 SEM Analysis of ILS Stack: Stack A, Module 3, Cell 15 .............................................. 32

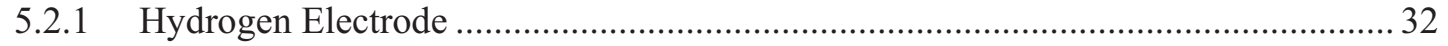

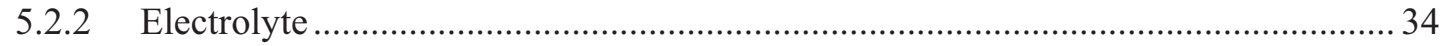

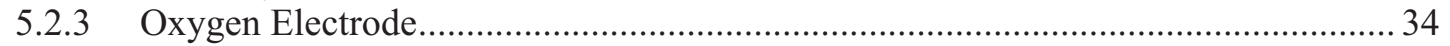

5.2.4 Oxygen Electrode Side Flow Channel (Flow Field) ............................................... 37

5.3 Post-Test Examination of SOEC by Argonne National Laboratory .................................... 39

5.4 Degradation Mechanisms in O2-Electrode Bond Layer in SOEC ...................................... 41

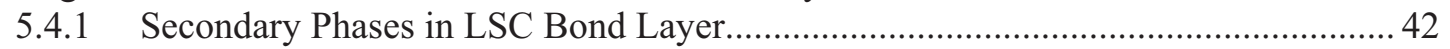

5.4.2 LSC Microstructure and Surface Composition - Auger Electron Spectrocopy Nanoprobe................................................................................... 42

5.4.3 Cation and Secondary Phase Distribution in LSC at the Nano-scale......................... 44

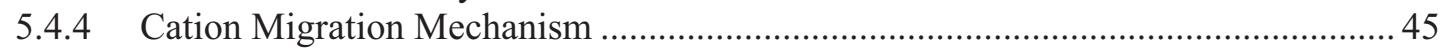

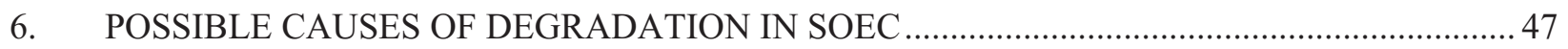

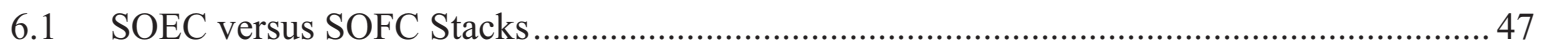

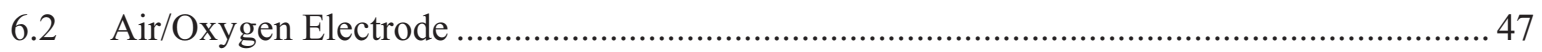

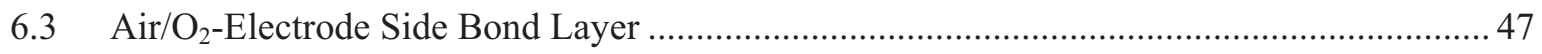

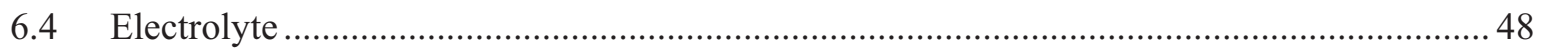

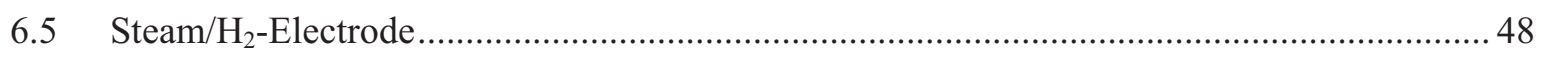

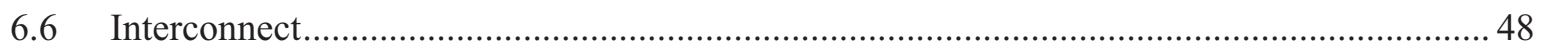

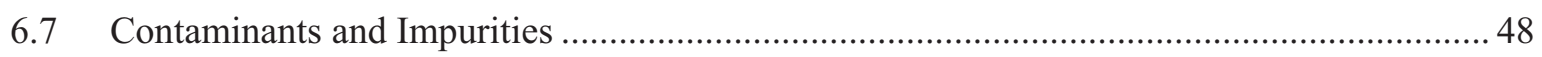


7. SUMMARY OF RESEARCH NEEDS TO MITIGATE SOEC DEGRADATION ........................50

7.1 Electrochemical Phenomena in SOEC Cells and Stacks .................................................. 50

7.2 Electrochemical Phenomena in SOEC Stacks and Cell Material Composition .................... 50

7.3 Modeling Electrochemical Phenomena and Stack Degradation .........................................50

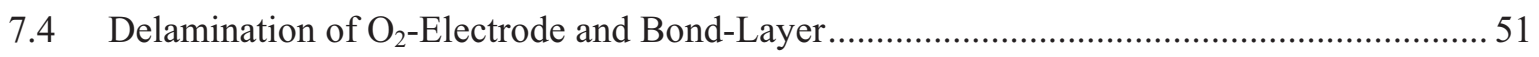

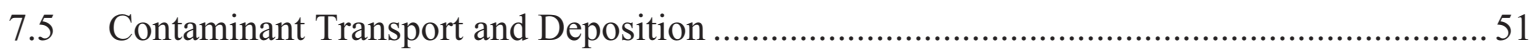

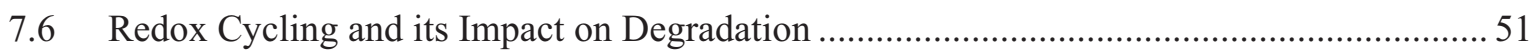

7.7 Interconnects and Seals Related Problems..................................................................... 51

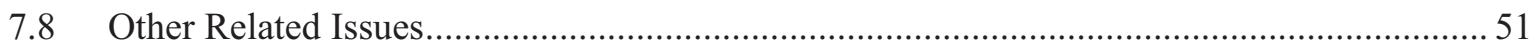

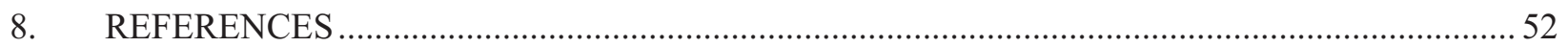

\section{FIGURES}

Figure 1. Schematic of HTE system coupled to an advanced nuclear reactor......................................... 1

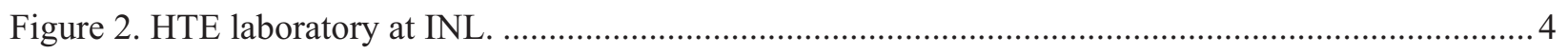

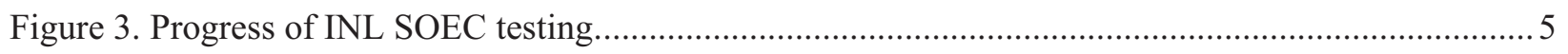

Figure 4. Photograph of installed module and lead placement. .......................................................... 6

Figure 5. Exploded view of heat exchanger, base manifold unit, and four-stack electrolysis unit.............. 8

Figure 6. Installation of electrolysis modules, base manifolds and paired heat exchangers....................... 9

Figure 7. (a) SOEC; (b) solid oxide fuel cell (SOFC) operating in reverse compared to an SOEC

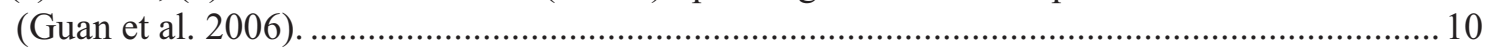

Figure 8. Ceramatec solid oxide cell/stack construction; (scanning electron microscopy figure on

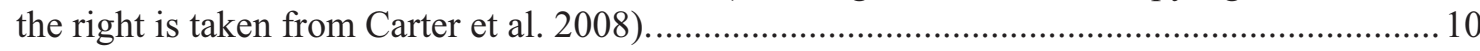

Figure 9. SOFC voltage-current characteristics for a single cell operating at $800^{\circ} \mathrm{C}$ (Windisch et

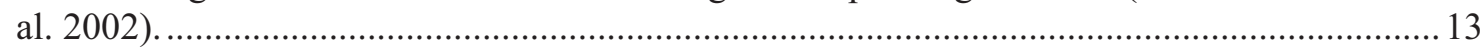

Figure 10. Operating mechanisms of solid oxide cells: (a) a SOEC in electrolysis mode, and (b) a

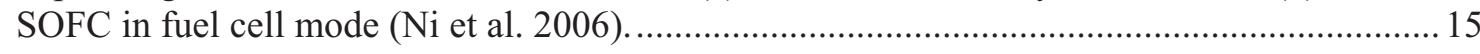

Figure 11. TPBs in a solid oxide cell, shown as red dots, where reactions take place (Hauch 2007a).

Figure 12. Area-specific resistance of a button cell as a function of time for the 1,100-hour test. ............ 19

Figure 13. Area-specific resistance of a 25 -cell stack as a function of time for a 1,000-hour test. ............20

Figure 14. Hydrogen production rates during 1,000-hour long-term test. ............................................. 20

Figure 15. Time history of ILS module ASR values, voltages, and current over 700 hours of

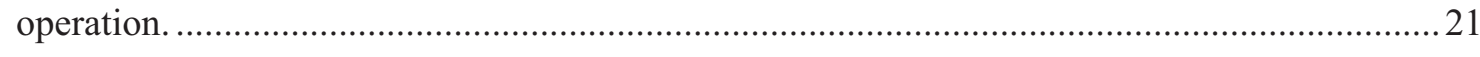

Figure 16. Time history of hydrogen production rate in the ILS. ................................................... 21

Figure 17. Full history of module ASRs and $\mathrm{H}_{2}$ recycle flow rates....................................................2 23

Figure 18. Peak electrolysis power, $\mathrm{H}_{2}$ production rate, and ASRs..................................................... 24 
Figure 19. Time history of electrolyzer power supply amperage and voltage.

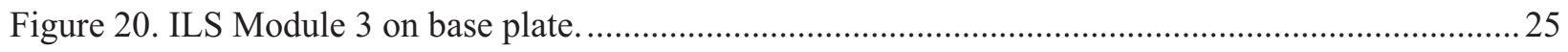

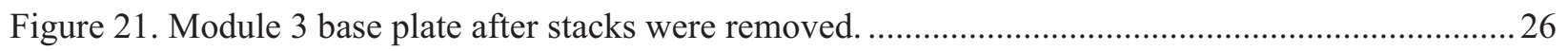

Figure 22. Hydrogen manifold showing green deposit due to gas mixing. ............................................2 27

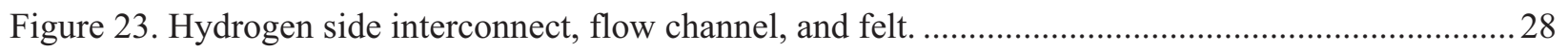

Figure 24. Cell hydrogen electrode after separation from interconnect................................................... 28

Figure 25. Cell and interconnect surfaces from the oxygen electrode side of Cell 18.............................29

Figure 26. Cell and interconnect surfaces from the oxygen electrode side of Cell 19.............................. 30

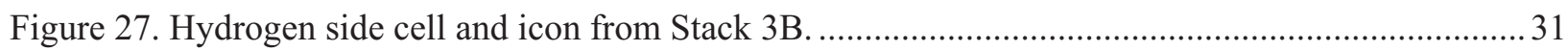

Figure 28. Air electrode of a typical cell from Stack 3B showing less electrode delamination than

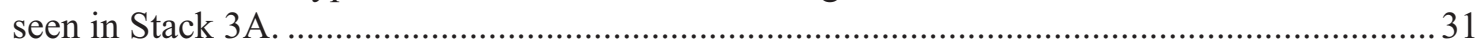

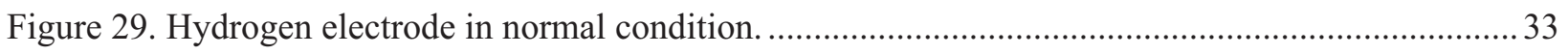

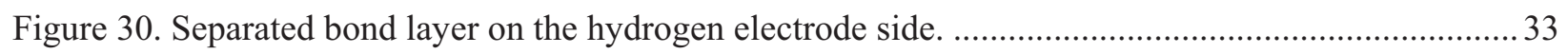

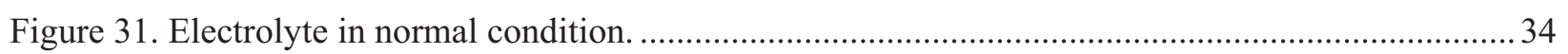

Figure 32. Separation at the oxygen electrode-zirconia electrolyte interface.......................................... 34

Figure 33. EDS picture (on the right) showing only zirconia electrolyte material at the interface. ............35

Figure 34. Separation of oxygen electrode from the electrolyte............................................................ 35

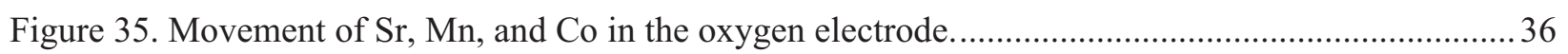

Figure 36. Oxygen electrode side flow channel (flow field) (upper) and oxygen electrode side flow channel-bond layer interface (lower) ........................................................................ 37

Figure 37. Separator plate- hydrogen electrode bond layer interface and hydrogen electrode bond

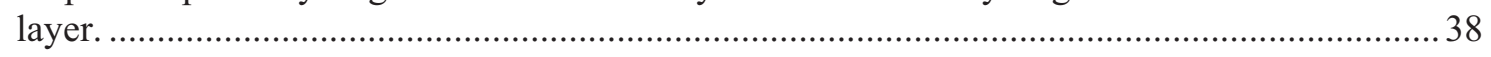

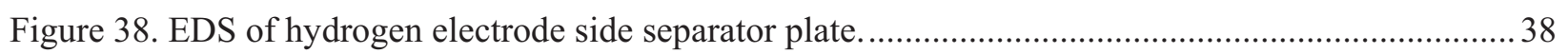

Figure 39. SEM view of the electrolyte and $\mathrm{O}_{2}$-electrode (Mawdsley et al. 2007) .................................. 39

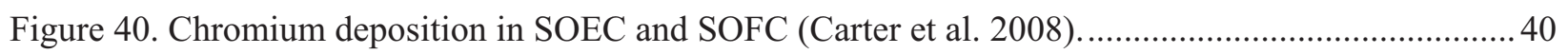

Figure 41. Electrode delamination after $1500 \mathrm{hrs}$ of operation (Carter et al. 2008) ................................. 40

Figure 42. Si capping layer on $\mathrm{H}_{2}$-electrode (Carter et al. 2008).............................................................. 41

Figure 43. Some reversal of SOEC degradation (Carter et al., 2008)...................................................... 41

Figure 44. SEM image of the cross section of cell CER\#3 (LSC region), AES data from areas 1, 2 , and 3 in the SEM image.

Figure 45. (A) AES spectrum comparing the Co-rich crystallites and the Sr-rich layer at the top of LSC to the Co- and Sr- spectra from the LSC cross-section. (B) Schematic for the transport of cations and charge carriers across the SOEC.

Figure 46. (a) A dark field TEM image in $\operatorname{LSC}(1.3 \mu \mathrm{m} \times 0.9 \mu \mathrm{m})$, with the elemental maps for (b) $\mathrm{La}$, (c) $\mathrm{Sr}$, (d) Co and (e) Cr.

Figure 47. Performance for the reference half cell at $0.4 \mathrm{~A} / \mathrm{cm}^{2}$ in air at $820^{\circ} \mathrm{C}$ degraded significantly during the first $125 \mathrm{hrs}$, and the anode+LSC resistance increased (inset). 


\section{TABLES}

Table 1. Commonly used materials in SOFC/SOEC (Gazzarri 2007) ..................................................... 11 


\section{ACRONYMS}

3-D three dimensional

ASR area-specific resistance

CFD computational fluid dynamics

EDS energy dispersive X-ray spectroscopy

EIS electrochemical impedance spectroscopy

HTE high-temperature electrolysis

ILS integrated laboratory scale

INL Idaho National Laboratory

LSC lanthanum strontium chromite

LSCF lanthanum strontium cobalt iron oxide

LSF strontium-doped lanthanum ferrite

LSM strontium-doped lanthanum manganite

LZO lanthanum zirconate

Ni-YSZ nickel-yttria stabilized zirconia

PNNL Pacific Northwest National Laboratory

ScSZ scandia-stablized zirconia

SDC samaria-doped ceria

SEM scanning electron microscopy

SOEC solid oxide electrolysis cells

SOFC solid oxide fuel cell

TEM transmission electron microscopy

TPB triple-phase boundary

YSZ yttria stabilized zirconia 


\section{Critical Causes of Degradation in Integrated Laboratory Scale Cells during High-Temperature Electrolysis}

\section{INTRODUCTION}

Idaho National Laboratory (INL) is performing high-temperature electrolysis (HTE) research to generate hydrogen using solid oxide electrolysis cells (SOECs). A schematic depicting a high-temperature gas-cooled reactor coupled to an HTE system is shown in Figure 1. This system produces hydrogen using the heat and electricity generated by a high-temperature nuclear reactor. The $\sim 900^{\circ} \mathrm{C}$ primary helium coolant uses about $85 \%$ of the thermal energy output of the reactor to drive a gas-turbine Brayton power cycle, which provides the electrical energy required for the HTE process. The remaining $20 \%$ of the reactor thermal energy is used to generate steam at about $850^{\circ} \mathrm{C}$. The combination of a high-efficiency power cycle and the direct utilization of nuclear process heat yields a high overall thermal-to-hydrogen conversion efficiency of $50 \%$ or higher.

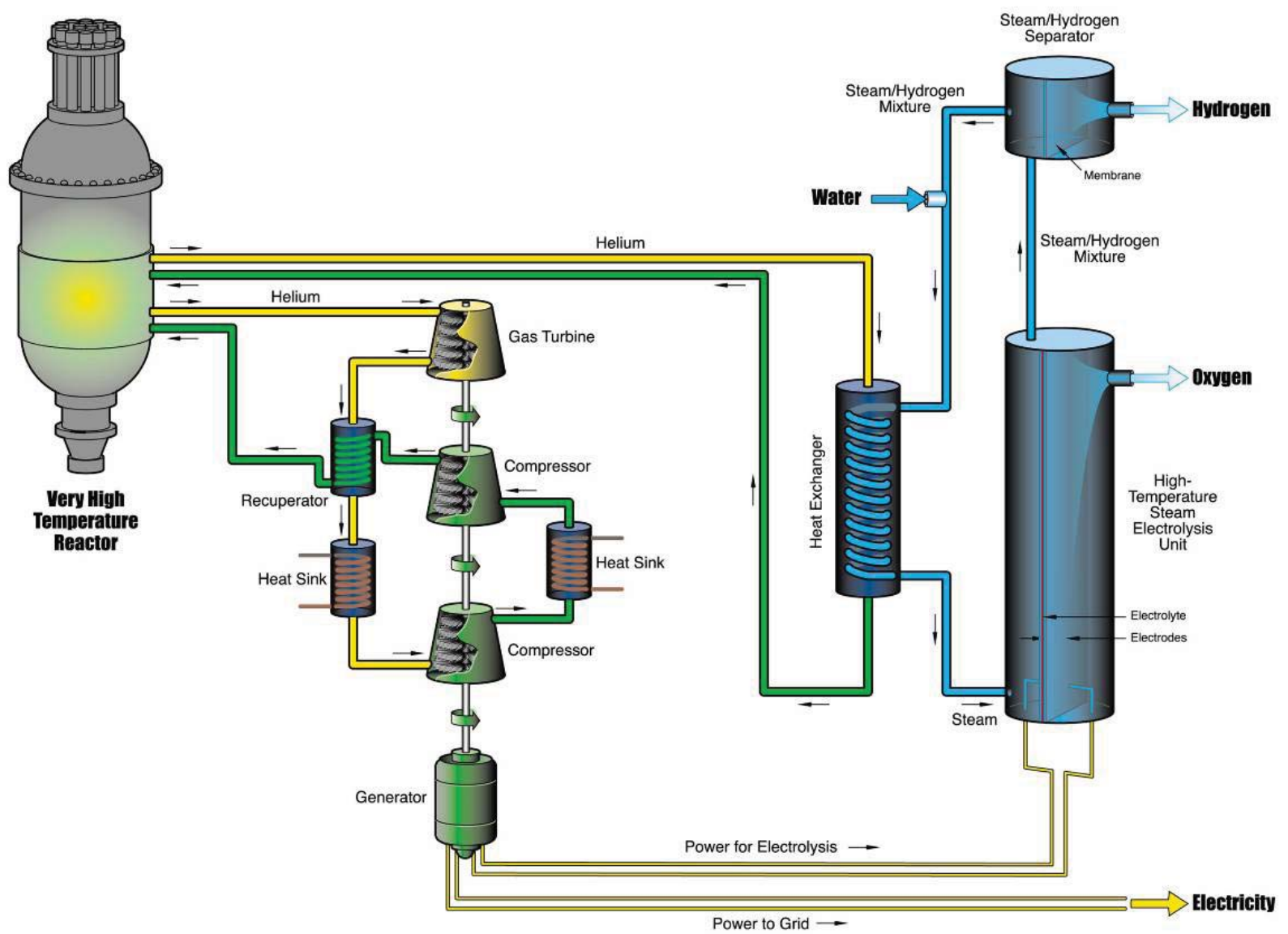

Figure 1. Schematic of HTE system coupled to an advanced nuclear reactor.

The objective of the INL project is to address the technical and scale-up issues associated with the implementation of SOEC technology for hydrogen production from steam. In the envisioned application, HTE would be coupled to an advanced nuclear reactor for efficient, large-scale, nonfossil, nongreenhouse-gas hydrogen production. The project supports a broad range of activities, including small 
bench-scale experiments, larger-scale technology demonstrations, detailed computational fluid dynamic modeling, and system modeling. A summary of the current status of these activities will be provided, with a focus on the problem of cell and stack degradation during operation of Integrated Laboratory Scale (ILS) experiments. It should be noted that most of this report is taken from four reports associated with related ongoing work on high temperature electrolysis at INL (Sohal 2009, Stoots et al. 2009, Hartvigsen et al. 2009, and O'Brien et al. 2009). For this technology to be successful in a large industrial setting, several technical, economical, and manufacturing issues have to be resolved. Some of the issues related to solid oxide cells include stack design optimization, identification and evaluation of cell performance degradation parameters and processes, integrity and reliability of the SOEC stacks, lifetime prediction, and extension of the SOEC stacks. The widespread commercialization of SOECs is subject to solving the problems related to their durability, reliability, and economics. 


\section{INL'S HIGH-TEMPERATURE ELECTROLYSIS PROJECT 2.1 Progression of High-Temperature Electrolysis}

This INL research project simultaneously addresses the technical and scale-up issues associated with the implementation of SOEC technology for efficient hydrogen production from steam. Researchers are coordinating a progression of electrolysis cell and stack testing activities at increasing scales while supporting research activities in the areas of materials development, single-cell testing, detailed computational fluid dynamics (CFD) analysis, and system modeling. A photograph of the INL HTE laboratory is shown in Figure 2. This part of the laboratory is dedicated to small-scale experiments with single cells and small stacks.

A mixture of steam and hydrogen is fed to the electrolytic cells where the oxygen migrates through the solid-state electrolyte as $\mathrm{O}^{=}$ions because of the imposed voltage. The cell voltage is about $0.3 \mathrm{~V}$ lower than that required in conventional electrolyzers because of the high operating temperature. In addition, electrolytic reaction kinetics are much faster than in room-temperature electrolyzers, thus avoiding polarization losses. The mixture exiting the cells, about $25 \mathrm{vol} \%$ steam and $75 \mathrm{vol} \%$ hydrogen, enters a separator where the two components are separated either by condensation of the steam or diffusion of the hydrogen. A fraction of the produced hydrogen is recycled and mixed with additional steam to achieve the required inlet mixture composition. It is then reheated and returned to the solid oxide cells. The remaining steam can be removed from the hydrogen product stream through condensation. Like the hydrogen stream, the oxygen stream exiting the cells has a temperature of about $830^{\circ} \mathrm{C}$, which can be effectively used as needed.

Herring et al. (2007) presented the progress of INL HTE research from small-scale bench testing to large-scale demonstration. INL has conducted experiments with following cells/stacks:

- $\quad$ Button cell testing $(\sim 1 \mathrm{~W})$

- Stack testing (200 W-5 kW) - electrode, electrolyte, and interconnect materials, flow channel materials and fabrication, inter-cell electrical contact, cell and manifold sealing issues, and cell durability

- ILS testing $(15 \mathrm{~kW})$ - all previous issues plus multiple-stack thermal management, heat recuperation, feedstock heating, and hydrogen recycling. 


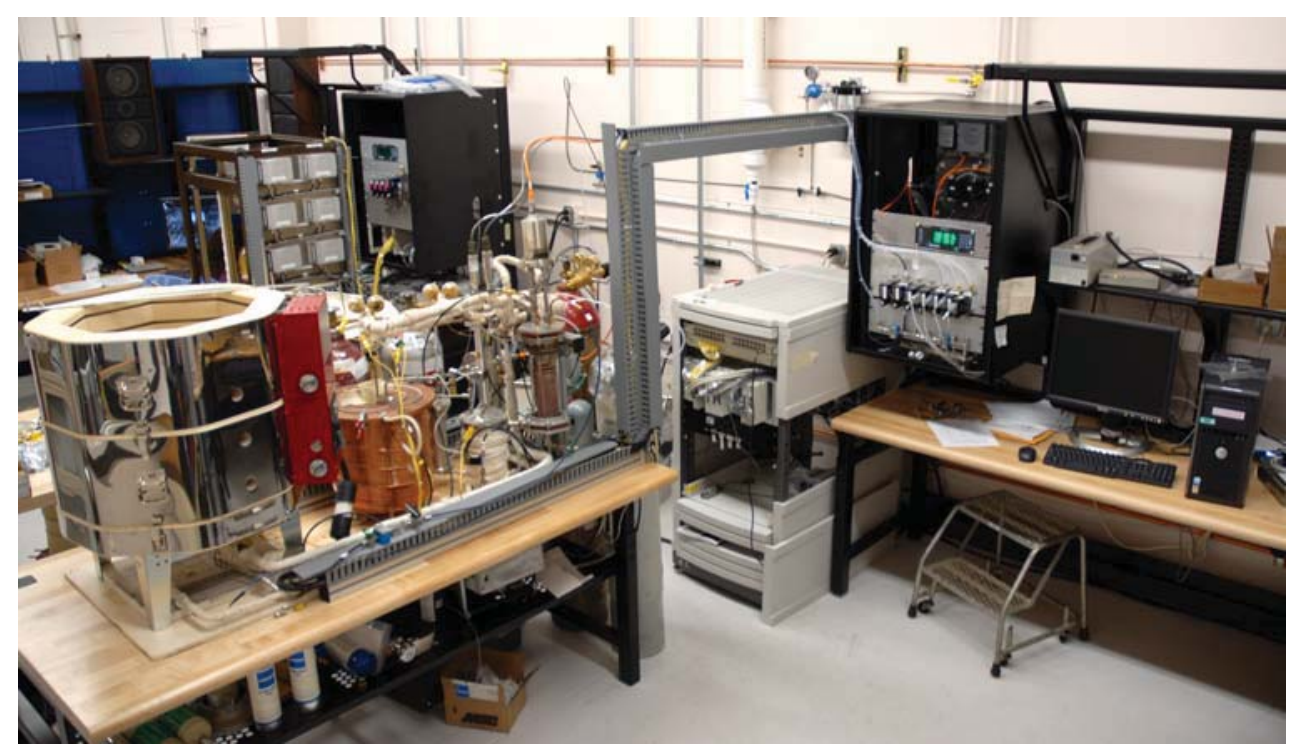

Figure 2. HTE laboratory at INL.

\subsection{ILS Test Stack Design}

Figure 3 shows the progression of the HTE experiments performed at INL during the last five years, from a $2.5 \mathrm{~cm}^{2}$ button cell to the ILS, which had an active area of $46,080 \mathrm{~cm}^{2}$ when all three modules were installed during 2008. This series of experiments represents a growth in active area (and in the hydrogen production rate) by a factor of 15,000. The ILS design includes three four-stack modules with 60 electrolysis cells in each stack for a total of 12 stacks and 720 cells in a single hot zone. This configuration utilizes the solid oxide cells similar to those used in the small stacks previously tested at INL. In the ILS, the inlet steam-hydrogen flow was preheated to $830^{\circ} \mathrm{C}$ (electrolyzer operating temperature) prior to entering the hot zone using superheaters and recuperators. The electrolysis module is configured so that the steam/hydrogen gas mixture enters through the bottom of the steam inlet manifold and exits through the bottom of the outlet manifold in the module's center. Airflow enters through the bottom of the air inlet manifold, flows through the stack perpendicular to the steam-hydrogen gas mixture, and exits at the front of the stacks directly into the hot zone. Furthermore, each electrolysis module has its own independent instrumentation system, which allowed for independent testing of each of the three HTE ILS modules under different operating conditions (gas mixture, current density, etc.). To measure fuel cell performance, the area-specific resistance (ASR) value was closely monitored. Fuel cell testing showed that the resistance of the cell gradually increased over time, reducing the hydrogen production rate. This degradation was evidenced by increased calculated ASR values. As the solid oxide cell technology improves, the cell's lifetime and degradation should also improve, resulting in efficiently producing large quantities of hydrogen over long periods $(\geq 50,000 \mathrm{hrs})$ of time. 


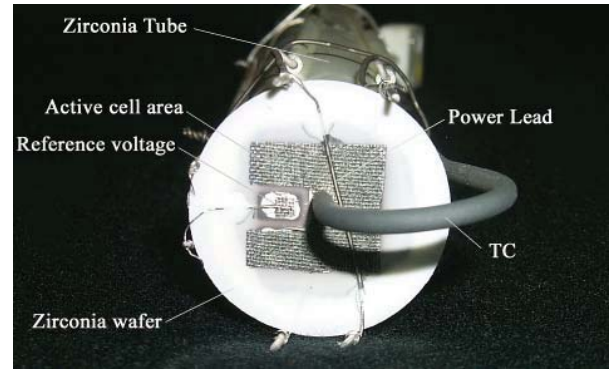

Button cell, $3.2 \mathrm{~cm}^{2}(2003)$

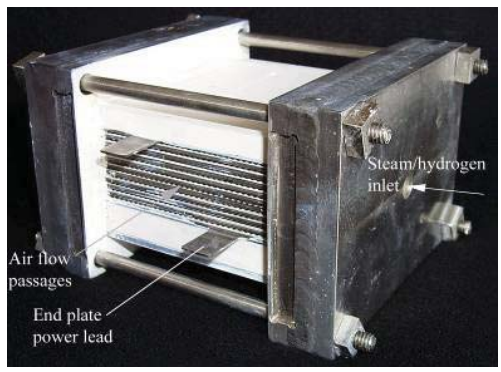

10-cell stack, $640 \mathrm{~cm}^{2}(2004)$

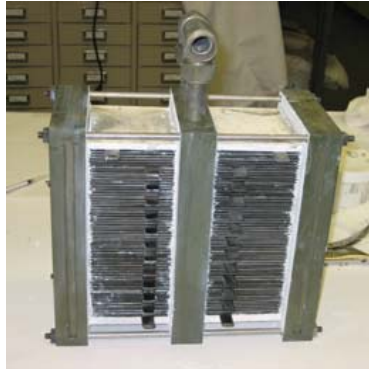

120-cell half-module, $7,680 \mathrm{~cm}^{2}(2006)$

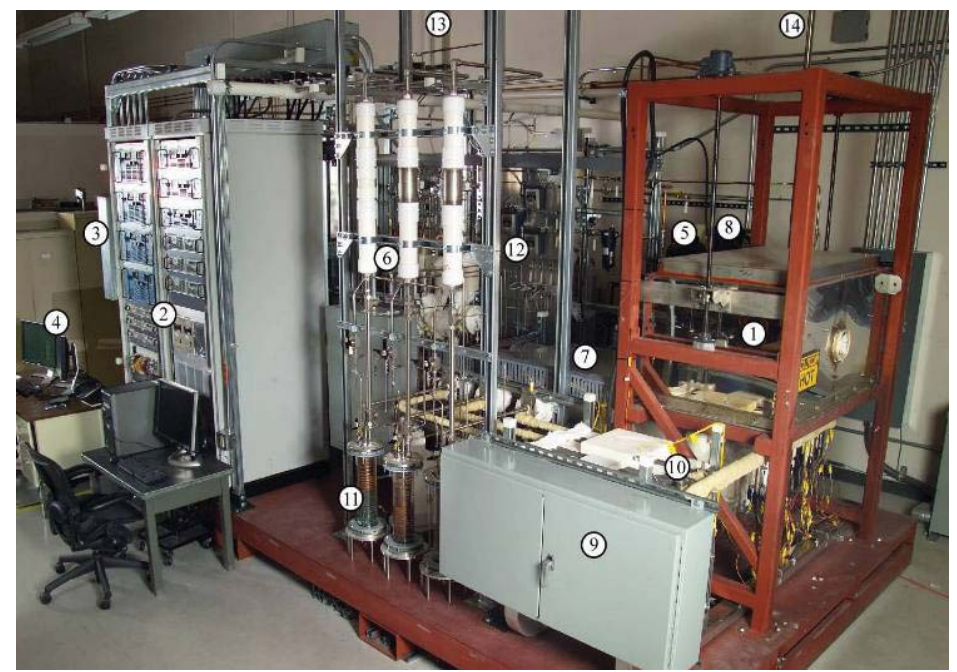

Integrated Laboratory Scale 720 cells, 3 modules, $46,080 \mathrm{~cm}^{2}$, (2008)

\begin{tabular}{|c|l|}
\hline ID & \multicolumn{1}{|c|}{ Component } \\
\hline 1 & Hot zone enclosure lid \\
\hline 2 & $\begin{array}{l}\text { Power supply and instrument } \\
\text { racks }\end{array}$ \\
\hline 3 & Electrical distribution cabinet \\
\hline & $\begin{array}{l}\text { Data acquisition and control } \\
\text { monitors }\end{array}$ \\
\hline 5 & Deionized water system \\
\hline 6 & Steam generator \\
\hline 7 & Steam and $\mathrm{H}_{2}$ superheaters \\
\hline 8 & Air compressor \\
\hline 9 & Patch panel \\
\hline 10 & Product finned cooler \\
\hline 11 & Steam condenser \\
\hline 12 & Mass flow controllers \\
\hline 13 & H $_{2}$ vent \\
\hline 14 & Air and $\mathrm{O}_{2}$ vent \\
\hline
\end{tabular}

Figure 3. Progress of INL SOEC testing.

\subsection{Stack Construction}

The ILS test was a 720-cell, three-module test comprised of 12 stacks of 60 cells each. The stacks were arranged on three internally manifolded base plates that sat upon the heat exchangers. Each base plate contained a module, which was comprised of two pairs of stacks. Paired stacks had individual steam inlet manifolds and shared a common hydrogen outlet manifold. Each stack pair sat on the base plate across from another stack pair, with the stacks and manifolds forming an air plenum between the pairs that was completed by metal sheet closure. The inlet and outlet ports were at the bottom of the hydrogen/steam manifolds, which slid over tube nipples extending up from the base plate. The seal at this connection was largely a slip fit between the tube and the manifold's port with a small amount of zirconia paste between the outside mating surfaces. Stacks were held down on the base plate with an applied axial load using crossbars; each crossbar loaded one stack of each opposing pair as shown in Figure 4. 


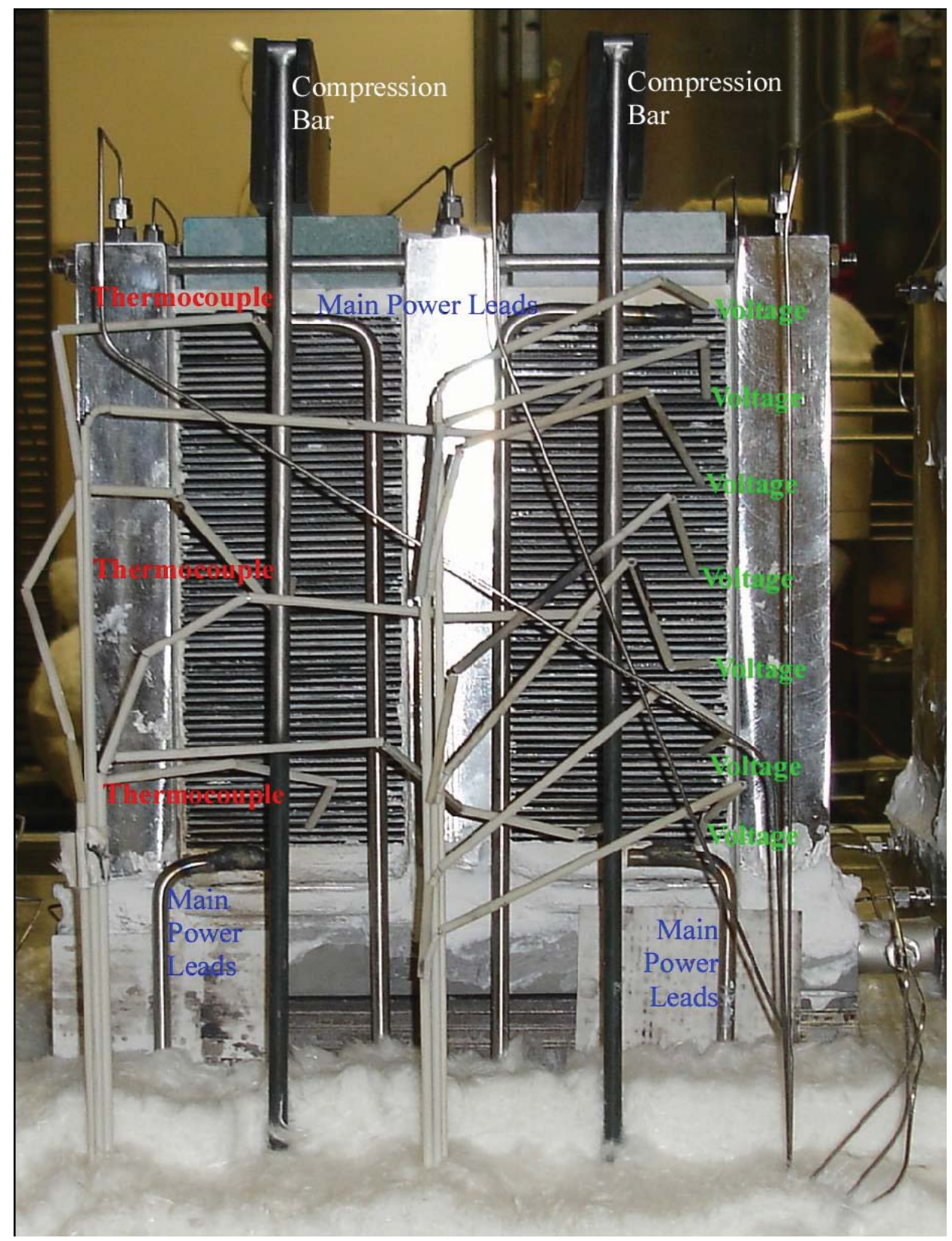

Figure 4. Photograph of installed module and lead placement.

All four stacks of a module were connected electrically in parallel using buss bars welded to interconnects tabs after every fifth cell. Each stack had its own set of current collecting bars welded to the top and bottom interconnects tabs. These bars exited out of the test furnace and were connected to the external power sources. Voltage taps were inserted into the air exhaust channels of one of the stacks every $10^{\text {th }}$ cell. Three internal thermal couples were also inserted into each of the four stacks at locations near the top, middle, and bottom of the stack.

Each stack consisted of 60 electrolyte-supported cells that were $10 \mathrm{~cm} \times 10 \mathrm{~cm}$ outside dimensions and had an active area of $61 \mathrm{~cm}^{2}$ per cell. The electrolyte was Sc stabilized zirconia, approximately 220 microns thick. The hydrogen electrode was Ceramatec's standard nickel cermet composite. The hydrogen electrodes were also printed with unfired nickel ink as a current distribution layer. The air electrode was 
Ceramatec's standard manganite formulation, with an unfired lanthanum strontium chromite (LSC) current distribution layer.

The interconnects were Ceramatec's standard treated metal components in a cross-flow configuration. The separator plate was stainless 400 with a rare earth scale treatment and a LSC current distribution layer applied on the air side. The current distribution layer was made of two applications, one that was pre-fired and another that was "green" at the time of assembly. The air side flow channel was an Alloy X corrugation with the scale treatment and was coated with a fired LSC layer. Stainless 400 edge rails were treated with yttria stabilized zirconia (YSZ) coating to inhibit steam corrosion and were held in place with glue during assembly. The hydrogen flow channel was an untreated Ni201 corrugation with a nickel felt spot welded to the flow channel-electrode contacts points. The hydrogen side of the separator plate had a green nickel ink current distribution layer printed on it. The edge rails were the same as on the air side.

The stack was assembled using the above components in an alternating pattern. The air flow channels were coated with a wet LSC contact ink on the separator side and a spinel ink on the cell side. This module was the only one to have this dual contact ink treatment on the air side. The other two modules had only wet LSC ink on both sides of the air flow channels. The edge seal was the standard YSZ paste placed along the interior edge of the edge rail and on the edge rail top surface that contacted the cell. The hydrogen side construction did not employ any wet contact layers and used the same YSZ edge seal material and configuration as the air side edge seal.

The stacks were built in an alignment jig and then compressed using clamps to fit inside the hydrogen manifolds. Once fit inside the manifolds, the clamps were released. The hydrogen manifold seal was a 1-mm-thick gasket of Zircar APA-1 paper. Gaps along the edge and corners of the stacks were packed with YSZ paste.

Figure 5 shows an exploded view of one of the ILS module assemblies including the recuperative heat exchanger, base manifold unit, and four-stack electrolysis unit. For each four-stack electrolysis module, there were two heat exchangers and one base manifold unit. Nine flow tubes entered or exited each base manifold at its top, and only four flow tubes entered or exited at the bottom of the unit and at the bottom of the heat exchangers, thereby reducing the number of tube penetrations passing through the hot zone base plate from nine to just four. This feature also reduced the thermal load on the hot zone base plate. An internally manifolded plate-fin design concept was selected for this heat recuperator application. This design provides excellent configuration flexibility in terms of selecting the number of flow elements per pass and the total number of passes in order to satisfy the heat transfer and pressure drop requirements. Theoretical counterflow heat exchanger performance can be approached with this design. This design can also accommodate multiple fluids in a single unit. More details of the design of the recuperative heat exchangers are provided by Housley et al. (2008). 


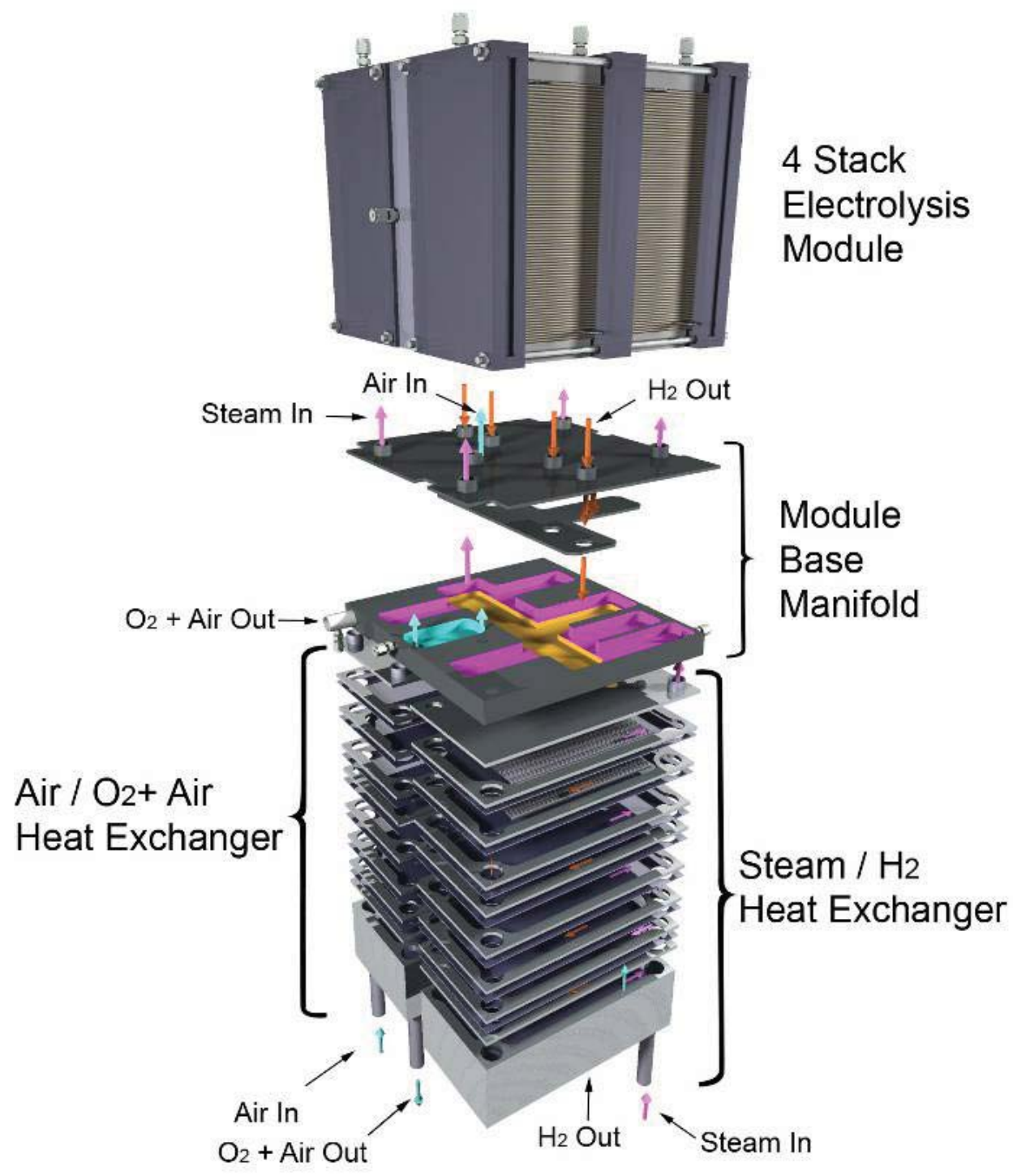

Figure 5. Exploded view of heat exchanger, base manifold unit, and four-stack electrolysis unit.

Figure 6 shows three ILS electrolysis modules with their base manifolds and heat exchangers beneath. This illustration also shows the instrumentation wires for intermediate voltage and temperature readings. Each module is instrumented with twelve 1/16" sheathed thermocouples for monitoring gas temperatures in the electrolysis module manifolds and in the base manifold. These thermocouples are attached to the manifolds using compression fittings. There are also 12 miniature $0.020^{\prime \prime}$-diameter inconel-sheathed type$\mathrm{K}$ thermocouples per module that are used for monitoring internal stack temperatures. Access to the internal region of the stacks is provided via the air outlet face. The internal thermocouples are inserted into the small exit air-flow channels. Similarly, seven intermediate voltage tap wires per module are inserted into the air-flow channels of the four stacks. Two compression bars are shown across the top of each module in Figure 6. These bars are used to maintain compression on all of the stacks during operation in order to minimize electrical contact resistance between the cells, flow channels, and interconnects. The bars are held in compression via spring-loaded tie-downs located outside of the hot zone under the base plate. 


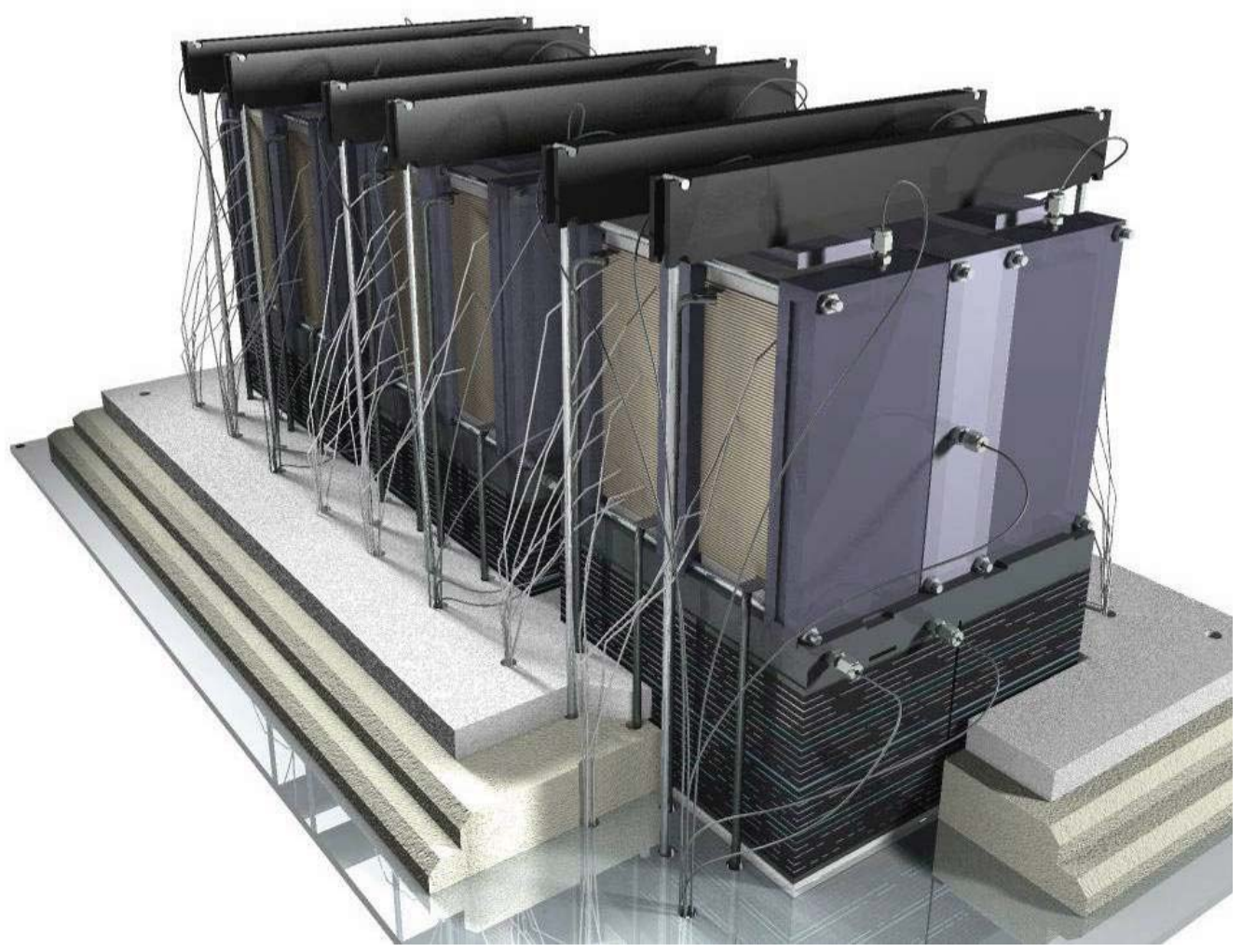

Figure 6. Installation of electrolysis modules, base manifolds and paired heat exchangers.

Note that the heat exchangers are partially imbedded in the insulation thickness. The top portion of each heat exchanger is exposed to the hot zone radiant environment, which helps to insure that the inlet gas streams achieve the desired electrolyzer operating temperature prior to entering the stacks. The temperature at the bottom of each heat exchanger will be close to the inlet stream temperature, minimizing the thermal load on the hot zone base plate in the vicinity of the tubing penetrations.

\subsection{Solid Oxide Cell}

A solid oxide cell is a key component of the electrolysis system. It consists of three main components: an electrolyte and two electrodes (Figures 7 and 8). The electrolyte is a ceramic membrane that can conduct ions and is sandwiched between two porous electrodes that can conduct electrons: the steam/hydrogen electrode (or anode in fuel cell mode) and the air/oxygen electrode (or cathode in the fuel cell mode). In the fuel cell mode, oxygen molecules dissociate at the oxygen electrode and combine with electrons coming from an external electric power source to form oxygen ions. The oxygen ions conduct through the electrolyte and migrate towards the hydrogen electrode. The fuel (hydrogen or natural gas) is fed to the anode and reacts with the oxygen ions to form water and $\mathrm{CO}_{2}$. If the fuel cell is operated in the electrolysis mode, the names and functions of the electrodes get reversed, as shown in Figure 7a. 


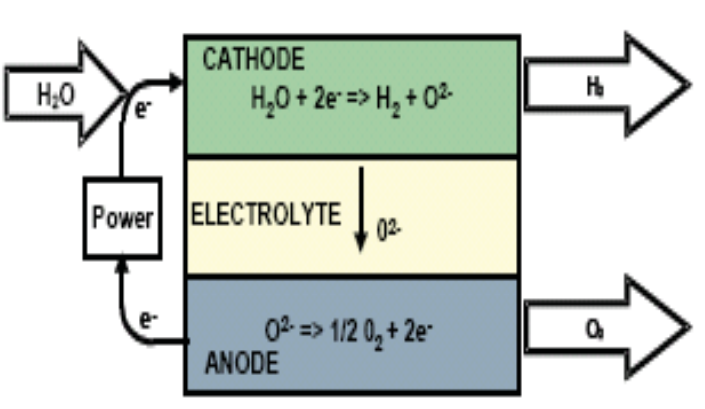

(a)

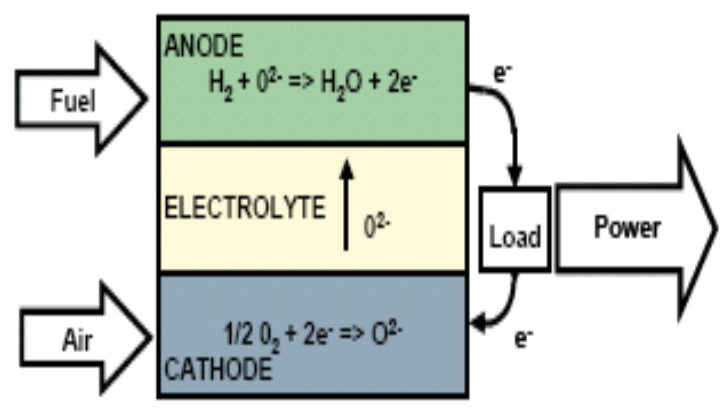

(b)

Figure 7. (a) SOEC; (b) solid oxide fuel cell (SOFC) operating in reverse compared to an SOEC (Guan et al. 2006).
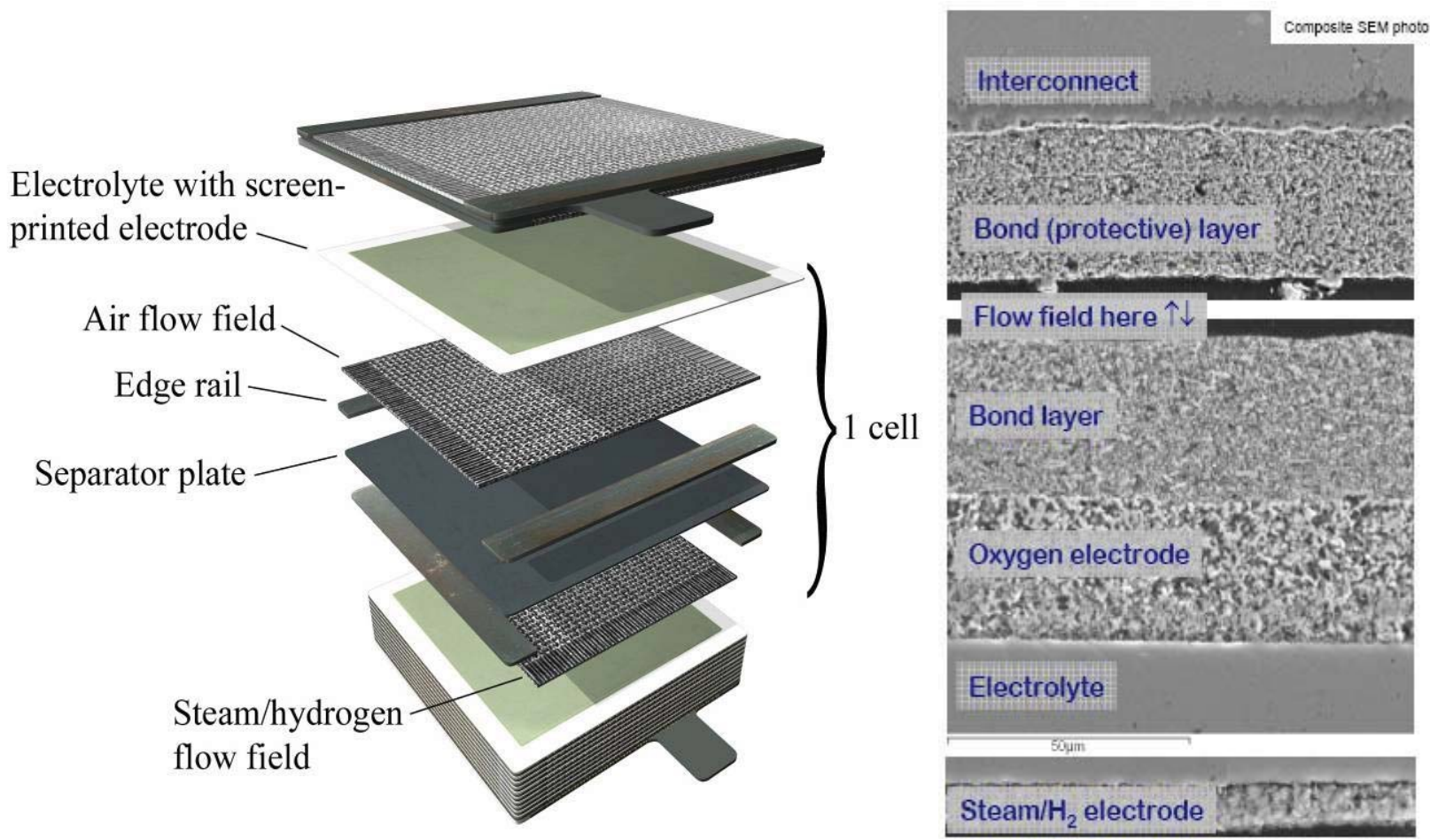

Figure 8. Ceramatec solid oxide cell/stack construction; (scanning electron microscopy figure on the right is taken from Carter et al. 2008).

The most common materials in use for the solid oxide cells are listed in Table 1 (Gazzarri 2007). The electrolyte is a dense gas-tight ceramic layer, usually made from YSZ with a yttria content of $8 \mathrm{~mol} \%$ to fully stabilize the electrolyte composition. The performance of the electrolyte depends on how well it can conduct oxide ions $\left(\mathrm{O}^{=}\right)$. The thinner the electrolyte, the higher its ion conductivity and the lower the cell's ohmic resistance. In an electrolyte-supported cell, the electrolyte thickness is large (150-250 $\mu \mathrm{m})$, which leads to relatively high ionic resistance. Therefore, if the mechanical strength can be provided by the steam $/ \mathrm{H}_{2}$ electrode, the electrolyte thickness can be reduced by a factor of $\sim 10$. 
Table 1. Commonly used materials in SOFC/SOEC (Gazzarri 2007).

\begin{tabular}{|l|l|l|}
\hline \multicolumn{1}{|c|}{ Component } & \multicolumn{1}{|c|}{ Material } & \multicolumn{1}{c|}{ Acronym } \\
\hline Steam/hydrogen electrode & $\mathrm{Ni}_{-}-\mathrm{Y}_{\mathrm{x}} \mathrm{Zr}_{1-\mathrm{x}} \mathrm{O}_{2-\mathrm{x} / 2}$ (nickel-yttria stabilized zirconia) & Ni-YSZ \\
\hline Electrolyte & $\mathrm{Y}_{\mathrm{x}} \mathrm{Zr}_{1-\mathrm{x}} \mathrm{O}_{2-\mathrm{x} / 2}(\mathrm{yttria}$ stabilized zirconia) & $\mathrm{YSZ}$ \\
\hline Air/oxygen electrode & $\mathrm{Sr}_{\mathrm{x}} \mathrm{La}_{1-\mathrm{x}} \mathrm{MnO}_{3-\delta}+\mathrm{Y}_{\mathrm{x}} \mathrm{Zr}_{1-\mathrm{x}} \mathrm{O}_{2-\mathrm{x} / 2}$ (doped lanthanum manganite) & $\mathrm{LSM}$-YSZ \\
\hline Interconnect & Chromium-based alloys/ceramics or stainless steel & $\mathrm{SS}$ \\
\hline
\end{tabular}

The most common anode material for SOFC is a porous cermet (ceramic-metal) made from Ni and YSZ. Electronically conductive, gas-tight interconnect plates connect the individual cells to form a stack. The ionic conductivity of ceramics is highly dependent on the ceramic temperature. Thus, high operating temperatures are required to obtain sufficient overall conductivity in the solid oxide cell. YSZ exhibits acceptable conductivity in the $700-1,100^{\circ} \mathrm{C}$ temperature range, but if thermal cycling occurs, such as at start-up, the high operating temperature results in large thermal stresses in the cell components. Stresses can also be caused by large thermal gradients generated by the uneven distribution of electrochemical reaction sites. Finally, fabrication of the cell components also requires high temperatures that can cause detrimental residual stresses within the cell components. Guan et al. (2006) performed studies for reversible solid oxide cells, which were tested in both fuel cell and electrolysis modes. They selected YSZ (8 mol\% $\mathrm{Y}_{2} \mathrm{O}_{3}$ doped zirconia) as electrolyte material. Selected oxygen electrodes were strontium-doped lanthanum manganite (LSM), strontium-doped lanthanum ferrite (LSF), and lanthanum strontium cobalt iron oxide (LSCF). They used a samaria-doped ceria (SDC) interlayer for LSF and LSCF. LSCFs have increased ionic conductivity and may reduce the degradation rate in electrolysis mode. For the hydrogen electrode, Ni-YSZ was selected with varying volume fraction of $\mathrm{Ni}(40-80 \%)$.

In the fuel cell mode, the oxygen electrode is fed with air while the hydrogen electrode is fed with hydrogen or natural gas. Thus, the properties of the oxygen electrode should be such that it provides a component for oxygen gas to be easily reduced and, similarly, the function of the hydrogen electrode is to oxidize the fuel gas. At the oxygen electrode, where electrons are supplied via the external electrical power, oxygen molecules are reduced to oxygen ions. The oxygen ions are conducted through the electrolyte to the hydrogen electrode. At the hydrogen electrode, oxygen ions oxidize the fuel gas which forms water and carbon dioxide, while the resulting free electrons are transported via the external circuit back to the oxygen electrode. The solid oxide electrolyte separates the reduction and oxidation reactions. Thus, in the electrolysis mode, the electrical energy is used to split hydrogen from steam. The electrolysis process is the reverse of the fuel cell process. 


\section{POLARIZATION LOSSES (DEGRADATION) IN A SOLID OXIDE CELL}

The polarization losses (degradation) definitions described in this chapter are written strictly for a SOFC. Appropriate care should be applied when applying the same fundamentals for a SOEC case.

When a fuel cell is not connected to an external load, there is no current flow and the maximum reversible cell voltage or open circuit voltage can be calculated by the equilibrium Nernst potential for the specific electrochemical reaction system. The Nernst potential, $\mathrm{V}_{\text {Nerst }}$, is calculated using the partial pressure of the chemical species at the cell inlet or outlet. However, it is more appropriate to calculate an average of the inlet and outlet values, $\mathrm{V}_{\text {Nernst }}^{\mathrm{i}}$ and $\mathrm{V}^{\mathrm{o}}$ Nernst, where superscripts "i" and "o" represent inlet and outlet locations.

$$
\begin{aligned}
& \mathrm{V}_{\text {Nernst }}=1 / 2\left(\mathrm{~V}_{\text {Nernst }}^{\mathrm{i}}+\mathrm{V}_{\text {Nernst }}^{\mathrm{o}}\right) \\
& V_{\text {Nernst }}^{i}=-\frac{\Delta G^{0}}{n_{e} F}-\frac{R T}{n_{e} F} \ln \left(\frac{p_{\mathrm{H}_{2} \mathrm{O}}^{i}}{p_{\mathrm{H}_{2}}^{i} \sqrt{p_{\mathrm{O}_{2}}^{i}}}\right) \\
& V_{\text {Nernst }}^{o}=-\frac{\Delta G^{0}}{n_{e} F}-\frac{R T}{n_{e} F} \ln \left(\frac{p_{\mathrm{H}_{2} \mathrm{O}}^{o}}{p_{\mathrm{H}_{2}}^{o} \sqrt{p_{\mathrm{O}_{2}}^{o}}}\right)
\end{aligned}
$$

where $\Delta G^{0}$ is change in Gibbs free energy at standard conditions and equals $-R T \ln [K(T)]$, $R$ is universal gas constant, $\mathrm{T}$ is cell temperature, $\mathrm{K}$ is equilibrium constant, $\mathrm{n}_{\mathrm{e}}$ is number of electrons participating in the electrochemical reaction, $\mathrm{F}$ is Faraday's constant, and $\mathrm{p}$ is the partial pressure of respective species.

When a fuel cell starts supplying electric current to an external load, its operating voltage drops because of irreversibilities associated with internal resistances. The difference between the maximum reversible cell voltage or open circuit voltage $\left(\mathrm{V}_{\mathrm{OCV}}\right)$ and the operating cell voltage $\left(\mathrm{V}_{\text {open }}\right)$ is termed polarization loss $(\eta)$. Cell performance depends on the overall cell reaction and the type of reactants at the electrodes and the reaction product(s). Ivers-Tiffée and Virkar (2003) and Akkaya (2007) give a detailed description of polarization losses. The total polarization loss of an operating cell consists of three dominant parts: activation (or charge transfer) polarization $\left(\eta_{\text {act }}\right)$, concentration (or diffusion) polarization which includes chemical reaction polarization $\left(\eta_{\text {conc }}\right)$, and ohmic resistance polarization $\left(\eta_{\text {ohm }}\right)$.

$\eta=\eta_{\text {act }}+\eta_{\text {conc }}+\eta_{\text {ohm }}$

The current efficiency can be stated as the percent of current passing through an electrolytic cell (or electrode) that accomplishes the desired chemical reaction compared to the ideal case. For example, in the hydrogen fuel cell, ideally every hydrogen $\left(\mathrm{H}_{2}\right)$ molecule would react to produce two electrons that would contribute to the current flow. The inefficiencies arise from reactions other than the intended one taking place at the electrodes or the side reactions consuming the current. Some hydrogen, for instance, may go through the electrolyte and not react at all, or the hydrogen does react but the resulting current is driven through the electrolyte (not the electrode) and never contributes to the current flow.

The voltage efficiency is defined as the net voltage (cell equilibrium voltage minus the irreversible losses) divided by the maximum voltage. The irreversible voltage losses are attributed to polarization losses that primarily originate from three sources: activation, concentration, and ohmic polarizations. 
Thus, the net cell voltage is the open circuit voltage, minus the various polarization losses, and can be written as:

$\mathrm{V}_{\text {cell }}=\mathrm{V}_{\text {open }}-\left(\mathrm{V}_{\text {act }}+\mathrm{V}_{\text {conc }}+\mathrm{V}_{\text {ohm }}\right)=\mathrm{V}_{\text {Nernst }}-\mathrm{V}_{\text {loss }}$

Figure 9, developed by Windisch et al. (2002), shows the relative magnitude of various polarization losses in a SOFC. It shows that activation losses are the dominant mode of three types of polarization losses. It also shows the upper limit of current density for the fuel cell to operate.

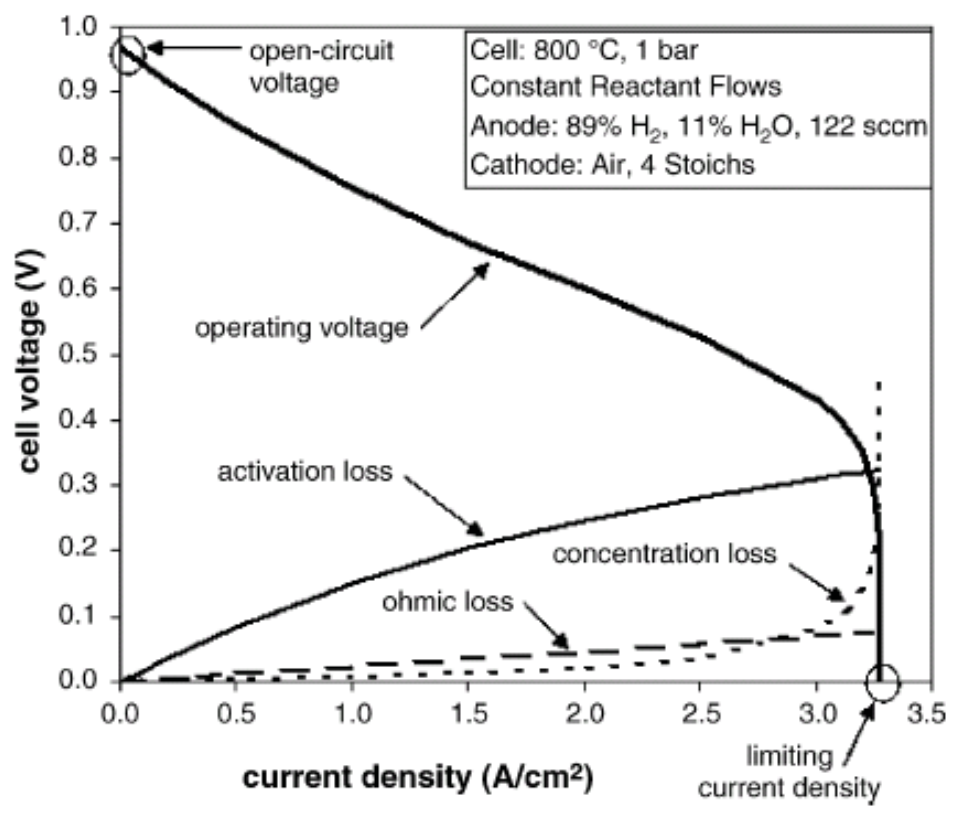

Figure 9. SOFC voltage-current characteristics for a single cell operating at $800^{\circ} \mathrm{C}$ (Windisch et al. 2002).

The overpotentials can be determined by the several models available in the literature-for example, Virkar (2007). However, the concentration overpotentials are different between the SOEC and SOFC modes because of the different gas transport mechanisms in the porous electrodes. Ni et al. (2006) showed that concentration overpotentials are the sole factor responsible for the different current-voltage (i-V) characteristics between the SOEC and SOFC modes. Their analytical model shows the difference between the SOEC and SOFC because of differences in the gas transport mechanisms of the two different modes. The selection of an electrode support can greatly affect the overall performance of a reversible solid oxide cell. A hydrogen-electrode (fuel cell anode) support is favorable for the SOFC mode while an oxygenelectrode (electrolysis anode) support is favorable for the SOEC mode. Therefore, the details of both SOEC and SOFC operating conditions should be carefully considered in their design. If a specified solid oxide cell is mainly used for hydrogen generation, an oxygen-electrode (electrolysis anode) supported cell is recommended. Therefore, corresponding resistance of a SOFC is the cell resistance normalized by its area $\left(\mathrm{k} \Omega \cdot \mathrm{cm}^{2}\right)$ and is called area-specific resistance (ASR). From the cell polarization and corresponding current density, an ASR can be defined as

$\operatorname{ASR}=(E-V) / i$

where $E$ can be either open circuit voltage potential $\left(E_{O C V}\right)$ or the ideal Nernst potential $\left(E_{N}\right)$, depending on whether one wants to (1) remove loss effects due to reactant leakage and variable reactant mixture supply and if one is focused on the cell material performance, or (2) focus on total cell performance (cell material and seals) (Gemmen et al. 2008). 
Some methods for reducing this resistance include using:

- Electrodes with high electronic/ionic conductivity

- Appropriate bipolar plate/interconnect materials that are low in ohmic resistance and also complement the other cell component materials

- Thin, but structurally stable electrolyte with the ability to prevent shorting from one electrode to the other.

The important factor to remember about various polarization components is that they are not independent of each other. A change in partial pressure affects the concentration polarization, and it will also affect the activation polarization. 


\section{DEGRADATION PHENOMENA IN SOLID OXIDE ELECTROLYSIS CELLS}

As INL progressively increases the scale of electrolyzer systems by increasing the number of solid oxide cells and stacks, it is important to understand and address the causes of performance degradation in SOEC stacks. Unfortunately, not many studies in the published literature address degradation and related issues in SOECs. Even for SOFCs, the issues of degradation, aging, and longevity are topics of ongoing research. As thinner electrolytes with higher ionic conductivity are developed, the overall cell polarization losses are dominated by the electrochemical losses at the anodes and cathodes. Even though the solid oxide cells have several differences while operating in power generating (fuel cell) and electrolysis modes, the degradation mechanisms in the two cases may have some similarities. Therefore, the knowledge of degradation mechanisms in SOFCs can be a starting point for the SOECs and can offer some guidance in identifying the research areas. Because of this reason, some known degradation background in SOFCs is reviewed here.

Ni et al. (2006) have developed models for concentration overpotential in SOECs and SOFCs, as shown in Figures 10(a) and 10(b), respectively. The cathode (hydrogen electrode) in the electrolysis mode is termed "anode" in the fuel cell mode. Similarly, the anode (oxygen electrode) in the electrolysis mode is termed "cathode" in the fuel cell mode.

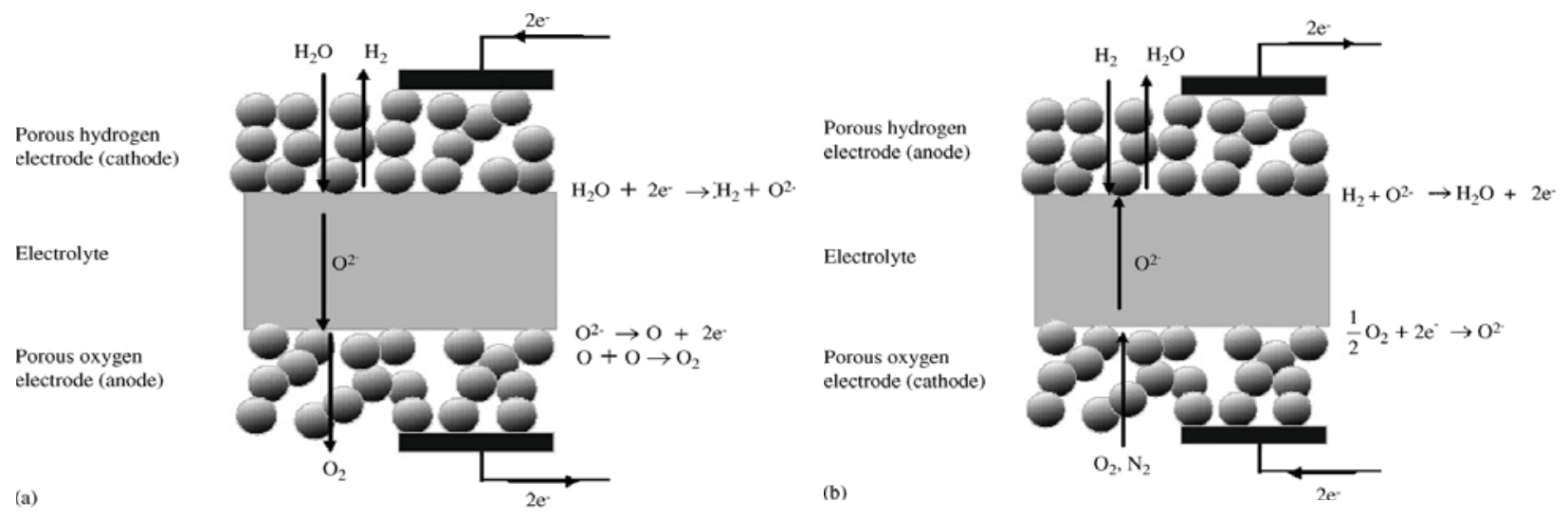

Figure 10. Operating mechanisms of solid oxide cells: (a) a SOEC in electrolysis mode, and (b) a SOFC in fuel cell mode (Ni et al. 2006).

\subsection{Degradation Magnitude}

There are two common definitions for quantifying degradation given by Gemmen et al. (2008). ASR is defined in Equation (11). The ASR represents the instantaneous degradation rate. Another degradation definition is termed "average degradation rate," $D \bar{R}(t)$. It is defined for a time period of $\left(\mathrm{t}-\mathrm{t}_{0}\right)$. Thus for any cell voltage $\mathrm{V}\left(\mathrm{I}_{\mathrm{s}}, \mathrm{t}\right)$, at a time $\mathrm{t}$, average degradation rate, $D \bar{R}(t)$, is given by (Gemmen et al. 2008):

$D \bar{R}(t)=\frac{V\left(i_{s}, t_{0}\right)-V\left(i_{s}, t\right)}{V\left(i_{s}, t_{0}\right) \times\left(t-t_{0}\right)} 100$.

ASR is best suited for comparing the performances of the same cell with two types of technologies, such as one type of interconnect design with another. However, DR is better suited to comparing cell performance with a stack performance of the same type of cells. To understand the degradation phenomena, a solid oxide electrolyzer needs to be operated and tested. Figures 8-10 show some of the 
data that were taken during the tests performed at INL. Current density, voltage, ASR, cell system temperature, reactants, and product flow rates are some of the commonly measured parameters during the tests. However, to understand the electrochemical behavior of the electrodes and electrolytes, their chemical microstructure has to be understood before and after an electrolysis operation. Also, the movement of impurities - for example, $\mathrm{Ni}, \mathrm{Cr}$ - as a result of the electrolysis operation should be identified. The impact of the impurities' movement on electrochemical performance of a single cell and a stack should also be determined by making relevant measurements.

Recently, Virkar (2007) developed an overpotential model for a typical planar SOFC stack comprising several cells connected in series. He also gave the following argument in favor of developing a fundamental understanding of the degradation. In a stack, cell-to-cell characteristics should be as uniform as possible so that, at a given operating current, the voltage across each cell is essentially the same. If, because of some structural/fabrication flaws, the cells are not identical, the resistance and voltage drop will vary from cell to cell. In such a case, the remainder of the cells in the stack will drive the cell with higher resistance. In an extreme case, for the stack to continue operating, the voltage across a cell with higher resistance can even become negative, which can eventually lead to cell failure and increased local temperatures. This phenomenon can spread to adjacent cells as a domino effect.

However, interpretation solely based on visual observations, without a sound theoretical basis for all the phenomena occurring in a cell, may be misleading. In a cell, observations are the aftermath result of some other critical damage to the cell that has already taken place, so the visual observation alone may not be able to show the root cause of the problem. Some of the likely reasons of cell degradation include small initial compositional inhomogeneities resulting in large changes in properties, the formation of local hot spots leading to local changes in microstructures and material properties, electrode delamination due to thermal cycling/rapid heating, reaction between electrode and electrolyte forming a high-resistance layer, fuel and/or oxidant maldistribution, nonuniform oxidation of the interconnect, degradation of the seals, etc. In a normal SOFC, the (oxygen) ionic current is in a direction opposite to that of electronic current. However, if a cell has degraded to cause negative voltage, the direction of electron flow will reverse and both ionic and electronic currents will flow in the same direction.

Virkar (2007) has developed a degradation model based on this premise; that is, a cell with higher resistance compared to the rest of the cells in the stack and operating under a negative voltage will be prone to degradation. Planar stacks are more likely to undergo such a degradation mechanism than tubular stacks. Therefore, the ability to measure voltage across each (planar) cell could help in preventing catastrophic failure by either performing preventive maintenance or shorting the bad cell. A similar degradation model of an SOEC can also offer some insight into the cell degradation phenomenon during the electrolysis mode.

Per Virkar (2007), one of the principal modes of failure of solid-state electrolytes is related to the generation of high chemical potentials and corresponding ultra-high pressure of neutral species within the electrolyte. For example, in an oxygen ion conducting solid electrolyte such as YSZ, under some thermodynamic conditions, oxygen chemical potential within the solid electrolyte, $\mu_{\mathrm{O}_{2}}^{Y S Z}$, may exceed the chemical potential of gaseous oxygen, that is, under certain conditions, $\mu_{\mathrm{O}_{2}}^{Y S Z}>\mu_{\mathrm{O}_{2}}^{\mathrm{O}_{2} \text { electrode }}$. The chemical potential of any reactant is a function of its partial pressure, $\mu_{\mathrm{O}_{2}}=f\left(p_{\mathrm{O}_{2}}\right)$. Therefore, under certain conditions, $p_{\mathrm{O}_{2}}^{Y S Z}>p_{\mathrm{O}_{2}}^{\mathrm{O}_{2} \text { electrode }}$; and in some cases, $p_{\mathrm{O}_{2}}^{Y S Z}>>p_{\mathrm{O}_{2}}^{\mathrm{O}_{2} \text { electrode }}$. If very high pressure develops, it may result in electrode delamination. This increases the cell resistance and then degradation propagates. 
Under the same operating conditions of temperature and current density, a SOFC and a SOEC are likely to have the same ohmic and activation overpotentials. Over the past few years, extensive research has been performed relating to SOFC. Yet SOFCs have not reached their complete commercial success because of problems relating to their degradation, longevity, and cost. Some of the degradation mechanisms include contact problems between adjacent cell components, microstructural deterioration (coarsening) of the porous electrodes, and blocking of the reaction sites within the electrodes. Contact problems include delamination of an electrode from the electrolyte, growth of a poorly (electronically) conducting oxide layer between the metallic interconnect plates and the electrodes, and lack of contact between the interconnect and the electrode. Examples of microstructural degradation are oxygen electrode sintering, carbon deposition, and sulfur or chromium poisoning.

Delamination caused by thermal cycling increases ohmic resistance proportional to the delaminated area. The delaminated area also becomes inactive for electrochemical transport of ions across the electrode and the electrolyte. Chromium-based interconnect oxidation is another important mode that contributes to reducing electrical conductivity between the electrode and interconnect. Sometimes ceramic coatings are used to slow down the rate of oxidation and reduce the rate of chromia evaporation from the interconnects. It was also shown that the loss of performance resulting from interconnect detachment is less severe than that caused by electrode delamination because blocked transport of electrons can now easily move laterally in the electrodes as compared to ions being able to move within the electrolyte. The modeling exercise indicated that results of delamination are highly dependent on the inaccuracies in the knowledge of various cell parameters.

The severe temperature and electrochemical conditions in a solid oxide cell create the need for special materials and pose important challenges to the longevity of the different cell components. The requirements of a solid oxide cell are to facilitate chemical reactions and remove reaction products with the lowest possible resistance. Therefore, in a cell, the density of reaction sites (sites per unit cell area) and transport paths should be maximized. For a solid oxide cell to be commercially viable, it should have a 40,000-50,000-hour lifetime. In order to facilitate such a long life, the degradation rate must be very low in all components of the cell stack. It is therefore important to have a fundamental understanding of the degradation mechanism for each component. During operation, any change in the cell that causes blocked reaction sites or transport paths for species will increase the overall cell resistance and thereby the degradation.

One important term used for describing reactions at both electrodes is the so-called triple-phase boundary (TPB). The TPB describes a site in the electrode where the electrochemical reaction takes place, shown as red dots in Figure 11 (Hauch 2007a). At the steam $/ \mathrm{H}_{2}$ electrode, this site is where all three phases (Ni, YSZ, and gas) are in contact with each other. Since the supply of oxygen ions at YSZ, supply of gas in the pores, and means of transporting the electrons away from Ni are simultaneously required, the electrochemical reactions are facilitated at the TPB. Therefore, in order to optimize the electrode performance, it is important to maximize the electrochemical activity at the TPBs. For a reaction to take place at the TPB, the gas stream must flow through the pores, Ni must be connected to the interconnect plate, and the YSZ must be connected to the electrolyte either directly or via YSZ in the electrode. Changes in the electrode-electrolyte interfaces and grain boundaries are highly influential in the degradation of the cell. These interfaces not only provide the TPB, but are also active for mass transfer, diffusion, and segregation of species involved in the fuel cell reactions during operation. Microstructural changes in the interfacial regions, such as impurity segregation, will also affect the cell's performance. 


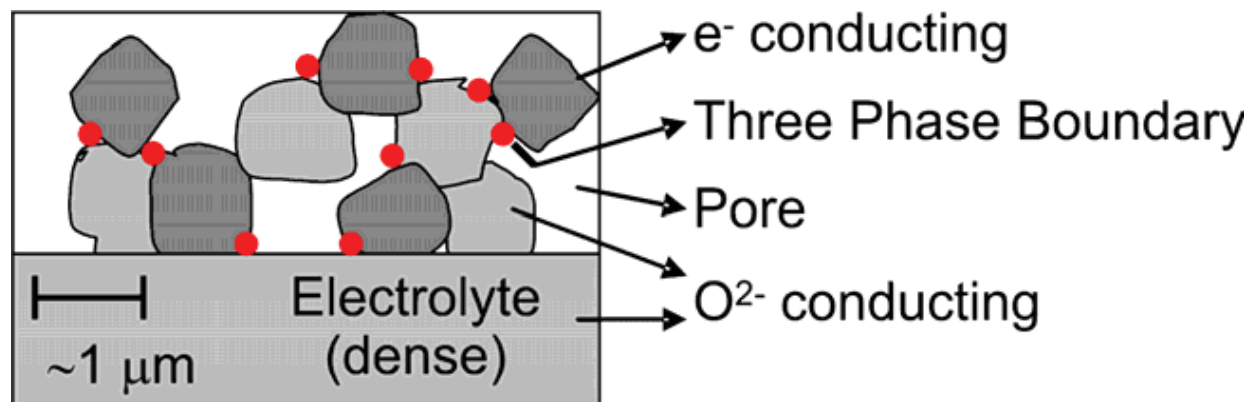

Figure 11. TPBs in a solid oxide cell, shown as red dots, where reactions take place (Hauch 2007a).

The problem of cell degradation also depends on the cell's operating conditions, such as operating temperature, because of increased atomic activity at higher temperatures. It has also been shown that the overall degradation in the cell voltage is more closely correlated to the polarization than to the current density. At high polarization and/or low temperatures $\left(\sim 750^{\circ} \mathrm{C}\right)$, the oxygen electrode (fuel cell cathode) degradation can be dominant. However, at low polarizations and/or higher temperatures, both electrodes contribute equally to the cell's degradation. From the impedance measurement, it is difficult to assign any degradation phenomenon responsible for overall cell degradation, which implies the importance of correlating electrical measurements with cell microstructural changes.

The mismatch in thermal expansion characteristics of the cell's different layers is a major cause of stresses during thermal cycling occurring during fabrication and operation. In addition, the nonequilibrium chemical reactions throughout the cell also generate large thermal gradients, which in turn generate thermal stresses. These thermo-mechanical phenomena cause the degradation of the contact between adjacent cell components, namely, the electrolyte-electrode and/or the interconnect-electrode interfaces. This degradation can lead to detachment of two adjacent layers, which results in reduced conductive paths available for electronic transport.

Another example of a degradation mechanism affecting SOFCs is the growth of an electrically insulating oxide layer between the interconnect plate and the electrodes, especially the fuel cell cathode. This leads to an increase in the cell ohmic resistance along the conductive path. The high temperature of operation promotes the kinetics of chromium oxide growth on the stainless steel interconnect plate. Extended periods of operation at high temperature and exposure to contaminants in the reactants also cause microstructural degradation. The electrochemical reactions in SOFCs are not restricted to the interface with the electrolyte, but take place within a few to tens of microns into the volume of the electrode. Therefore, a suitable electrode microstructure is of great importance in providing active surface area at the TPB for electrochemical reaction and sufficient porosity for gas species transport.

Consequently, degradation mechanisms that affect electrode microstructure can compromise the cell's performance, stability, and durability.

\subsection{INL Tests on Degradation in Short Stacks and ILS Stacks}

O'Brien (2009) recently summarized INL's test results on HTE tests using Ceramatec solid oxide cells including observations of long-term performance degradation of SOECs. Note that INL cells and stacks utilize scandia-stablized zirconia (ScSZ) electrolyte-supported cells, which do not necessarily represent the state-of-the-art in cell design. The scandia dopant level in these cells was only about 6 mol\%, which is not high enough to be considered fully stabilized. In addition, ScSZ with dopant levels less than $10 \%$ have been shown to exhibit an aging effect with annealing at $1,000^{\circ} \mathrm{C}$ (Haering et al. 2005).

Long-term degradation in button cell tests can only be due to degradation of the electrodes, the electrolyte, or electrode-electrolyte delamination. There are no effects associated with corrosion, contact 
resistance, flow channels, or interconnects, because these components are not present. The results of a long-term, button-cell test are presented in Figure 12. This figure shows the ASR of a button cell plotted as a function of time over the duration of an 1,100-hour test. The ASR increases quite rapidly at the start of the test from an initial value of $\sim 0.6 \mathrm{ohm} \mathrm{cm}$ to a value of $0.9 \mathrm{ohm} \mathrm{cm}$ over about 40 hours. Between 100 and 1,100 hours, the ASR increases from $0.98 \mathrm{ohm} \mathrm{cm}$ to $1.33 \mathrm{ohm} \mathrm{cm}$. If the initial 100 hours is considered to be a cell conditioning period, the degradation rate over the following 1,000 hours is about $35 \%$. This is obviously an unacceptable rate of degradation. As a comparison, the Phase-III DOE Solid State Energy Conversion Alliance (SECA) target degradation rate is 0.1\%/1,000 hours. Several companies are currently coming very close to meeting that target in the SOFC mode of operation.

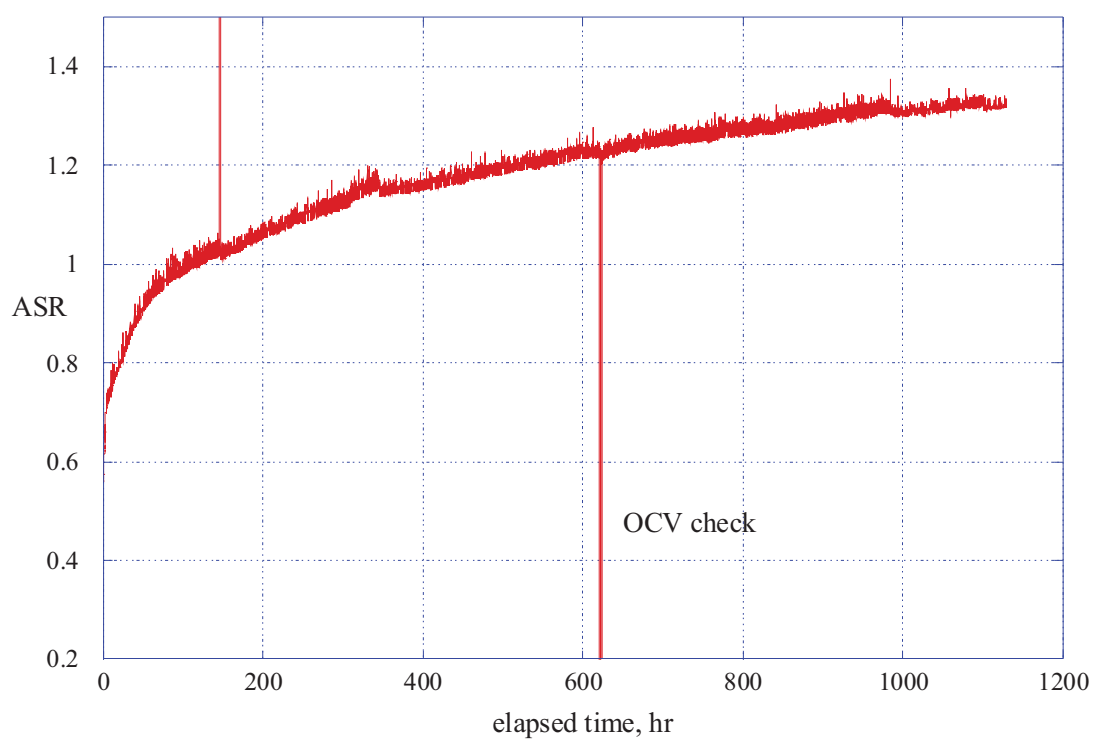

Figure 12. Area-specific resistance of a button cell as a function of time for the 1,100-hour test.

Performance degradation results with a 25-cell Ceramatec SOEC stack tested for 1,000 hours at INL were presented by O'Brien et al. (2007) and are shown in Figures 13 and 14. Figure 13 plots the stack $\mathrm{ASR}$ as a function of time for the 1,000 hours. The furnace temperature was increased from 800 to $830^{\circ} \mathrm{C}$ over an elapsed time of 118 hours, resulting in a sudden drop in ASR. The increase in ASR with time represents degradation in stack performance. The degradation rate decreases with time and is relatively low for the last 200 hours of the test. However, from the 118-hour mark to the end of the test, the ASR increased more than $40 \%$ over approximately 900 hours. Reduction of this performance degradation is an objective of ongoing research. Figure 14 shows the corresponding generation of hydrogen. 


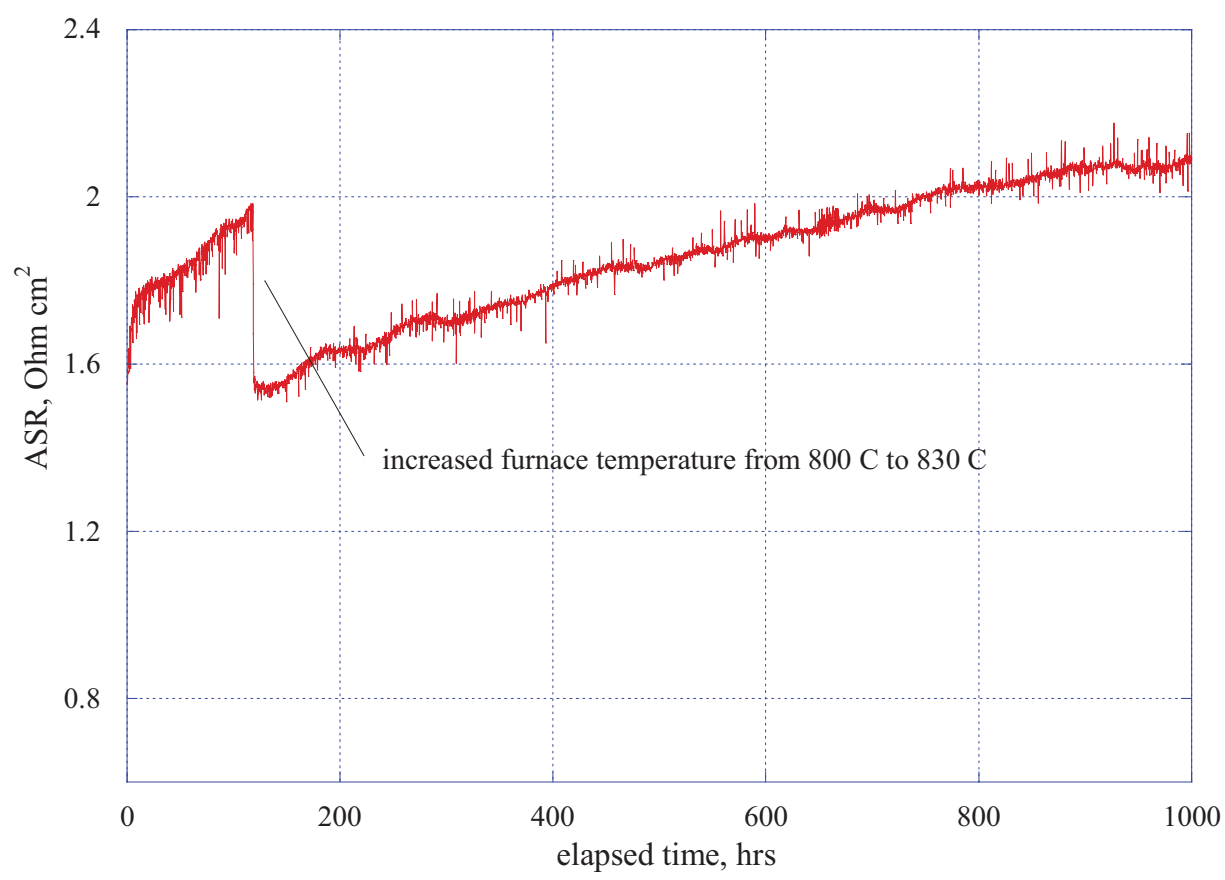

Figure 13. Area-specific resistance of a 25 -cell stack as a function of time for a 1,000-hour test.

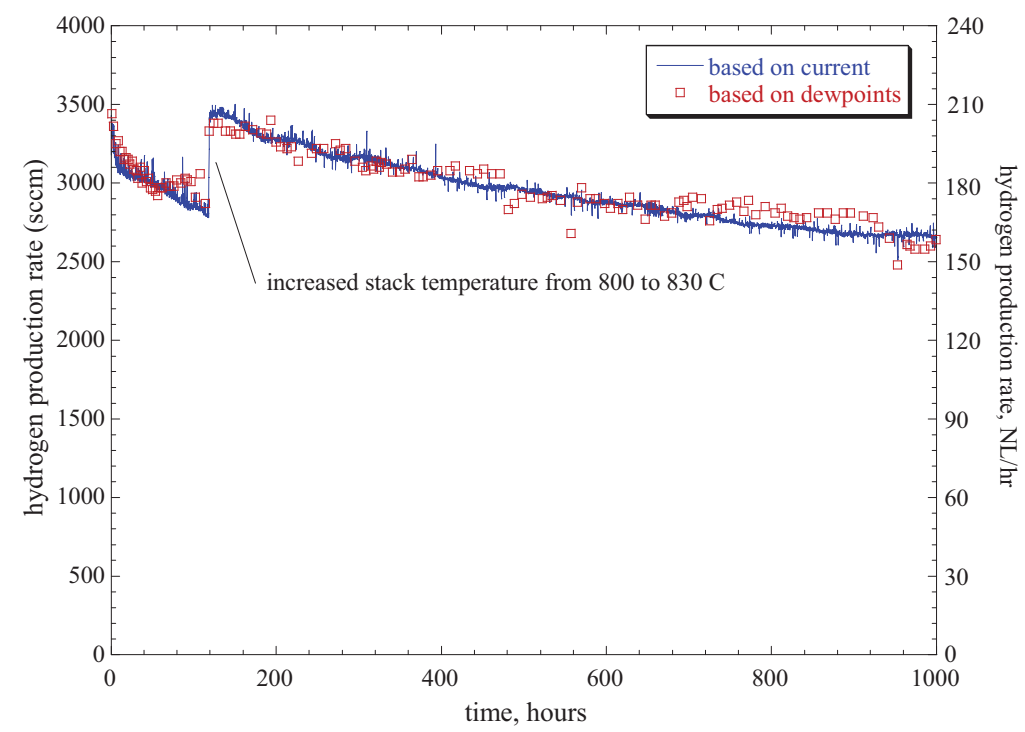

Figure 14. Hydrogen production rates during 1,000-hour long-term test.

Performance degradation of the ILS system using Ceramatec stacks is documented in Figure 15. Over a test period of 700 hours, module-average ASR value increased by about a factor of $\sim 5$, from an initial value near $1.5 \mathrm{ohm}-\mathrm{cm}^{2}$. Some of the observed degradation was caused by balance-of-plant issues. For example, prior to $\sim 480$ hours of testing, unexpected condensation occurred in the hydrogen recycle system. It led to erratic behavior of the hydrogen mass flow rate controller due to the presence of liquid water in it. This problem led to time periods during which there may have been no hydrogen flow to the ILS stacks, leading to accelerated performance degradation associated with oxidation of the nickel cermet electrodes. A plot of the time history of ILS hydrogen production is given in Figure 16. Peak electrolysis 
power consumption and hydrogen production rate were $18 \mathrm{~kW}$ and $5.7 \mathrm{Nm} / \mathrm{hr}$, respectively, achieved at about 17 hours of elapsed test time.

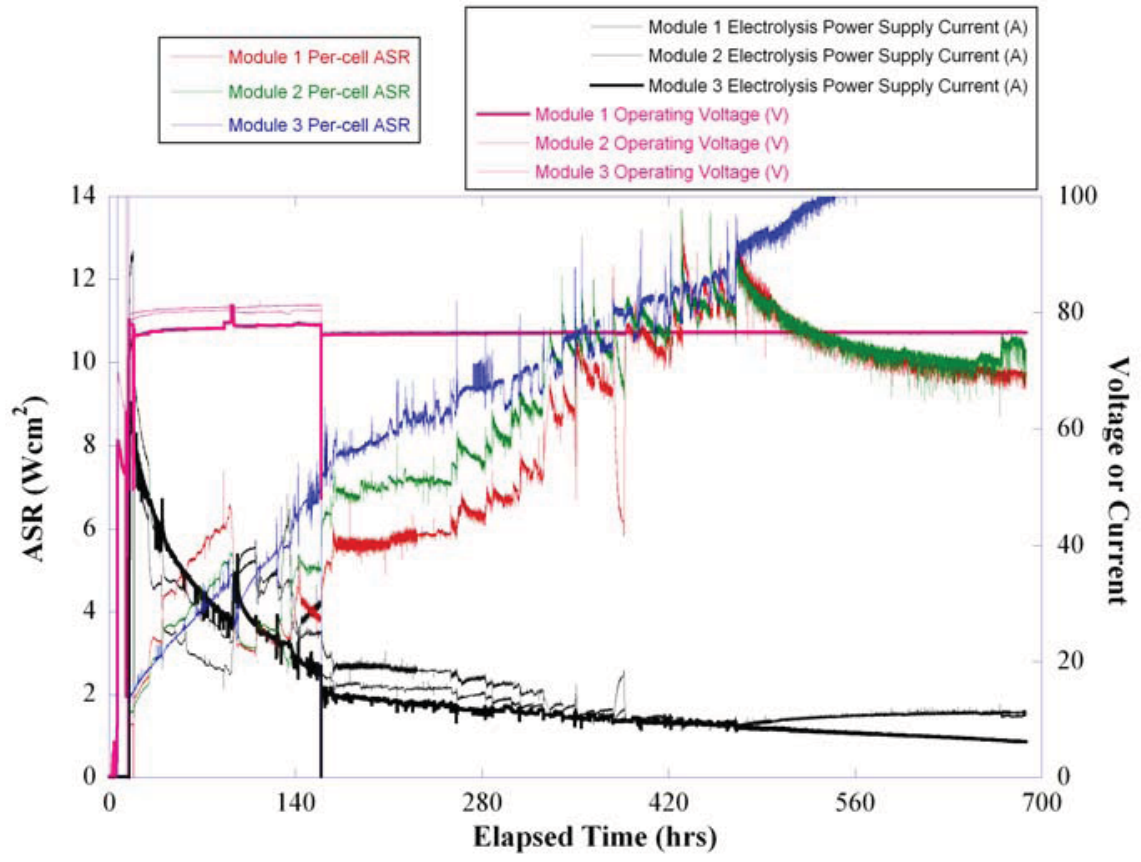

Figure 15. Time history of ILS module ASR values, voltages, and current over 700 hours of operation.

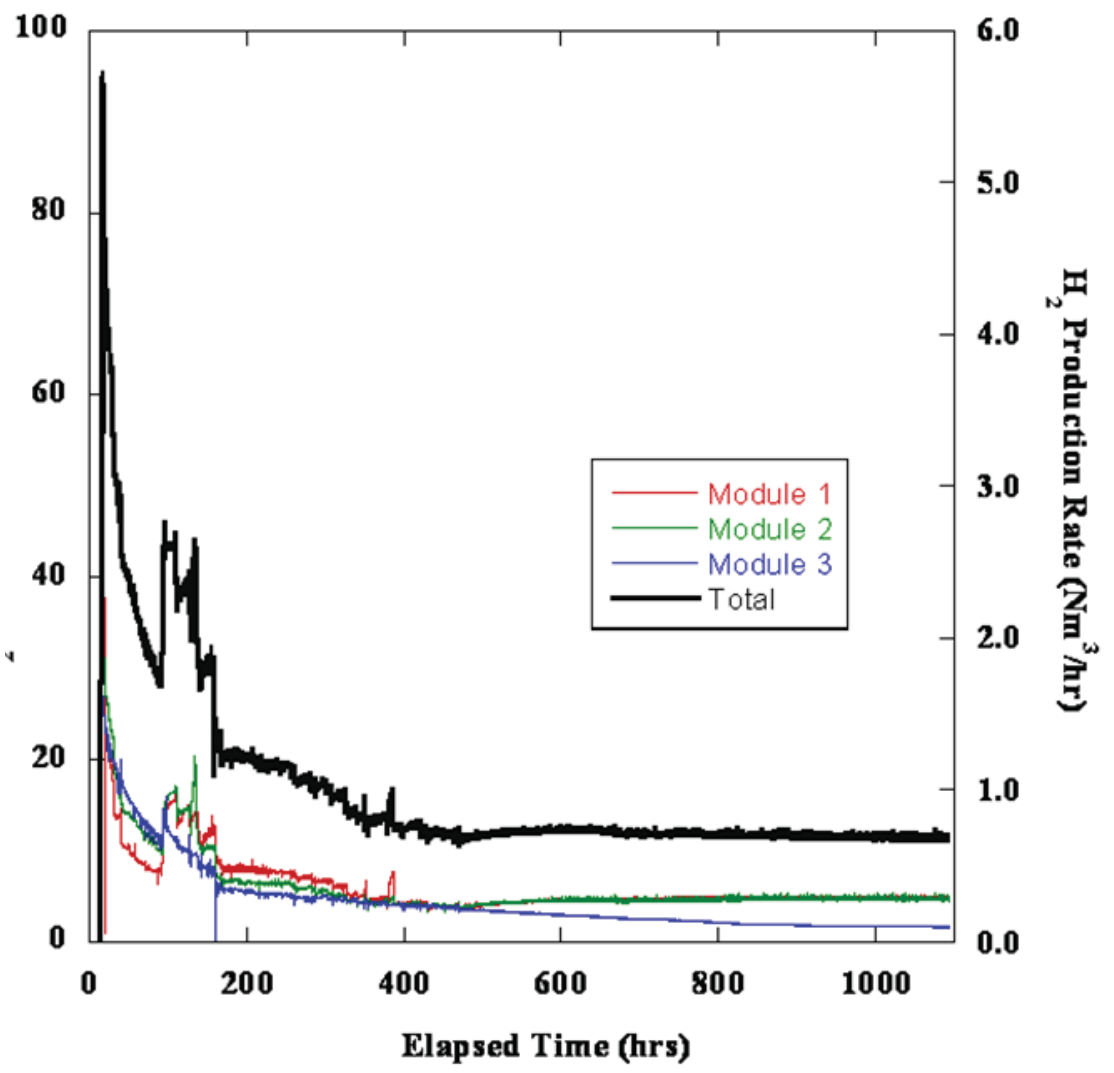

Figure 16. Time history of hydrogen production rate in the ILS. 


\subsection{Discussion on Some Aspects of ILS Test Results}

The ILS was operated continuously for 1,080 hours. Operation and performance of each major component of the ILS is discussed in detail in the following sections.

On many of the data plots shown in the following sections, complex system performance may be observed until approximately 480 hours test duration. This behavior was due to condensation forming in the hydrogen recycle system. The hydrogen product passes through a condenser before entering the hydrogen recycle system. The condenser removes excess water vapor from the gas stream, but a residual amount remains (about $3 \%$ by volume). Since the hydrogen recycle system operates at elevated pressure, additional water condenses out in the system. When designing the system, INL engineers assumed that this additional water condensate would collect in the hydrogen recycle storage tank. In reality, condensate formed throughout the hydrogen recycle system, including upstream of the hydrogen mass flow controllers. Occasionally, liquid water droplets were driven downstream by the gas flow and entered the mass flow controllers. This caused erratic behavior in the mass flow controllers, as displayed graphically in Figure 17.

Figure 17 is a complete time history trace for ILS module area-specific resistance (ASR) and $\mathrm{H}_{2}$ recycle flow rate for each module. For elapsed times earlier than 480 hours, $\mathrm{H}_{2}$ recycle flow rates exhibited spikes. After the problem was discovered, operators periodically removed the suspect mass flow controller and shook out liquid water. When reinstalled, the mass flow controller operated properly again until the behavior reappeared. Operators also installed heat tracing on the tubing upstream of the controllers, but this did not improve performance. Finally, a liquid water trap and receiver vessel were installed immediately upstream of the mass flow controllers. A water-cooled sleeve was added as well. These modifications solved the problem and only required periodic emptying of the receiver vessel. The improvement in mass flow controller behavior is obvious in the values in Figure 17 beyond 480 hours test time.

Unfortunately, the condensate problem may have caused accelerated degradation of the ILS modules. Again referring to Figure 17, the module ASR values rise sharply with time up to 480 hours. Beyond 480 hours, the ASR values for modules 1 and 2 actually decrease and ultimately level out while the ASR for module 3 continues to increase. Condensate interfering with the $\mathrm{H}_{2}$ recycle mass flow controllers caused interruptions in $\mathrm{H}_{2}$ flow. These interruptions could have caused electrode oxidation to occur in the modules. Once $\mathrm{H}_{2}$ flow resumed, reduction would occur on the electrode surfaces. This cycling of oxidation and reduction may have contributed to the high rate of performance degradation observed. The reason for the continued performance degradation of Module 3 after the condensation problem was solved, while Modules 1 and 2 improved, is not understood. 


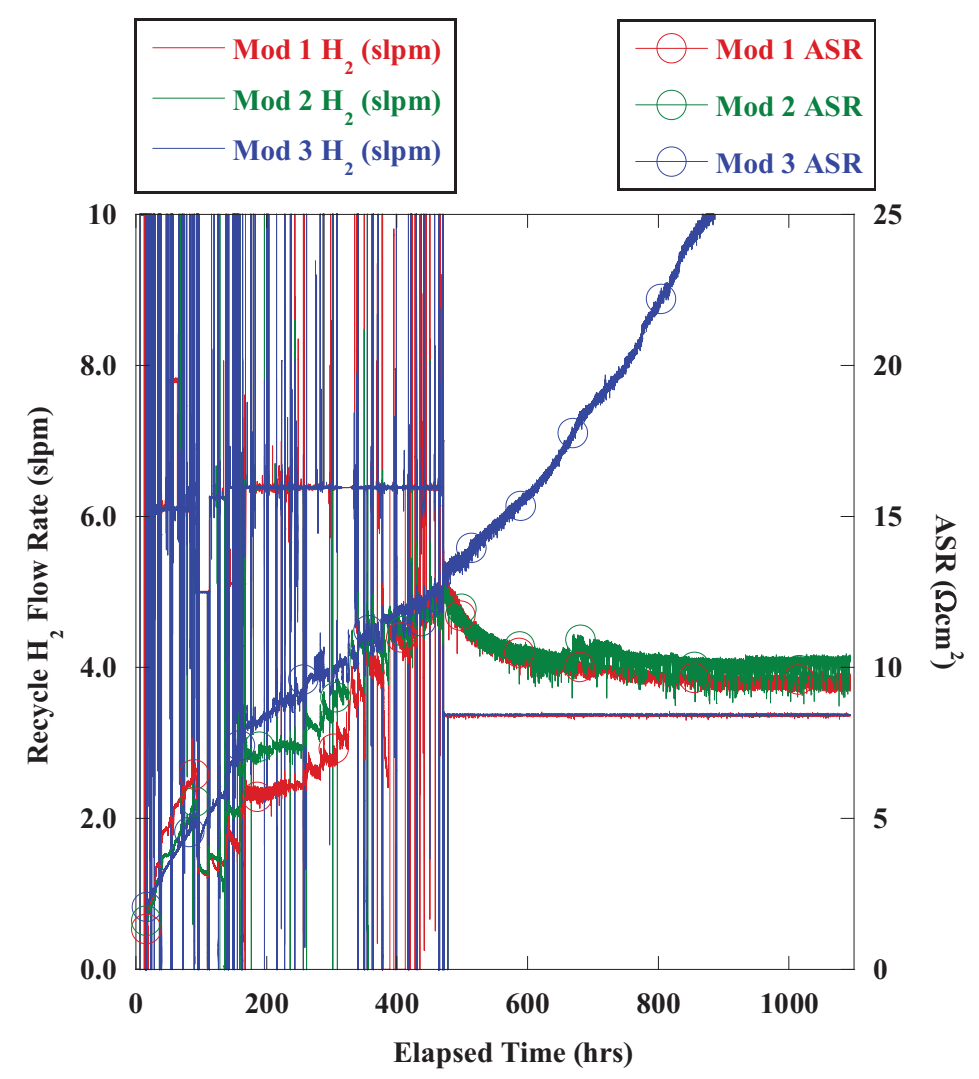

Figure 17. Full history of module ASRs and $\mathrm{H}_{2}$ recycle flow rates.

Hydrogen production rate for the test duration is displayed in Figure 16. Peak $\mathrm{H}_{2}$ production rate of $5.7 \mathrm{Nm}^{3} / \mathrm{hr}$ and peak electrolysis power input of $18 \mathrm{~kW}$ were achieved after $\sim 17$ hours elapsed test time (Figure 18). Module ASRs ranged from $1.25 \Omega \mathrm{cm}^{2}$ to just over $2 \Omega \mathrm{cm}^{2}$. Total $\mathrm{H}_{2}$ production rate decreased from $5.7 \mathrm{Nm}^{3} / \mathrm{hr}$ to a steady state value of $0.7 \mathrm{Nm}^{3} / \mathrm{hr}$. The decrease was primarily due to cell degradation. Adjustments in electrolyzer power supply voltage had to be made as well to maintain internal stack temperatures within an acceptable range (Figure 19). Most of the test was conducted at a constant electrolyzer power supply voltage of $76 \mathrm{~V}$. 


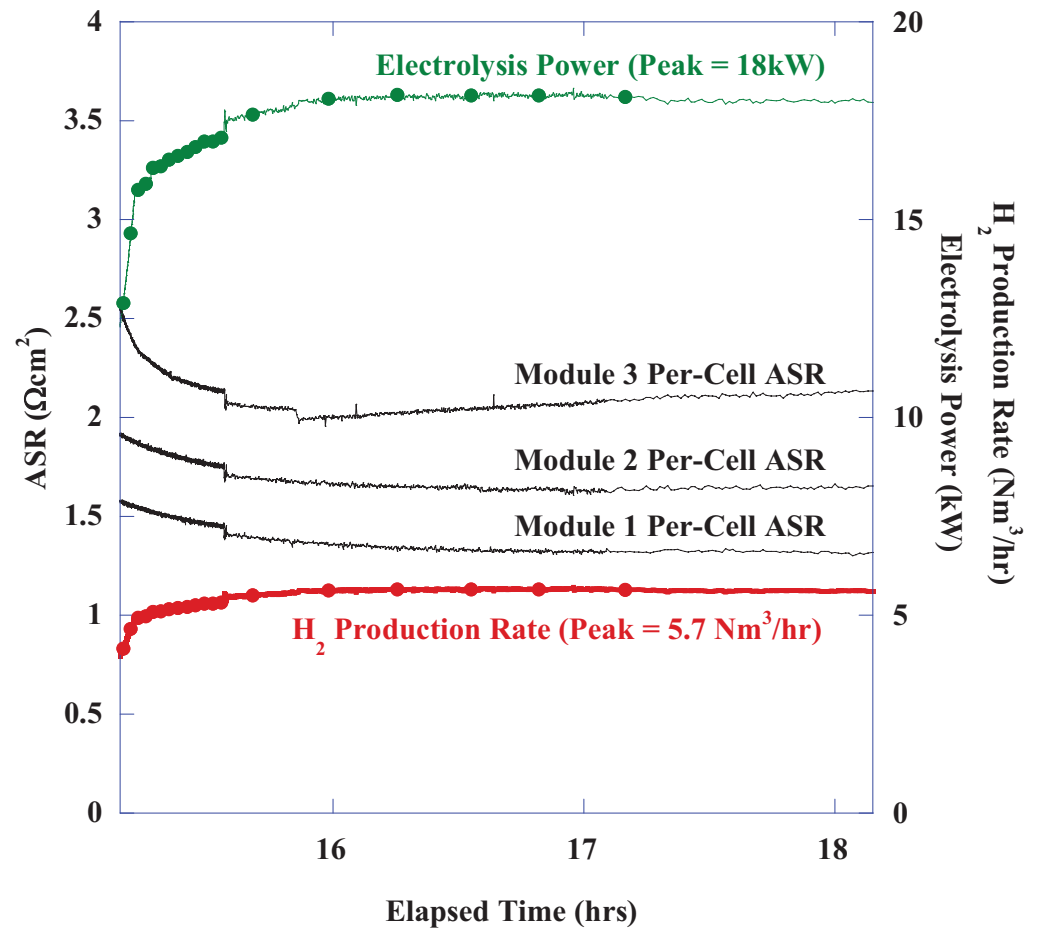

Figure 18. Peak electrolysis power, $\mathrm{H}_{2}$ production rate, and ASRs.

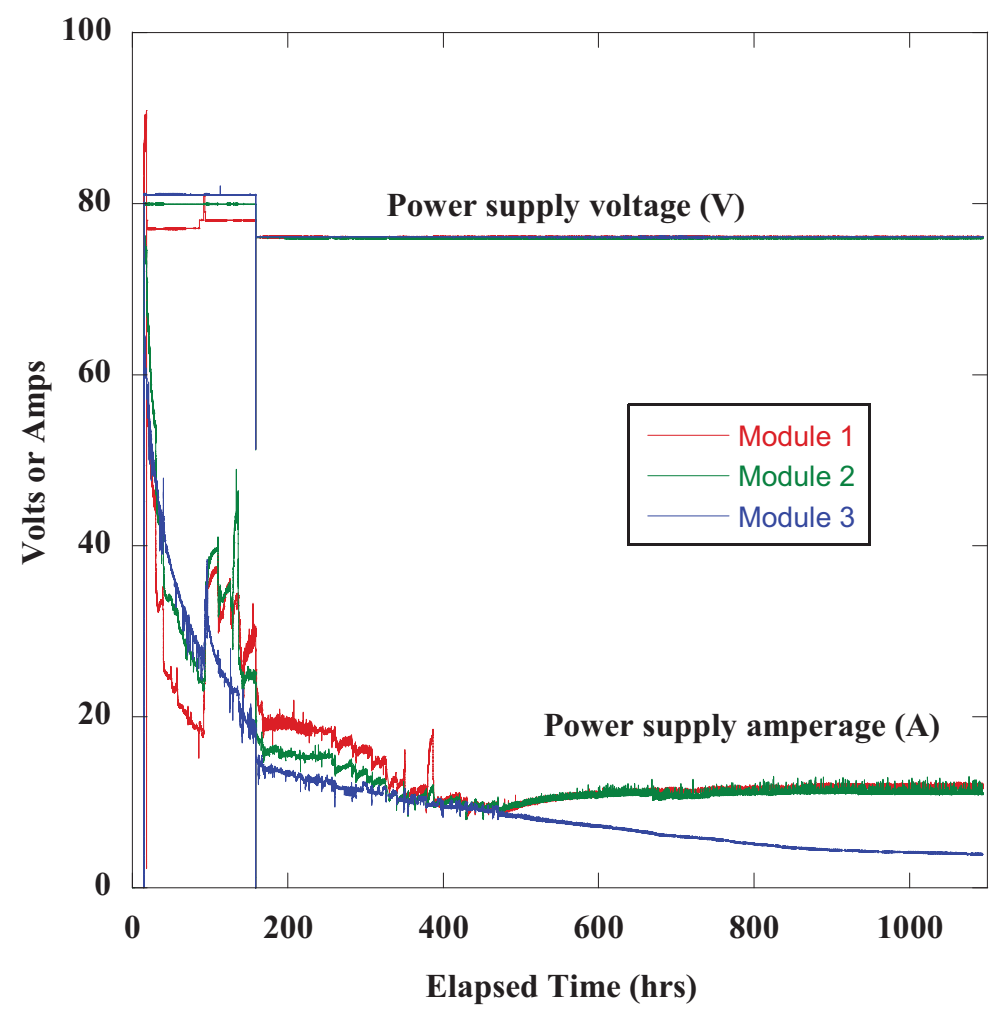

Figure 19. Time history of electrolyzer power supply amperage and voltage. 


\section{POST-TEST EXAMINATION OF SOLID OXIDE ELECTROLYSIS CELLS}

In order to understand the degradation behavior of SOECs, material composition, microstructure, and microchemistry of both, the cells' electrodes, electrolyte, and interconnects must be known prior to performing the experiments. This is essential in understanding cell degradation when post-test examinations are performed on a cell. However, some proprietary details about the cell composition and patented fabrication technique are unlikely to be disclosed.

\subsection{Post-Test Examination of ILS SOEC by Ceramatec}

\subsubsection{Stack Disassembly}

Module 3 was delivered to Ceramatec with the base plate attached (Figure 20). The stainless steel bolts that held the hydrogen manifolds on were cut or broken off and the air manifold cover removed. The electrical tie bars were cut and each pair of stacks was removed from the base plate. Then the tie bars were cut from the interconnect tabs using an abrasive cutoff wheel on an angle grinder.

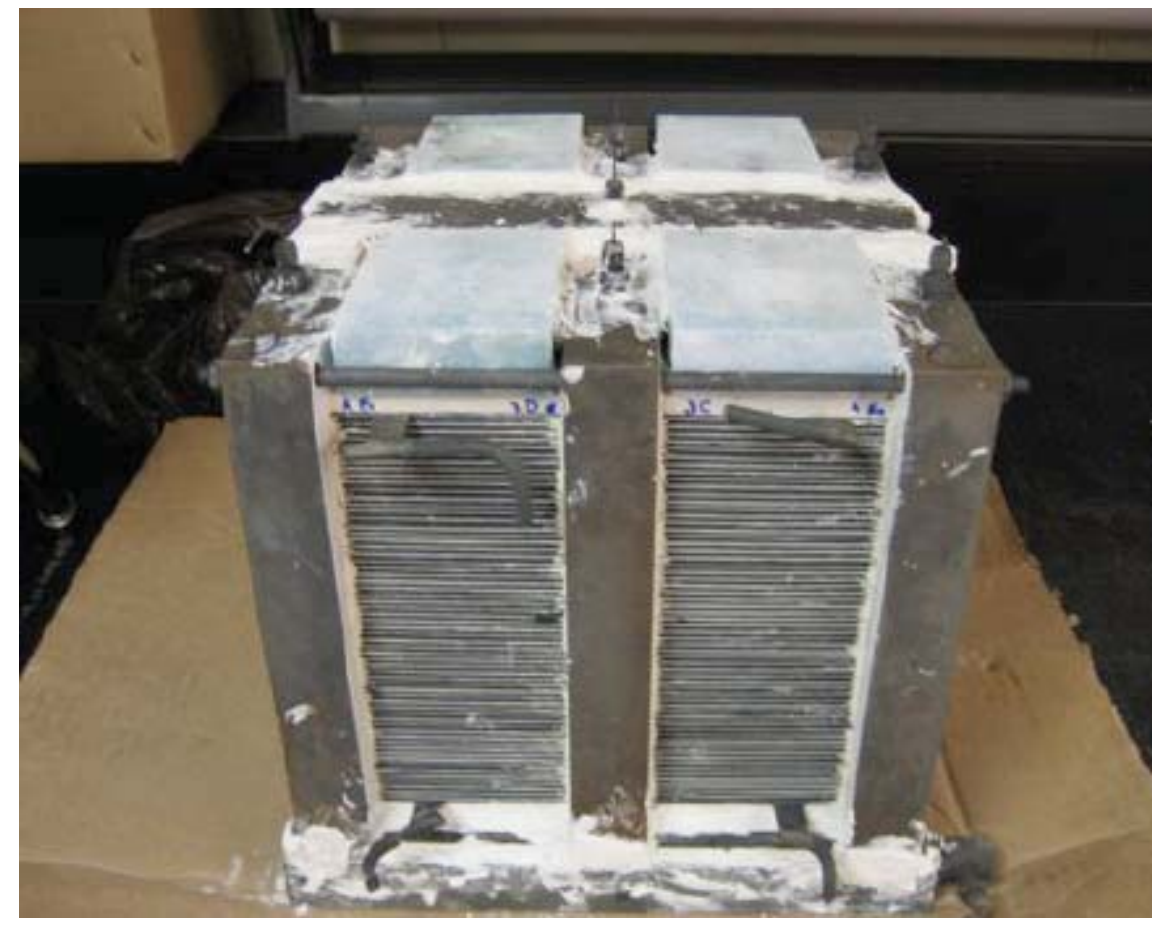

Figure 20. ILS Module 3 on base plate.

The base plate condition was good, with no evidence of gas leaking from the ports or seals although the seal paste was heavily cracked (Figure 21). The overall appearance of the exterior faces of the stacks was also good. There was very little evidence of hydrogen burning due to cracked cells or leaking manifold seals. No areas of runaway scale growth on the edge rails could be observed from the exposed air exhaust side. 


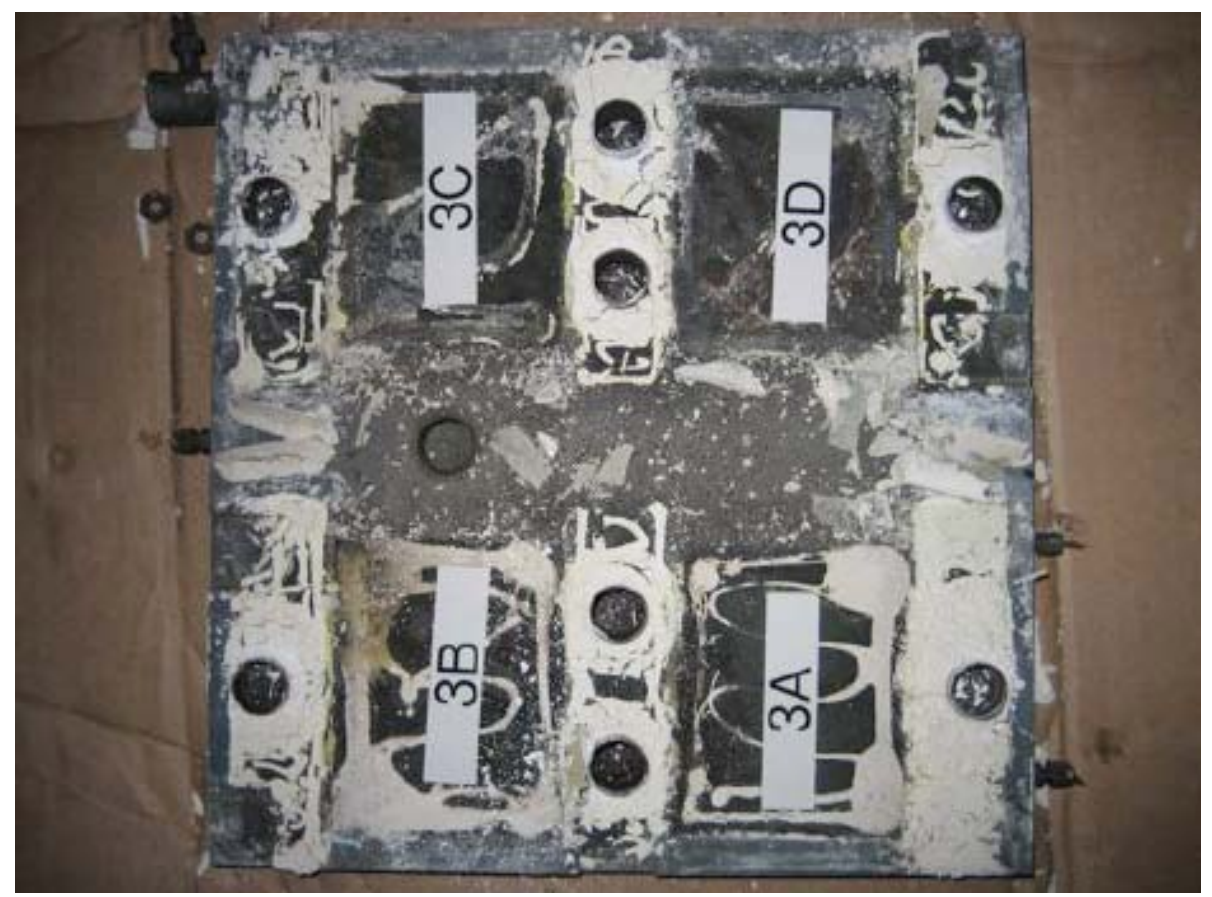

Figure 21. Module 3 base plate after stacks were removed.

Before the stacks were disassembled, sections were tied together using wire ribbon spot-welded to icon edges to save areas undisturbed for future examination or for cross sectioning and SEM evaluation. Cells 6-10 were welded together as well as Cells 31-35 and Cells 51-55. These have been saved for future examination. Repeat units around Cell 15 and Cell 46 were welded together to be potted up for cross-section examination.

After the stacks were clamped to compress them enough to be removed from the manifolds, the manifolds were removed by lightly tapping on the corners with a hammer. The stacks were then righted and the clamps removed. The hydrogen manifolds showed small signs of gas mixing by the presence of greenish stains at various locations (Figure 22). The manifold plasma spray insulation layer had spalled off in some non-critical areas. 


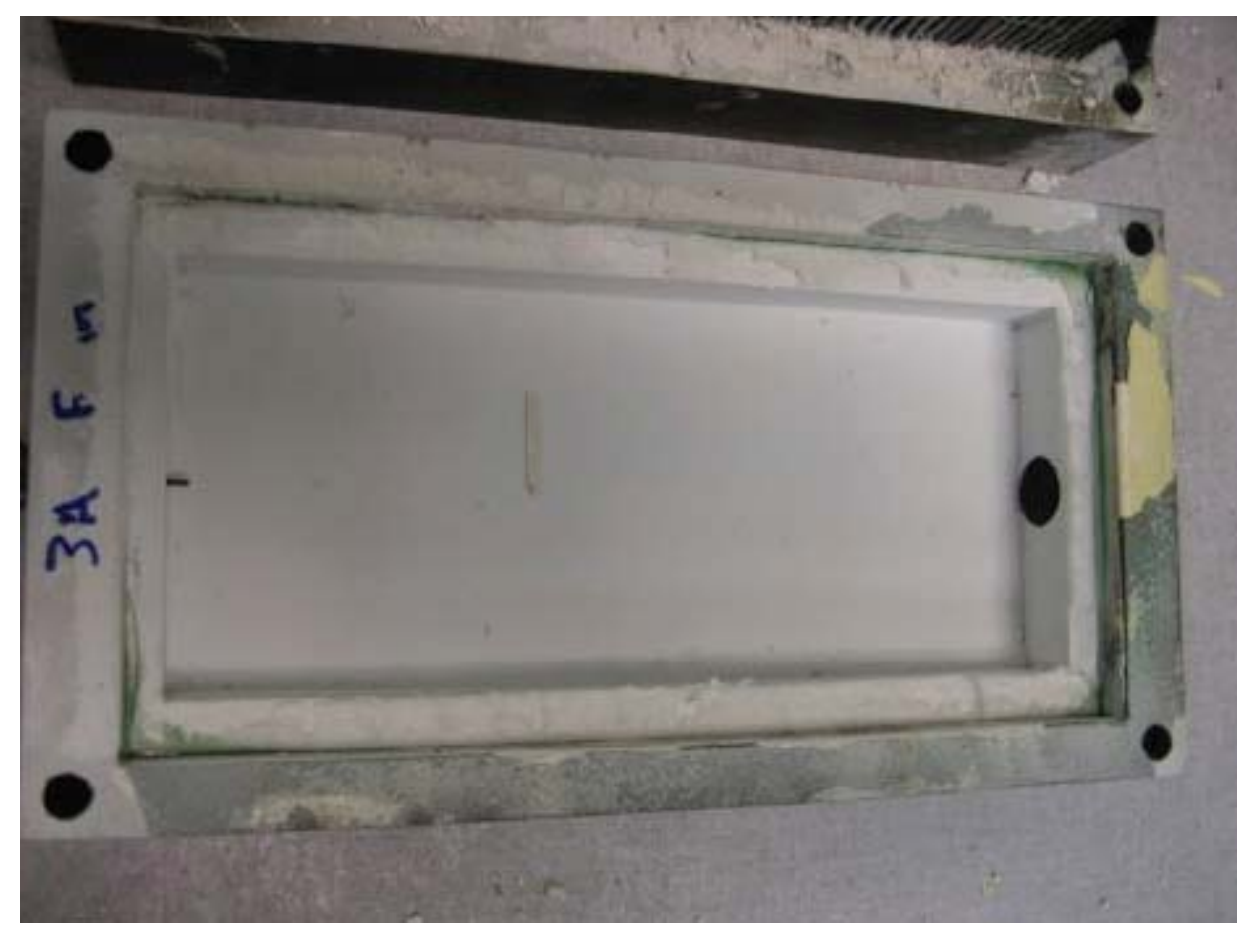

Figure 22. Hydrogen manifold showing green deposit due to gas mixing.

\subsubsection{Stack $3 A$}

Overall impression of the cells is that all the hydrogen side electrodes were partially to mostly oxidized. It is likely that this is from the lack of hydrogen on cool down after the test operation was concluded. The electrode was well attached and grayish in appearance but nonconductive. The Ni bond layer was green, indicating some oxidation. This layer had low resistance (around $3 \Omega$ ) where it pulled away from the electrode, but the flow channel side of the layer was nonconductive. The nickel felt was dark grayish black and could have been conductive around $6 \mathrm{ohms}$ or nonconductive, depending on how deeply the probe contacted. The hydrogen side flow channels were a dark metallic color and had high resistances on the order of $50 \mathrm{M} \Omega$. The Ni bond layer on the separator plate under the flow channel had low resistance at about $15 \Omega$. The cells were difficult to separate from the hydrogen side flow channels and a few cells cracked during separation. There was a little evidence of gas mixing on the hydrogen side, and most cells had a darker green electrode region that extended into the first hydrogen channel on each side from the small amount of air leaking through the edge seal. Figures 23 and 24 show representative samples of hydrogen side components. 


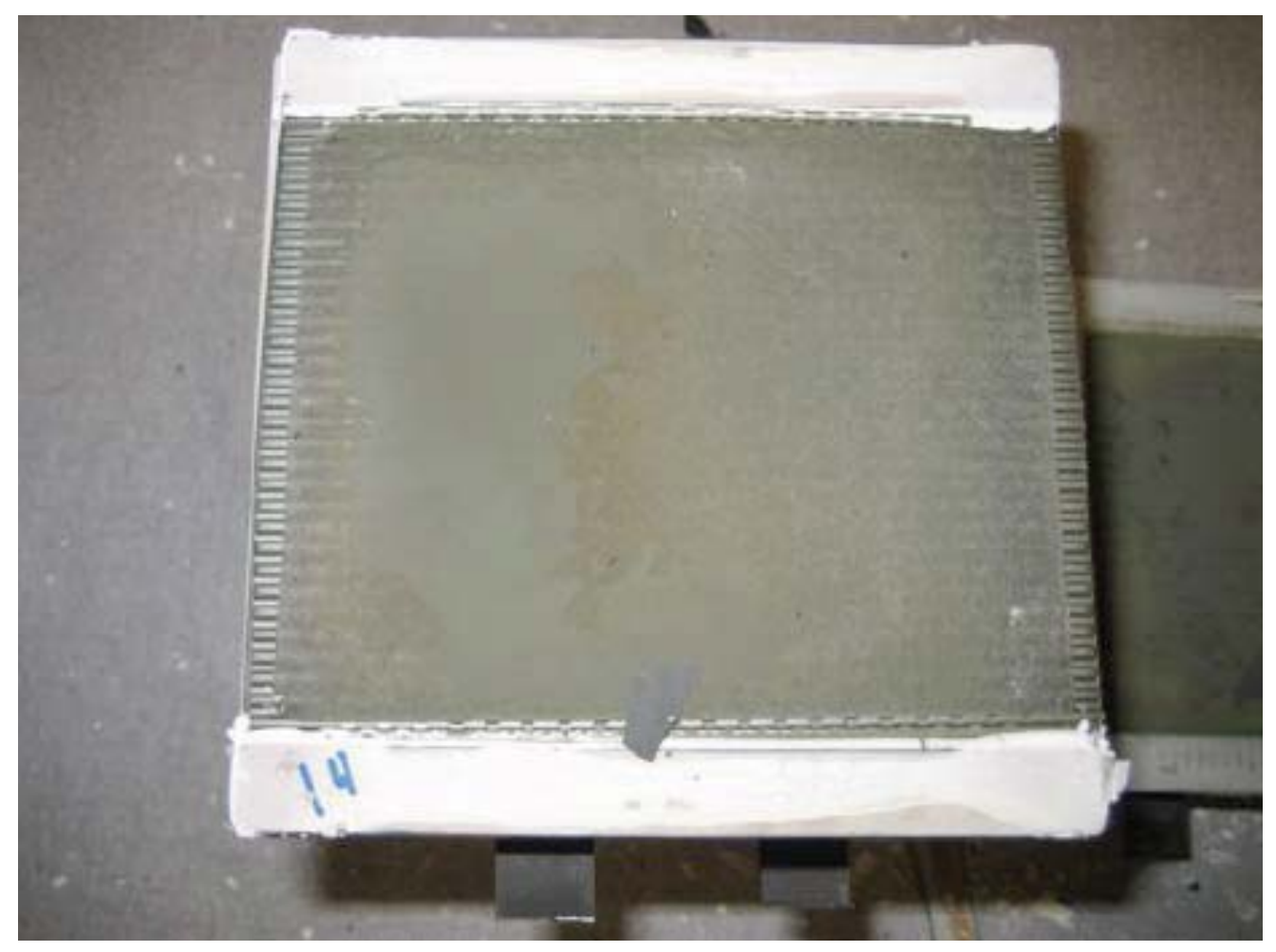

Figure 23. Hydrogen side interconnect, flow channel, and felt.

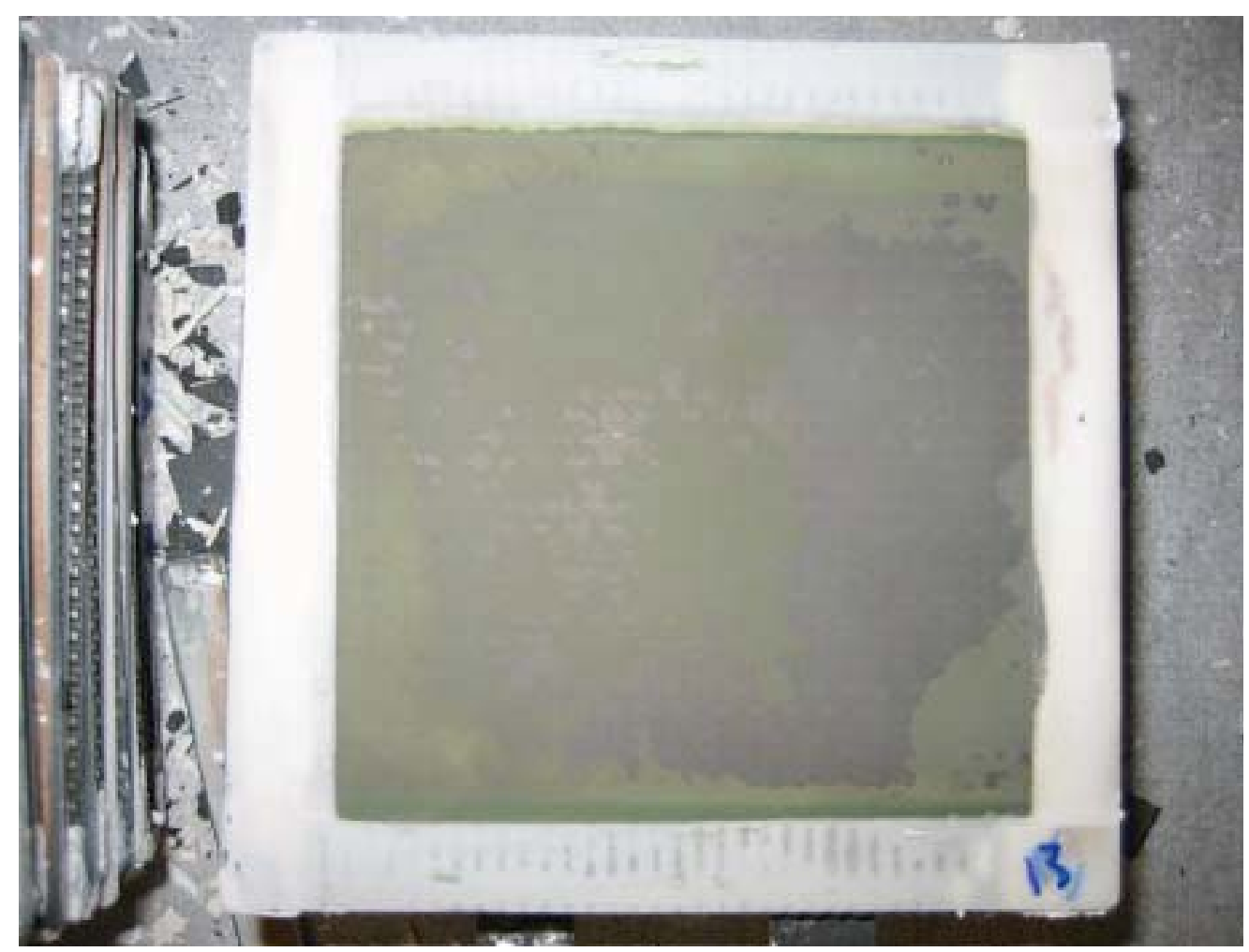

Figure 24. Cell hydrogen electrode after separation from interconnect. 
The air/oxygen electrodes of most cells have $50 \%$ or greater of the electrode area showing delaminating from the electrolyte. There were at least three cells with $100 \%$ delamination of oxygen electrode. The oxygen electrode was delaminated in large sections of roughly $2 \mathrm{~cm} \times 2 \mathrm{~cm}$ that curled away from the electrolyte. Along the edges of the cell positioned inside the hydrogen inlet and exhaust manifolds, the electrode was still mostly attached, but darker in color. This may be an indication of a slight hydrogen leak through the edge seals. This leak rate was relatively low, since the electrode material was still intact and not crumbling off or greenish, as has been seen in stacks where hydrogen leakage was sufficient to partially reduce the perovskite. The exposed electrolyte underneath the delaminated electrode showed a dark stain at the locations that corresponded to the flow channel ribs. Figures 25 and 26 show typical air side cell and interconnect parts.

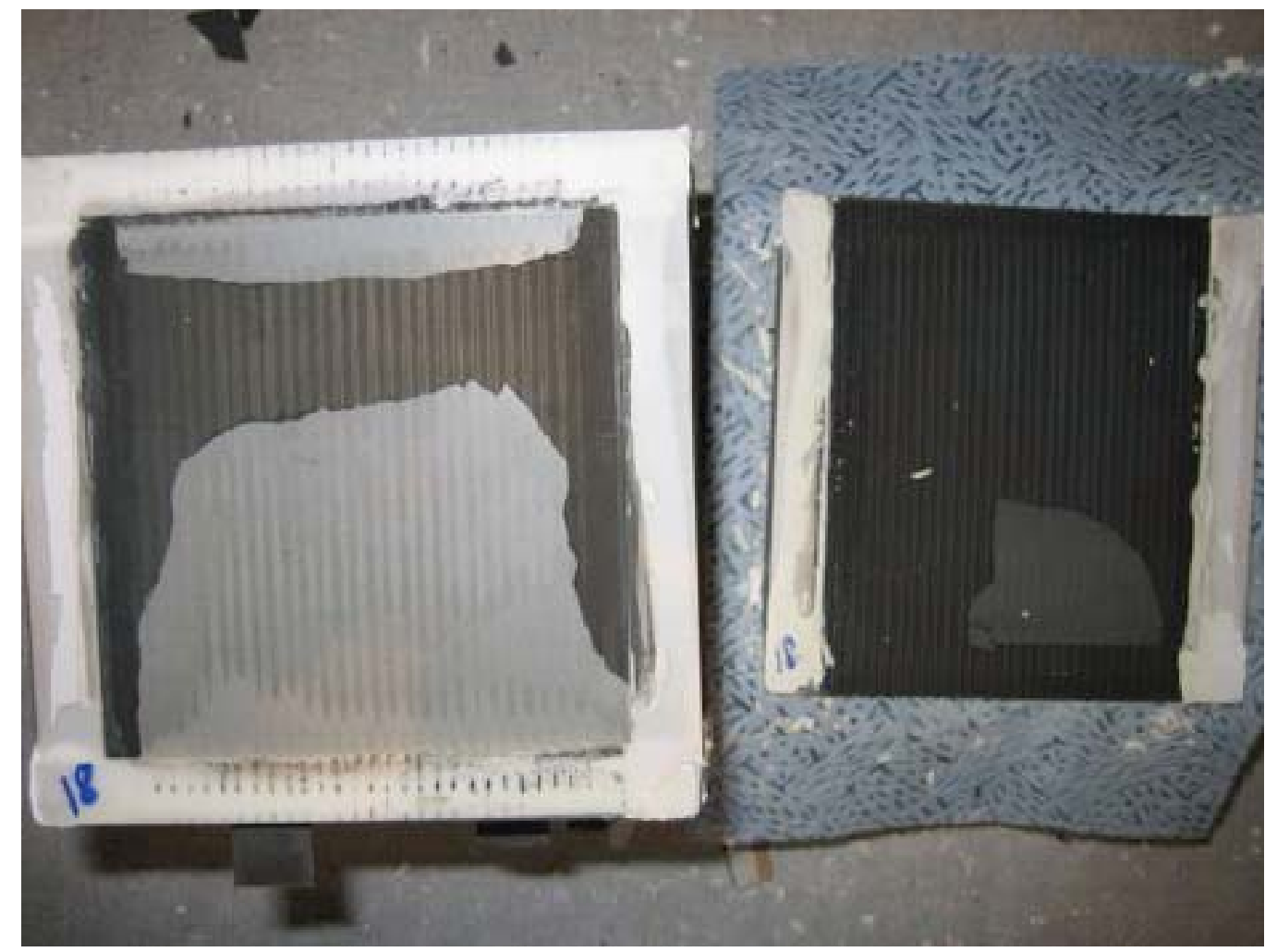

Figure 25. Cell and interconnect surfaces from the oxygen electrode side of Cell 18. 


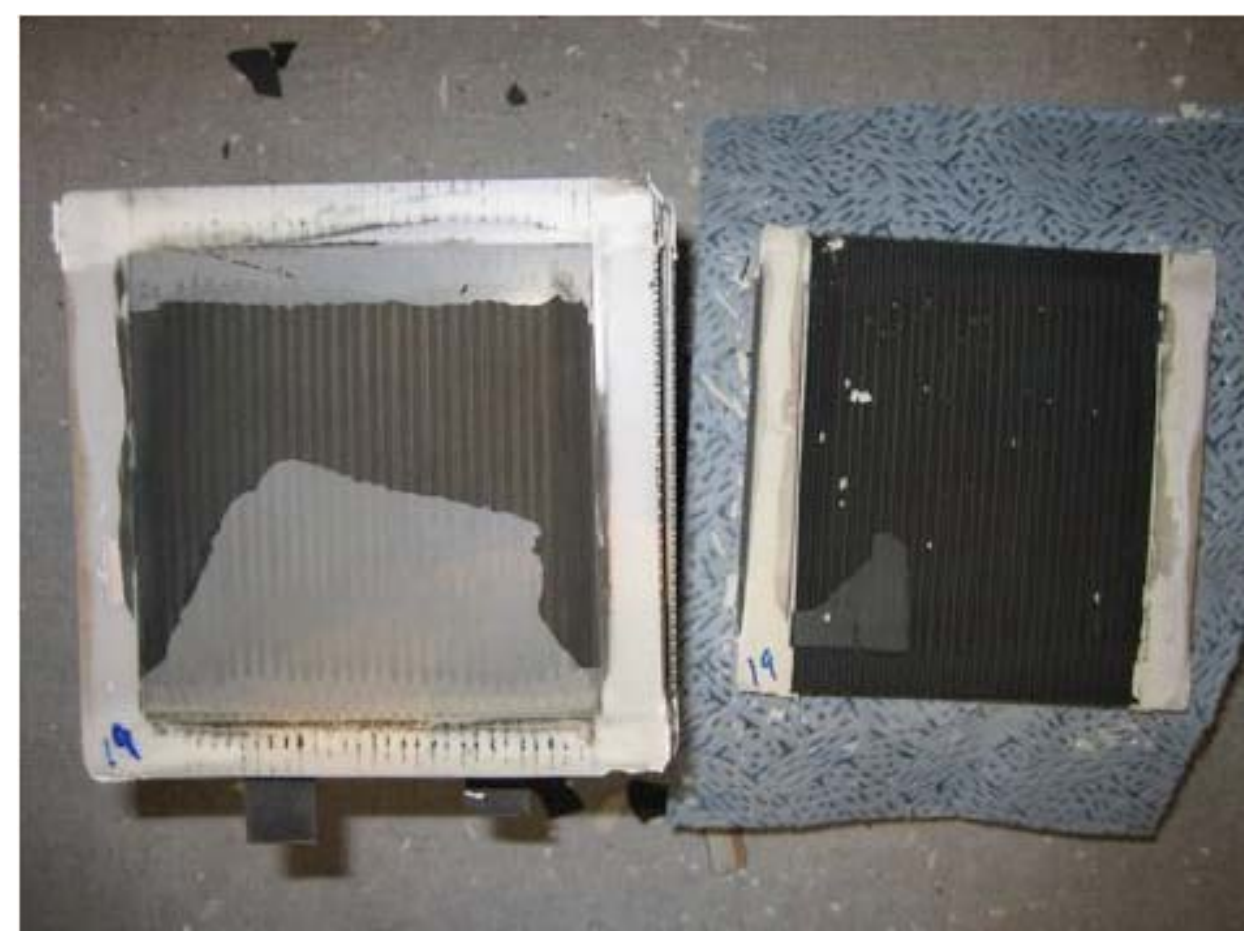

Figure 26. Cell and interconnect surfaces from the oxygen electrode side of Cell 19.

The attached regions of oxygen electrode had typical room temperature resistances of $100 \mathrm{k} \Omega$ across the cell. Cell side flow channel resistance values varied from $800 \mathrm{k} \Omega$ on the outer edges to less than $200 \mathrm{k}$ ohms about $0.5 \mathrm{~cm}$ in from the edges. The resistance of the flow channels from one side to the other was on the order of $60 \mathrm{k} \Omega$. The thin spinel ink layer did not impact the resistance values. The air side separator plate gave resistance probe measurements around $40 \mathrm{k} \Omega$. The separator plate LSC layer looked well bonded, but showed signs of leak from under the edge rails.

\subsubsection{Stack 3B}

The hydrogen side appearance and resistance values of cells and interconnects from Stack 3B were almost identical to those of $3 \mathrm{~A}$, but it was slightly harder to separate the cells from the interconnects (Figure 27). 


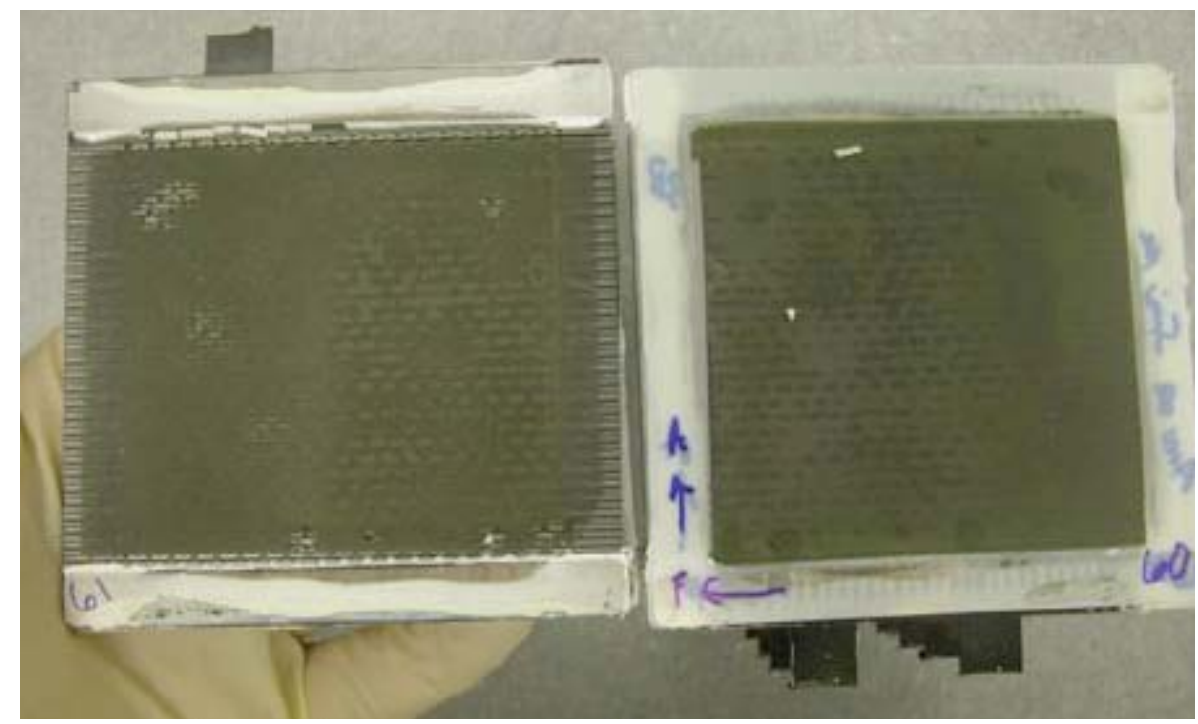

Figure 27. Hydrogen side cell and icon from Stack 3B.

The oxygen electrode side of cells from this stack looked better than those from 3A, since the electrode was delaminated less, with most of the cells only having electrode delamination along the oxygen inlet and exhaust edges to a distance of only $0.5 \mathrm{~cm}$ to $2 \mathrm{~cm}$ (less than $25 \%$ ). There were just a few cells that had over 50\% delamination, with the exception of the cell in contact with the air single flow (bottom cell), which was 100\% delaminated (Figure 28). The resistance measurements on the electrode and interconnect materials were in the same range as for Stack $3 \mathrm{~A}$.

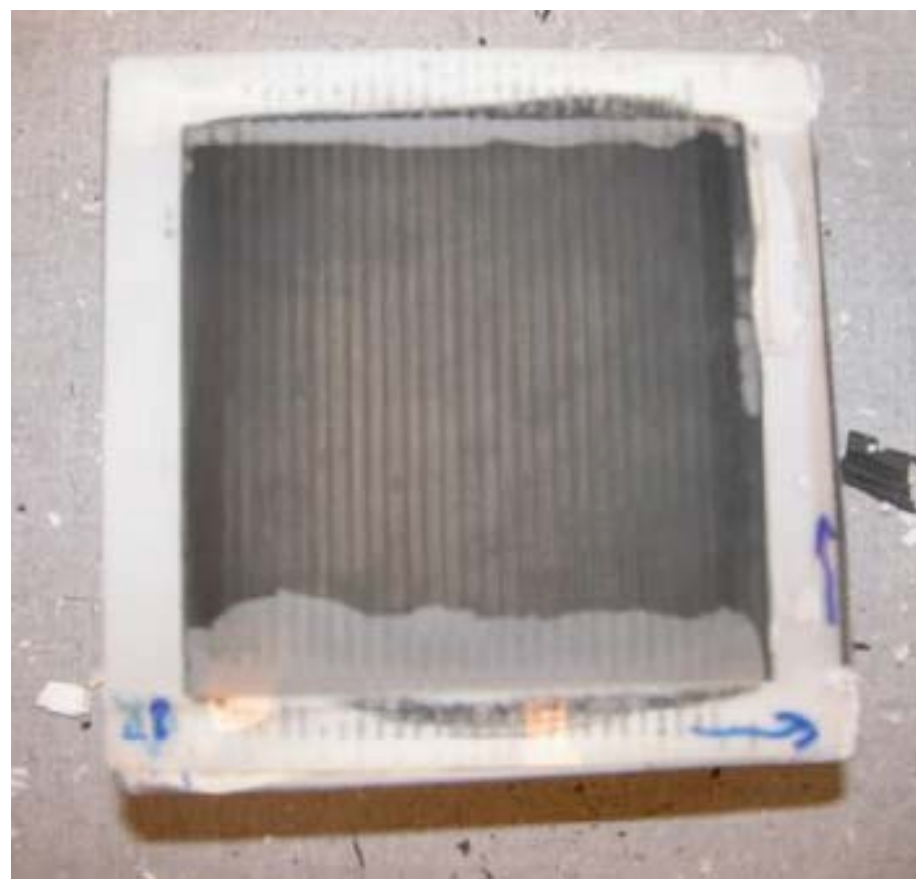

Figure 28. Air electrode of a typical cell from Stack 3B showing less electrode delamination than seen in Stack 3A. 


\subsubsection{Summary of Post-Test Examination}

The manifolds were tight fitting and the tested stack faces and edges looked good and did not show signs of significant leaking or burning. The hydrogen electrode side of all cells looked to be the same in both stacks, with the electrode and interconnect partially oxidized and mostly non-conductive. This is most likely caused by the hydrogen stream composition and flow rate during cool down. The resistance values for the oxygen electrode components of both stacks were consistent with expectations for roomtemperature material and were similar from cell to cell. The only notable difference between the two stacks would be the size of the areas of oxygen electrode delamination. The oxygen electrode side of both stacks seemed to be responsible for the observed degradation due to large areas of electrode delamination. Based on the oxygen electrode appearance, the degradation of these stacks was largely controlled by the oxygen electrode delamination rate. A post-test visual observation of the cells cannot tell why the electrodes delaminated like they did. The scanning electron microscopy (SEM) examination (in Section 5.2) will shed some light on why the oxygen electrodes experienced such extensive delamination. Initial SEM results are given here.

Nearly all cells were intact with the exception of one cracked cell in each stack that showed some leakage from one side to the other. Stack $3 \mathrm{~A}$ did have small cracks at the hydrogen exhaust corners on some cells from the tight-fitting manifolds, but they did not appear to cause leakage in the cell. They could have caused some gas mixing in the manifold corners and formed the greenish deposits on the manifolds that were previously noted. This lack of cracked cells in both stacks is an improvement from past stacks. The cell to flow channel contact appeared to be consistently achieved over the full cell area and did not appear to be as problematic as it had been in earlier stacks.

Stacks 3C and 3D were not disassembled based on the similarities between 3A and 3B and were saved for future disassembly based on potential SEM findings.

\subsection{SEM Analysis of ILS Stack: Stack A, Module 3, Cell 15.}

The SEM sample was prepared from the air inlet area of the cell/interconnect couple.

\subsubsection{Hydrogen Electrode}

The hydrogen electrode appeared to be in good condition and no abnormal chemistry changes were noted (Figure 29). This is consistent with the findings reported by Argonne National Laboratory (Carter 2008). A cross section of the cell is shown in the image below. The hydrogen electrode is on top and the oxygen electrode is on the bottom. The hydrogen electrode bond layer appears to have pulled away in separating the stack from the interconnect; however, indications are that this was attached in operation. The oxygen evolution electrode does show delamination in operation and an apparent foreign layer deposited at the electrolyte interface. 


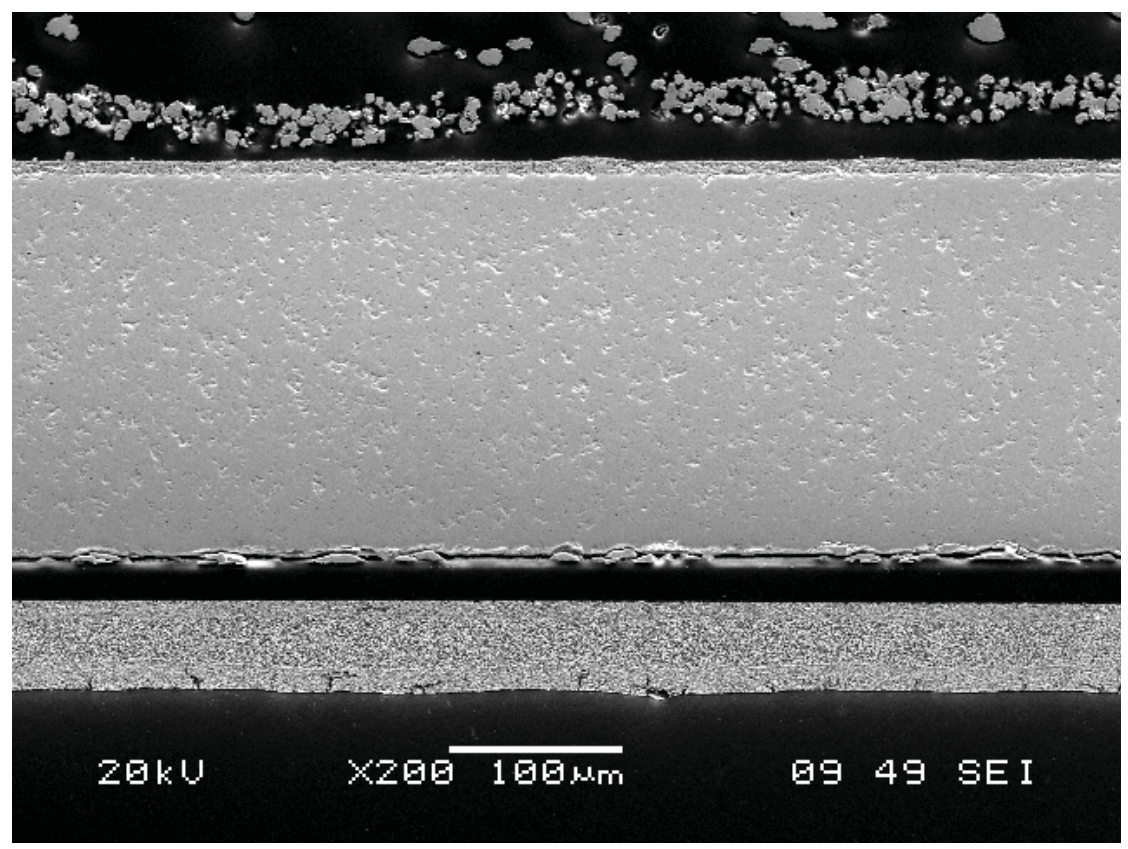

Figure 29. Hydrogen electrode in normal condition.

Current distribution layer (bond layer) got separated in disassembly (Figure 30).
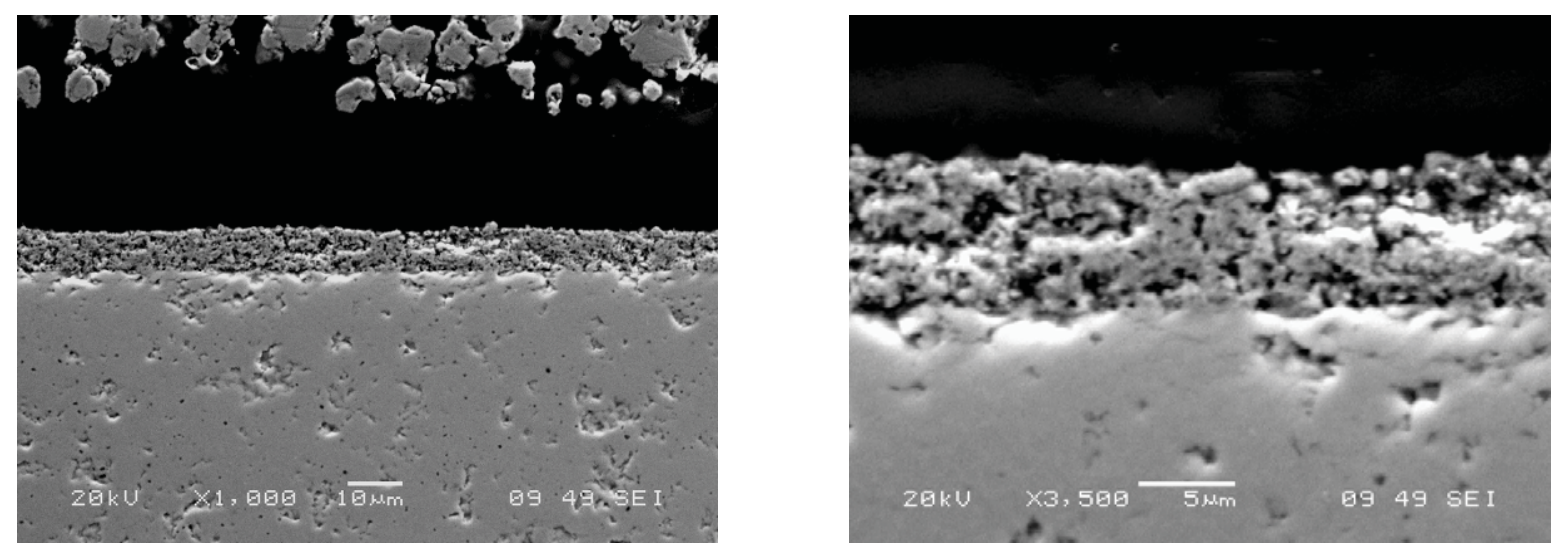

Figure 30. Separated bond layer on the hydrogen electrode side. 


\subsubsection{Electrolyte}

The 6Sc zirconia electrolyte material shows good density and no indication of excessive grain growth or microcracking (Figure 31).

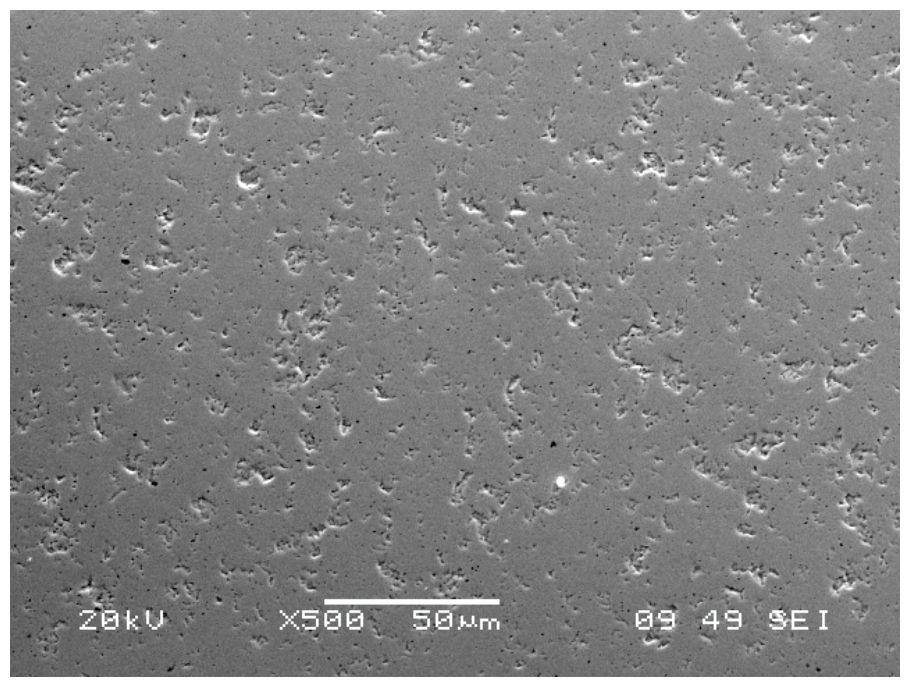

Figure 31. Electrolyte in normal condition.

\subsubsection{Oxygen Electrode}

The oxygen electrode and current distribution layer (bond layer) remain attached to each other but the oxygen electrode has delaminated from the electrolyte as shown in Figure 32. Visually, it appears that there is a foreign layer deposited at the interface; however, energy dispersive X-ray spectroscopy (EDS or EDX) of the delamination region of the electrolyte shows only electrolyte materials (Figure 33).
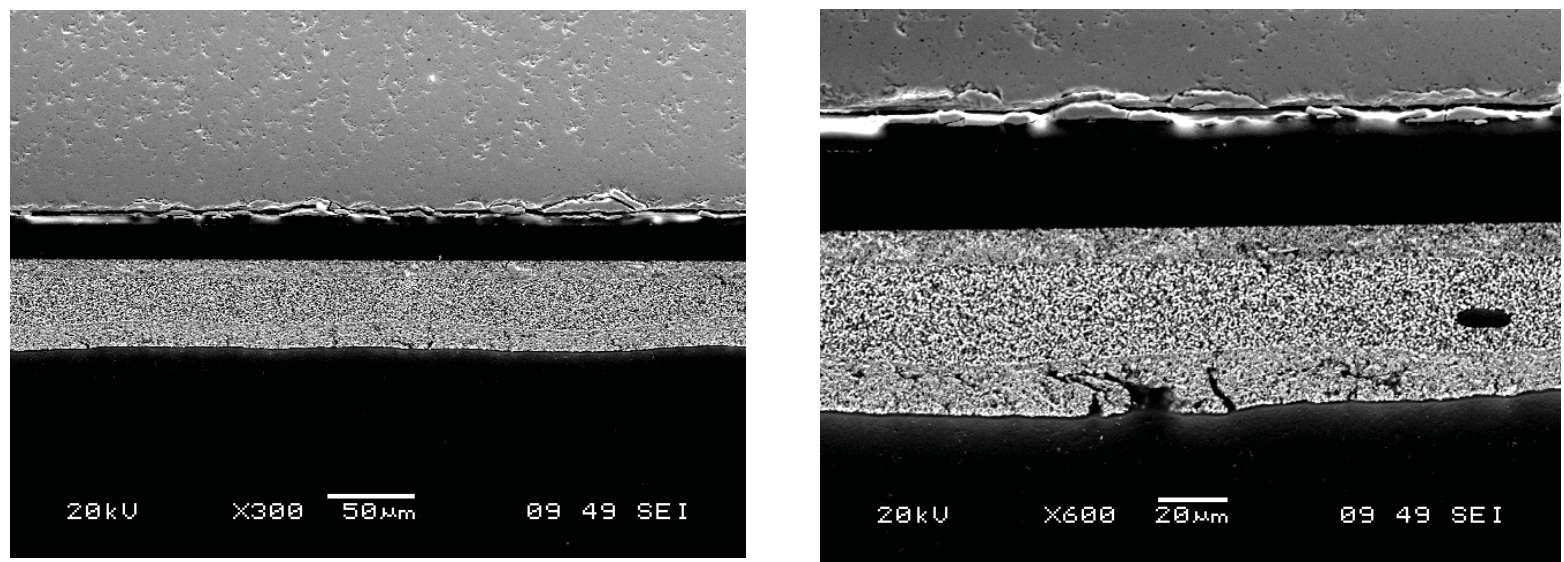

Figure 32. Separation at the oxygen electrode-zirconia electrolyte interface. 

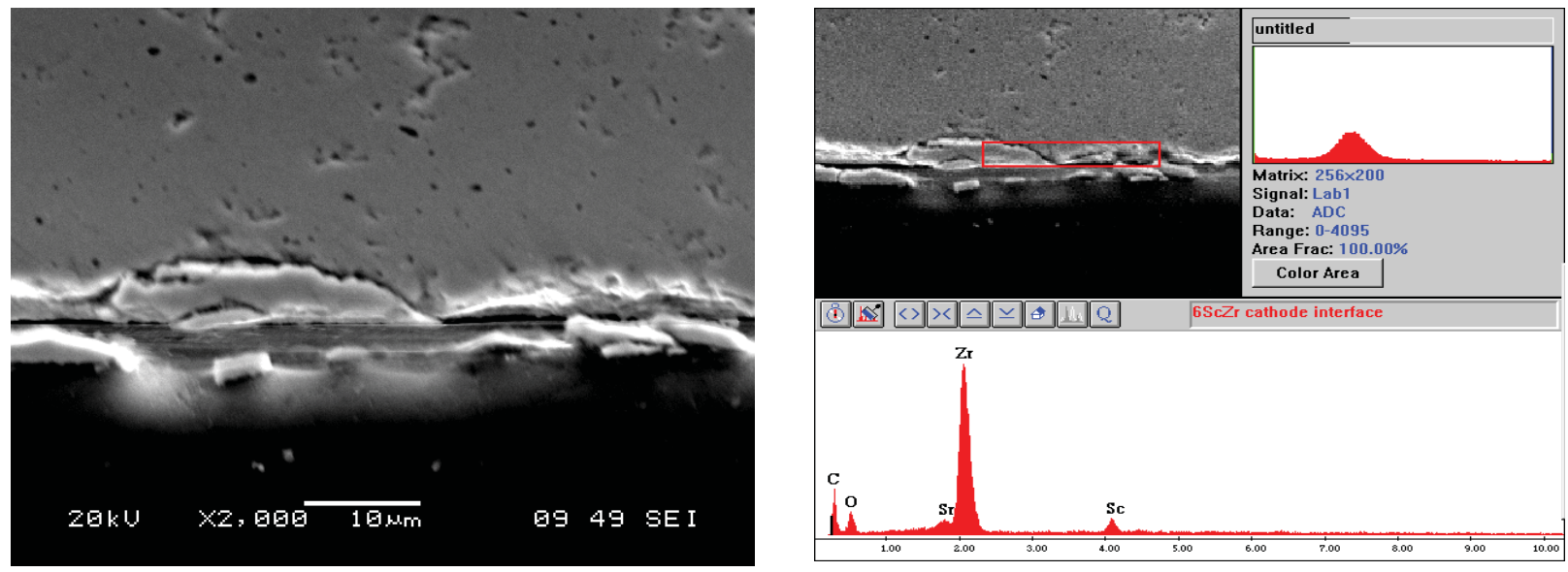

Figure 33. EDS picture (on the right) showing only zirconia electrolyte material at the interface.

This view of the delaminated electrode and bond layer (Figure 39) shows the top layer (electrolyte interface) consisting of the manganite-zirconia composite, a center layer of manganite and an outer layer (interconnect interface) of lanthanum cobaltite. These layers are well attached to each other but have separated from the electrolyte.

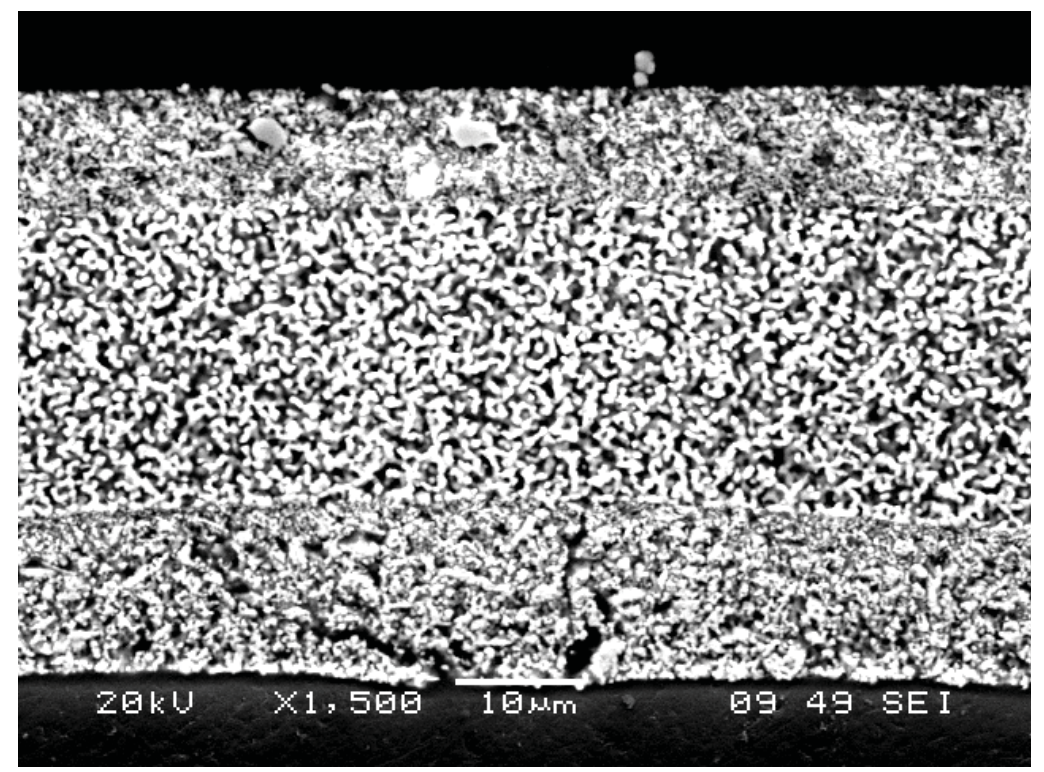

Figure 34. Separation of oxygen electrode from the electrolyte.

The element distribution maps (Figure 35) show the $\mathrm{Zr}$ in the composite layer and some migration of $\mathrm{Sr}, \mathrm{Mn}$, and Co between layers. 


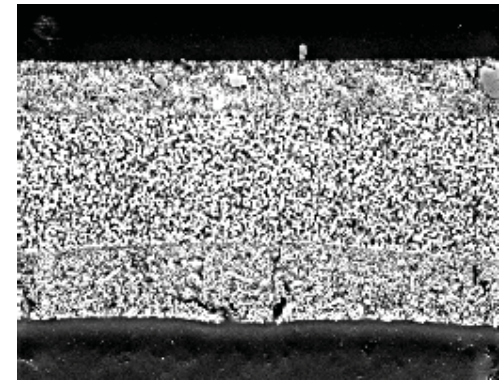

Oxygen electrode

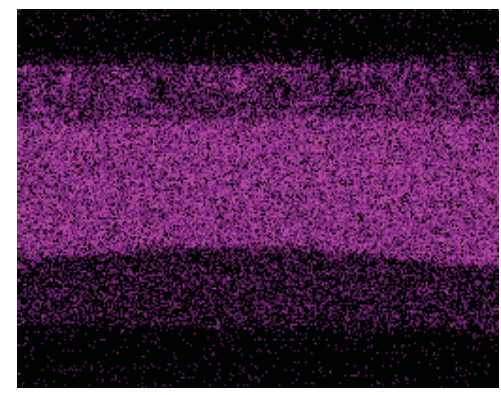

$\mathrm{Mn}$

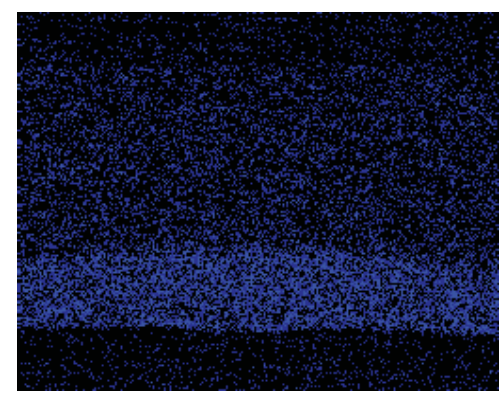

Co

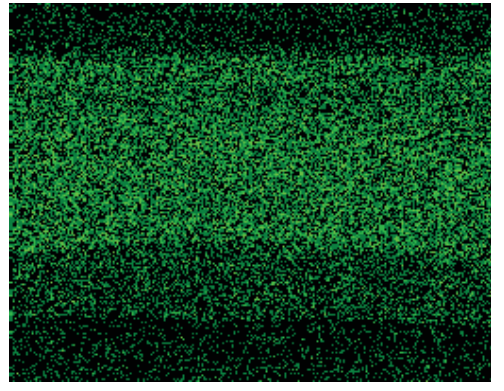

$\mathrm{Sr}$

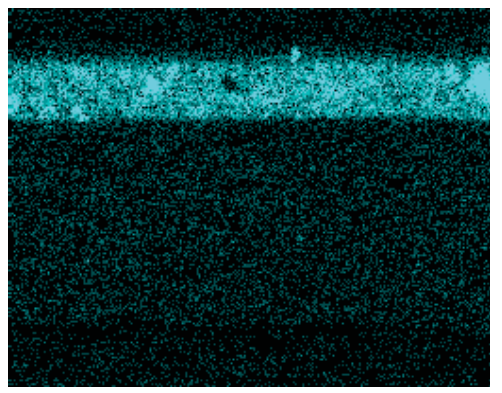

$\mathrm{Zr}$

Figure 35. Movement of $\mathrm{Sr}, \mathrm{Mn}$, and $\mathrm{Co}$ in the oxygen electrode.

The oxygen electrode bond layer interface to the interconnect appears to be well adhered and does not show indications of excessive oxide scale growth on the metal interconnect.

These images show the metal corrugation contact with the metal separator plate. There is some disruption of the bond layer between the two metal layers that probably developed during cooling due to expansion differences between metal and ceramic. However, a high-resolution view of the metal to bond layer interface shows little oxidation of the metal surface. 


\subsubsection{Oxygen Electrode Side Flow Channel (Flow Field)}

The oxygen electrode side flow channel and oxygen electrode separator plate are shown in Figure 36.
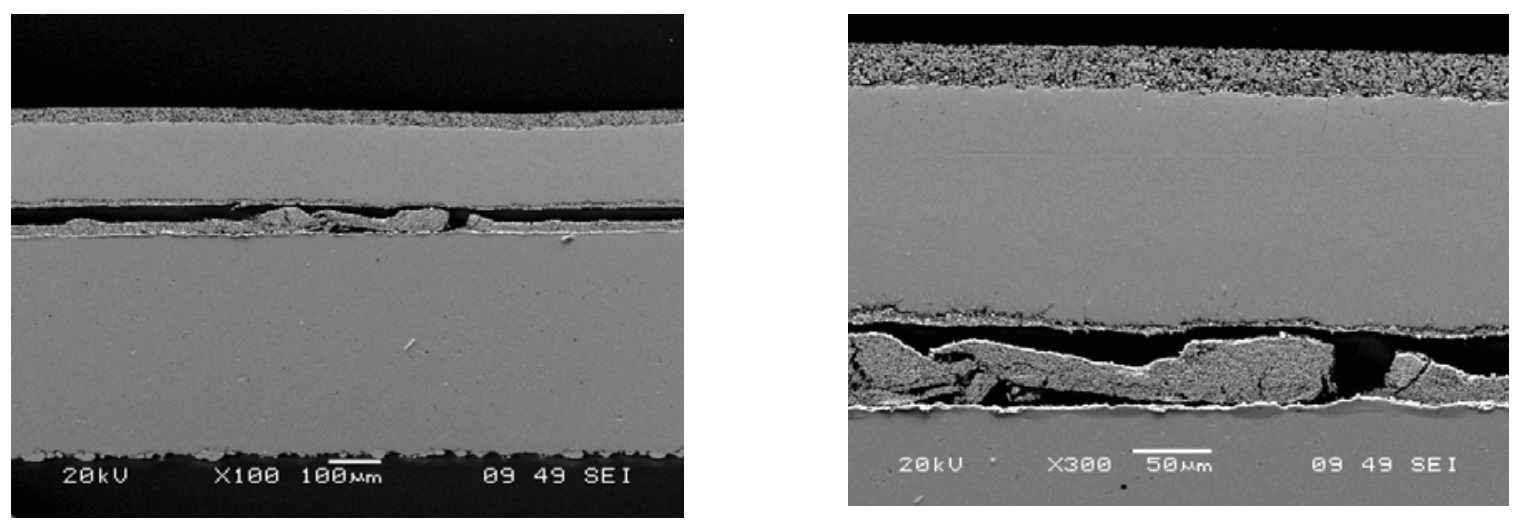

Oxygen electrode flow channel and oxygen electrode bond layer interface.

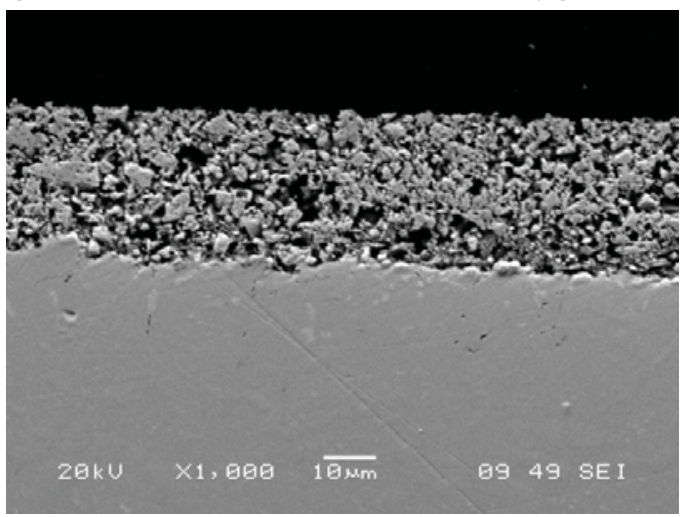

Figure 36. Oxygen electrode side flow channel (flow field) (upper) and oxygen electrode side flow channel-bond layer interface (lower). 
Hydrogen electrode side of separator plate is shown in Figure 37.
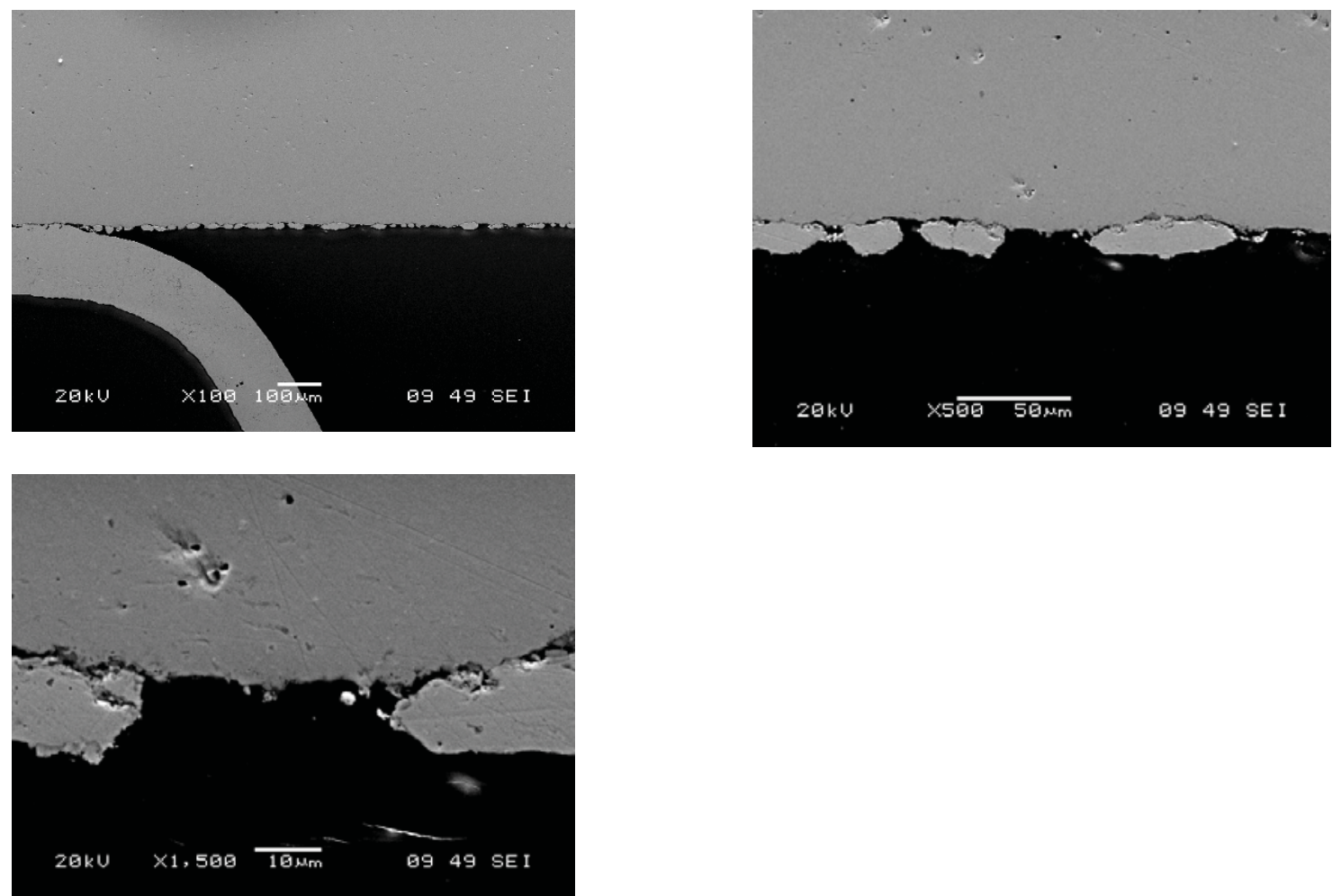

Figure 37. Separator plate- hydrogen electrode bond layer interface and hydrogen electrode bond layer.
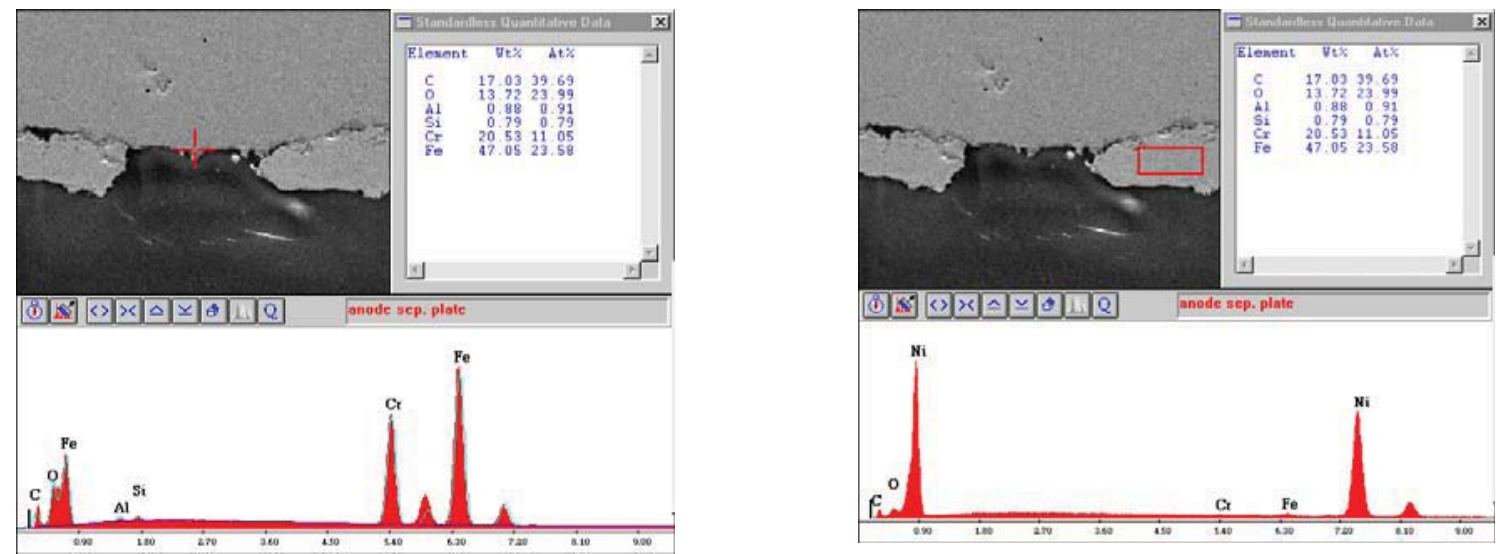

Figure 38. EDS of hydrogen electrode side separator plate. 


\subsection{Post-Test Examination of SOEC by Argonne National Laboratory}

Some Ceramatec cells were examined by Argonne National Laboratory (ANL) and Mawsdley et al. (2007) presented results of a 1,000-hour test at $\sim 830^{\circ} \mathrm{C}$ (O'Brien et al. 2007). The cells were examined using four-point resistivity measurements, X-ray fluorescence, and Raman spectroscopy. The surface characteristics of cells and bipolar plates were examined for potential causes of long-term degradation. The X-ray fluorescence measurements revealed that during the test, $\mathrm{Mn}$ and Co from the oxygen electrode and bond layer showed no macroscale interdiffusion. On the other hand, $\mathrm{Cr}$ had diffused from the ferritic stainless steel bipolar plate toward the electrode-electrolyte interface preferentially through the active electrode area. Raman spectroscopy identified a monoclinic phase in the exposed regions of the zirconia plate near the edge of the plates, which gives evidence of the instability of the zirconia cubic phase. Also, Cr-doped $\mathrm{Al}_{2} \mathrm{O}_{3}$ was identified in areas near the seal. SEM images showed delamination and cracking on the edges of the electrodes, where most of the cell degradation occurred. For example, the image in Figure 39 shows that the $\mathrm{O}_{2}$ electrode had begun to delaminate from the electrolyte near the edge where the four-point measurements had shown a large increase in resistivity. Cracks can also be seen within the $\mathrm{O}_{2}$ electrode, which would increase resistivity. Towards the center of the cell (right), adherence to the electrolyte improves and the cracks begin to disappear. If this delamination continues, it would be a source of cell degradation.

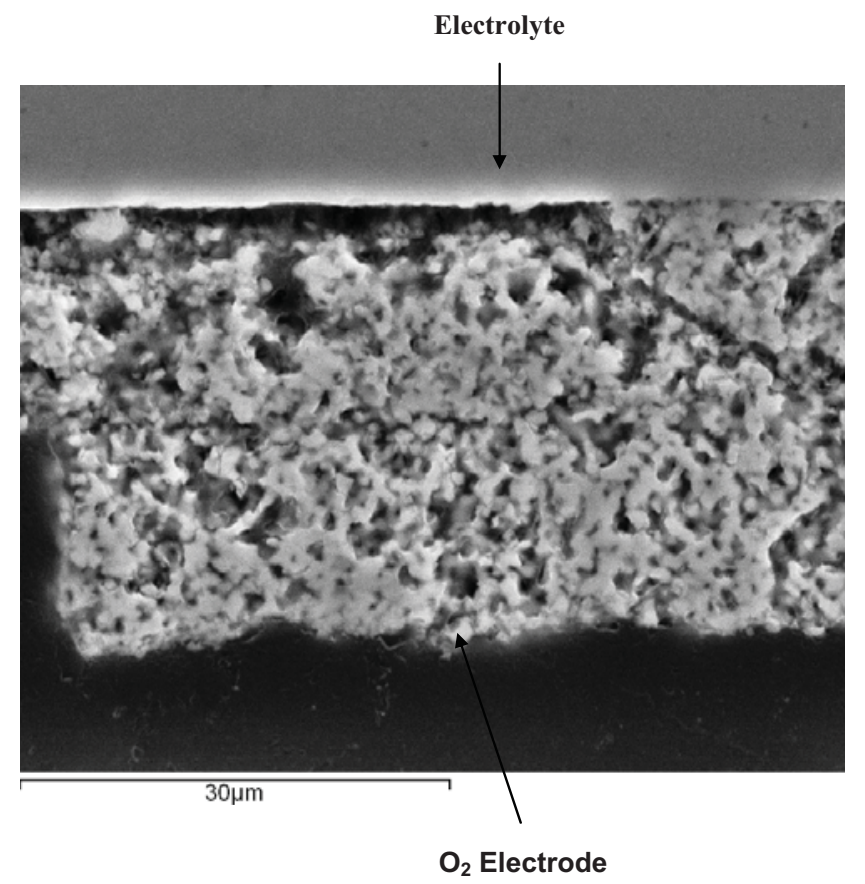

Figure 39. SEM view of the electrolyte and $\mathrm{O}_{2}$-electrode (Mawdsley et al. 2007).

In an effort to understand degradation in a Ceramatec SOEC, Carter et al. (2008) performed another series of post-test examination of the electrolysis cells at ANL. The outcome of these investigations reinforced the need for a comprehensive investigation of the degradation phenomena to advance SOEC technology. ANL employed Raman microspectroscopy to identify the formation of secondary phases at the electrolyte-bond layer interface. SEM and energy dispersive X-ray spectroscopy (EDX) was also employed to identify the microstructural and compositional distribution at a microscale. ANL determined that $\mathrm{Cr}$ movement (contamination) in SOEC is different than in SOFC. In the SOEC, because oxygen flows away from $\mathrm{O}_{2}$-electrode-electrolyte interface (see Figures 7, 8, and 40), chromium uniformly diffuses into the cell as seen in the left side of Figure 40. In SOFC, the direction of oxygen flow is 
reversed and chromium diffuses discretely in various regions of the cell as shown in the right side of Figure 40. However, the severity of chromium contamination is not well understood because of conflicting opinions.

At the inlet of the $\mathrm{O}_{2}$-electrode, ANL found delamination of the electrode from the electrolyte as determined by X-ray fluorescence mapping and SEM imaging. One possible reason for this delamination is excessive pressure buildup with high $\mathrm{O}_{2}$ flow in over-sintered (larger grain size and smaller pores formed at higher temperature) region. Delamination between $\mathrm{O}_{2}$-electrode and electrolyte is shown in Figure 41 (Carter et al. 2008).

Steam at the steam $/ \mathrm{H}_{2}$-electrode inlet can also carry $\mathrm{Si}$ from the seal and deposit it on the $\mathrm{H}_{2}$-electrode as shown in Figure 42 (Carter et al. 2008). $\mathrm{SiO}_{\mathrm{x}}$ can also come from interconnects, but the bond layer on the $\mathrm{H}_{2}$-electrode does not show the same kind of degradation/delamination as is seen on $\mathrm{O}_{2}$-electrode in Figure 41. Evidence of Mn, Si, and Ti deposition on the interconnect surface and interconnect-passivation layer interface was also found.

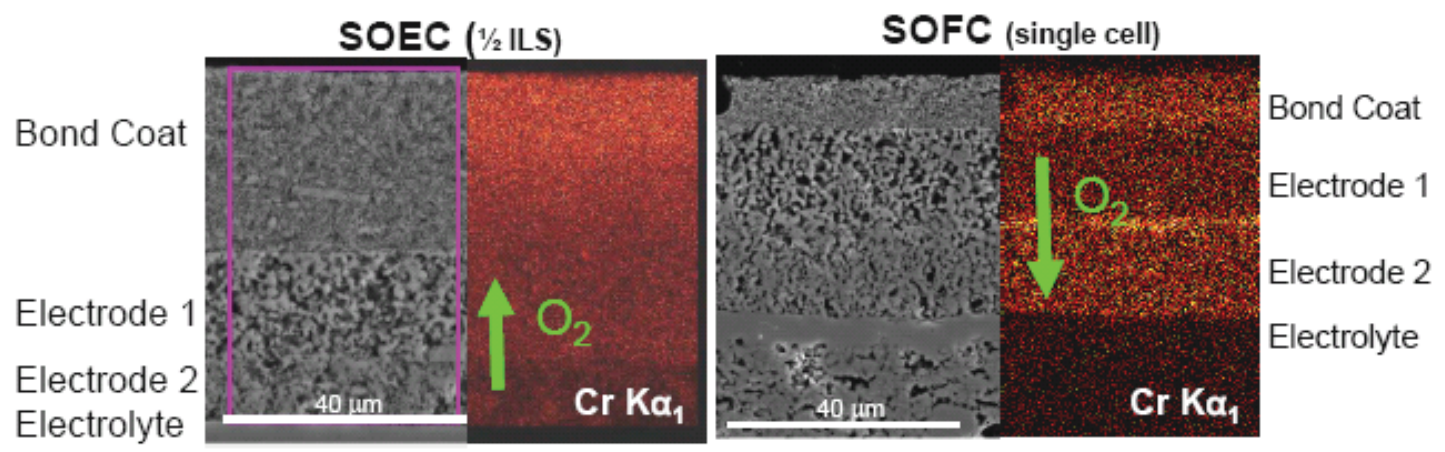

Figure 40. Chromium deposition in SOEC and SOFC (Carter et al. 2008).

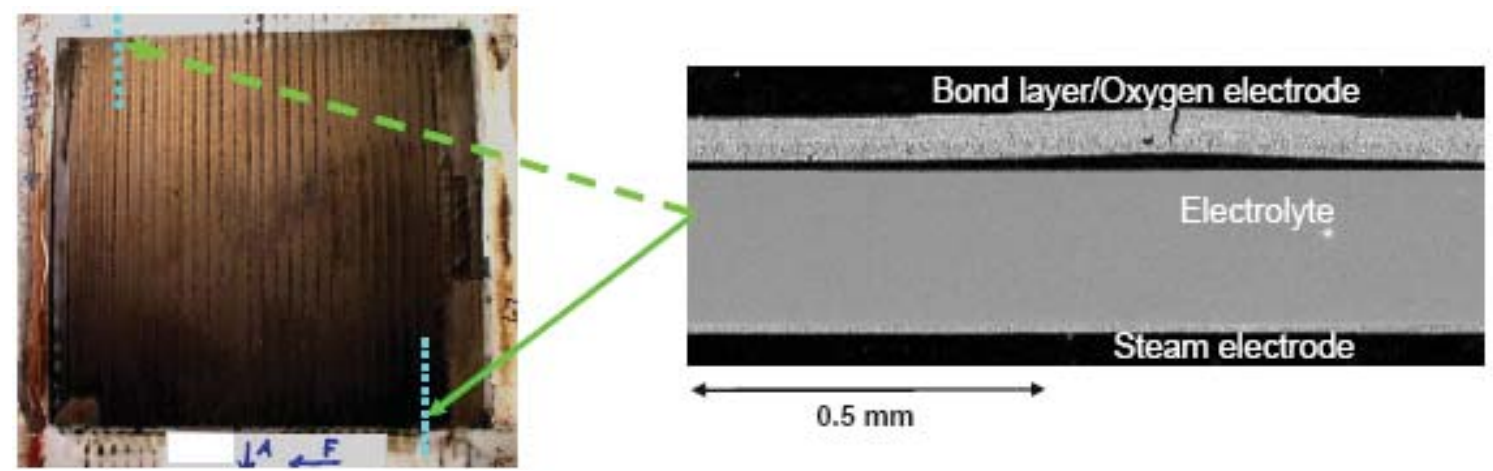

Figure 41. Electrode delamination after 1500 hrs of operation (Carter et al. 2008). 


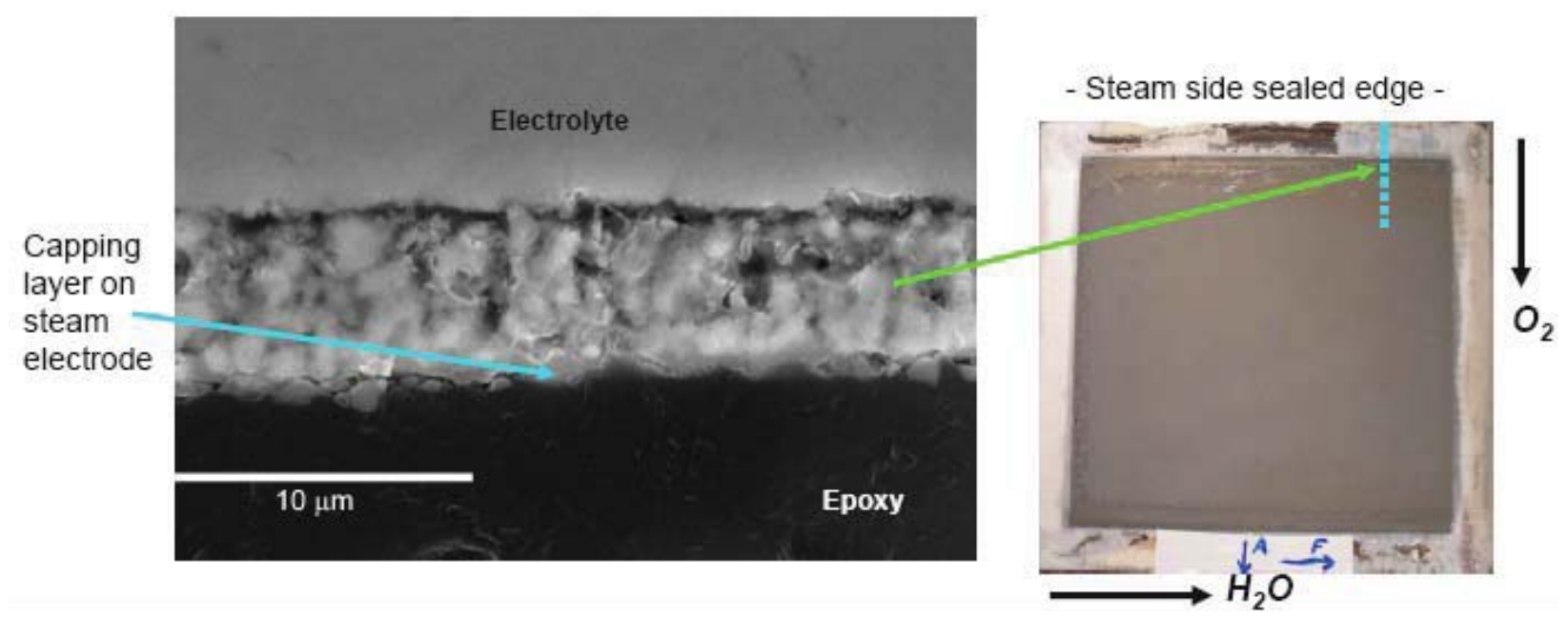

Figure 42. Si capping layer on $\mathrm{H}_{2}$-electrode (Carter et al. 2008).

ANL tested certain cells in both electrolysis and fuel cell (reversible) mode (Carter et al. 2008). As shown in Figure 43, a cell was operated in electrolysis mode for $\sim 310$ hours. It was then reversed to be operated in fuel cell mode for $\sim 100$ hours, and finally operated again in the electrolysis mode for $\sim 100$ hours. Two SOEC cells were tested. The only difference between the two cells was in the shape of the flow channels (corrugated and square). As shown in Figure 40, reversing the mode of operation provides improved cell performance. A similar cell operated in the fuel cell mode showed stable or even some improvement in performance. The flow channels do not show any signs of degradation. In all the investigations, it was noted that the bond layer on the $\mathrm{O}_{2}$-electrode degraded.

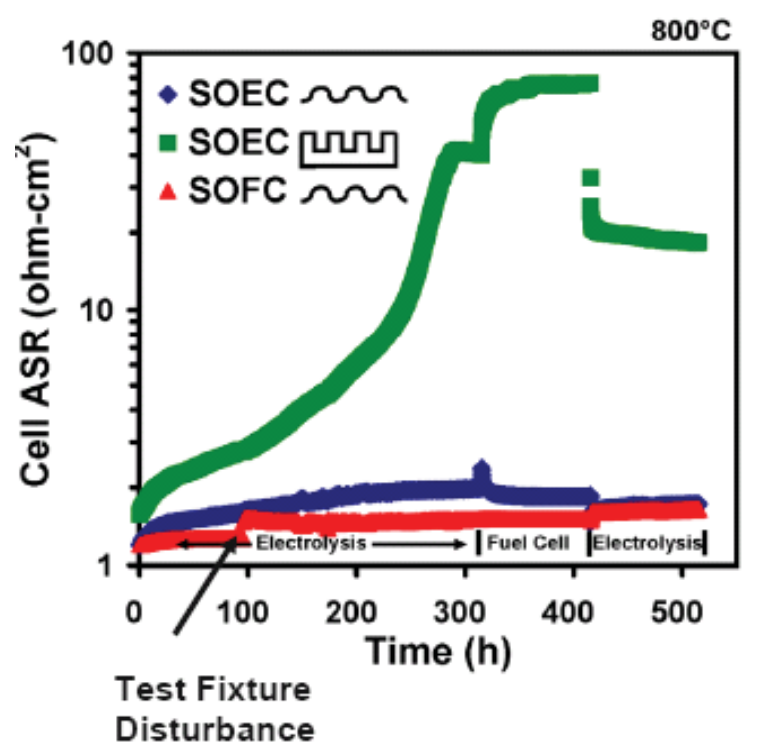

Figure 43. Some reversal of SOEC degradation (Carter et al., 2008).

\subsection{Degradation Mechanisms in the $\mathrm{O}_{2}$-Electrode Bond Layer in the SOEC}

Massachusetts Institute of Technology (MIT) studied the interaction of different constituents of SOECs at the high operating temperature. The electrochemical reactions have been recognized as one of the prevalent causes of their degradation. Specifically, two important degradation mechanisms were 
examined: (1) transport of Cr-containing species from steel interconnects into the oxygen electrode and $\mathrm{La}_{0.8} \mathrm{Sr}_{0.2} \mathrm{CoO}_{3}$ (LSC) bond layer in SOECs, and (2) cation segregation and phase separation in the bond layer. In order to identify the nature of these degradation processes and why they occur in the bond layer, MIT integrated a range of spectroscopy and microscopy techniques - from a high-level to a highresolution post-test examination.

\subsubsection{Secondary Phases in LSC Bond Layer}

In order to identify the possible presence of secondary phases in the oxygen side of SOECs, Raman spectroscopy was performed on the top surface of the LSC bond layer (at the LSC-interconnect interface) for both the used and unused SOECs. Raman spectroscopy results clearly showed that the LSC bond layer had degraded and the poorly conducting secondary phases of $\mathrm{Co}_{3} \mathrm{O}_{4}, \mathrm{Cr}_{2} \mathrm{O}_{3}, \mathrm{LaCrO}_{3}$ and $\mathrm{La}_{2} \mathrm{CrO}_{6}$ were formed. These observations indicated the Cr migration from the steel interconnects into LSC.

\subsubsection{LSC Microstructure and Surface Composition - Auger Electron Spectrocopy Nanoprobe}

MIT investigated the variation in the surface chemistry and microstructure of the air/hydrogen electrode and the bond layer using the Scanning Auger Electron Spectroscopy (AES) with nanoprobe capability. Figure 44 is a SEM image from LSC cross-section. AES results show an average chromium fraction of approximately $10 \%$ on the surface of the LSC bond layer. At the surface of LSC grains, phases containing higher $\mathrm{Co}$ and $\mathrm{Cr}$ and lower La content co-existed. Furthermore, the LSC layer exhibited local variation in chemical constituents on the surface of its grains, with the $\mathrm{La} / \mathrm{Co}$ ratio varying from 0.65 to 9 . Particularly Sr and Co cations migrated from the bond layer structure to the LSC-interconnect interface. This indicates severely inhomogeneous segregation of the A- and B-site cations in the LSC layer and dissociation of LSC. 


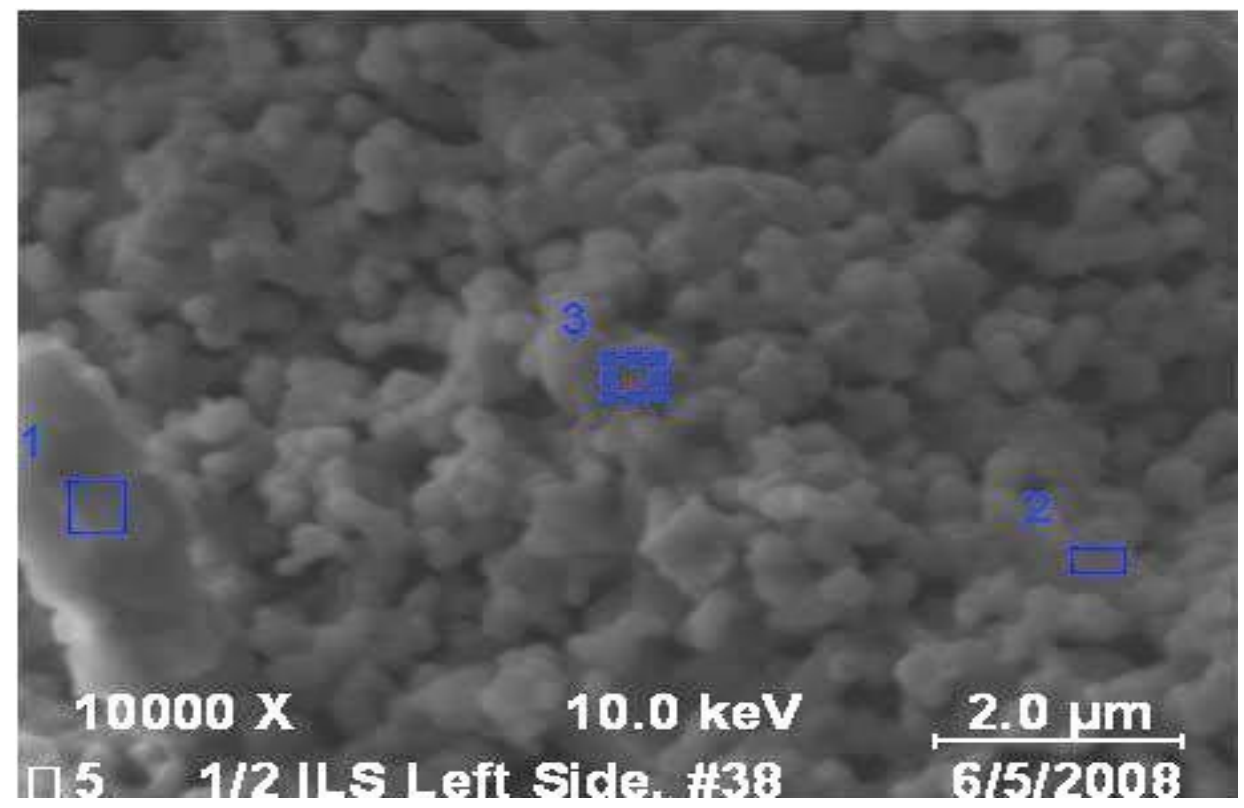

\begin{tabular}{|c|c|c|c|c|c|}
\hline Element & o & $\mathrm{Cr}$ & La & Co & $\mathrm{Cr} /(\mathrm{La}+\mathrm{Co}+\mathrm{Cr})$ \\
\hline Area 1 & 0.70 & 0.08 & 0.08 & 0.13 & 0.27 \\
\hline Area 2 & 0.57 & 0.01 & 0.38 & 0.04 & 0.02 \\
\hline Area 3 & 0.61 & 0.02 & 0.29 & 0.07 & 0.05 \\
\hline
\end{tabular}

Figure 44. SEM image of the cross section of cell CER\#3 (LSC region), AES data from areas 1, 2, and 3 in the SEM image.

While there was no Sr and only a small fraction of Co was identified as remaining in the LSC crosssectional surface, AES spectra at the top of LSC (LSC-interconnect interface) showed the presence of Corich crystallites and a Sr-rich surface layer. The spectra for Co and Sr showing this contrast are compared for the top and the cross section of LSC in Figure 45(a). Thus, it was concluded that the Sr and Co cations migrated over a long range to the LSC-interconnect interface. The direction of the migration of cations, Cr-species, and the electronic and ionic current in the SOEC are shown in Figure 45(b). 


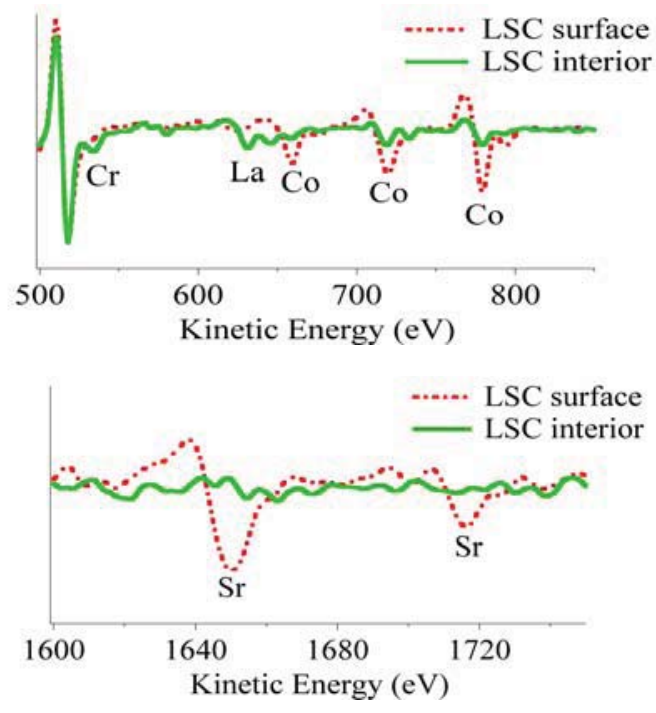

(a)

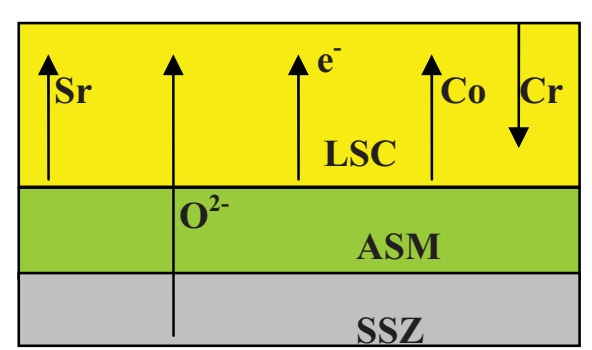

(b)

Figure 45. (a) AES spectrum comparing the Co-rich crystallites and the Sr-rich layer at the top of the LSC to the Co and Sr spectra from the LSC cross section. (b) Schematic for the transport of cations and charge carriers across the SOEC.

\subsubsection{Cation and Secondary Phase Distribution in LSC at the Nano-scale}

To identify the length-scale of the cation segregation and phase dissociation in the bulk of LSC grains at high resolution, MIT utilized transmission electron microscopy (TEM) and energy dispersive x-ray spectroscopy (EDX). The bulk-sensitive results from this technique complement the surface-sensitive results obtained by AES. MIT found that nano-scale Cr-rich regions were associated with enrichment of $\mathrm{La}$ and depletion of $\mathrm{Co}$, indicating a new phase between $\mathrm{Cr}$ and $\mathrm{La}$, contrary to the surface chemical correlation between $\mathrm{Cr}$ and $\mathrm{Co}$. Furthermore, the $\mathrm{Cr}$ content in the LSC bulk was more than at the LSC surface, on average $20 \%$ and $10 \%$, respectively. Results for Sr were consistent with those obtained from AES; only $2.24 \%$ was found in the bulk of LSC and none on the surface. The results from TEM/EDX confirm the severe dissociation of LSC. It shows that the secondary phase formation was of the nanoscale magnitude, as shown in Figure 46, a dark field TEM image with the scanning TEM elemental maps for $\mathrm{La}, \mathrm{Sr}, \mathrm{Co}$, and $\mathrm{Cr}$. 


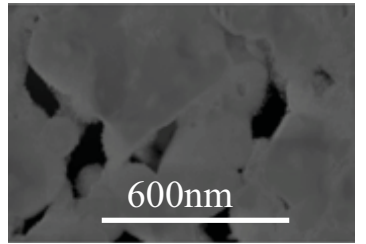

(a)

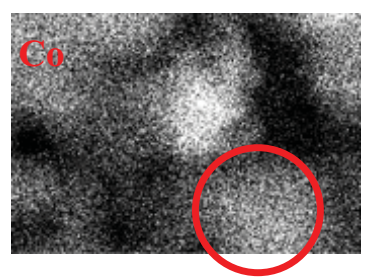

(d)

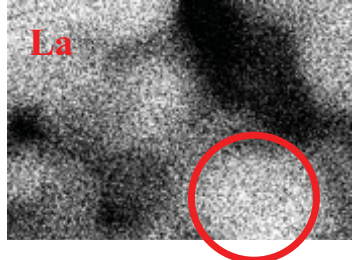

(b)

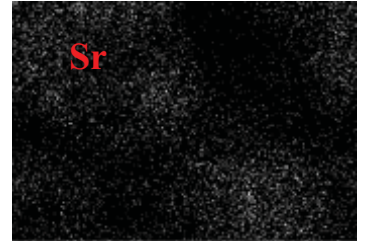

(c)

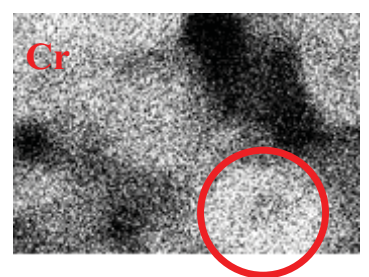

(e)

Figure 46. (a) A dark field TEM image in LSC $(1.3 \mu \mathrm{m} \times 0.9 \mu \mathrm{m})$, with the elemental maps for (b) La, (c) $\mathrm{Sr},(\mathrm{d}) \mathrm{Co}$ and (e) Cr.

\subsubsection{Cation Migration Mechanism}

MIT hypothesizes that the long-range transport of Sr and Co can be caused by two primary mechanisms: (1) the Cr-containing species (i.e. at the vicinity of the interconnect) could thermodynamically favor the presence of select cations (i.e. Sr and $\mathrm{Co}$ ) at the region interfacing the interconnect; and (2) the $\mathrm{Cr}$ containing species could be driven by the electronic or oxygen ion current (Figure 45[b]). To test these hypotheses and to isolate the governing mechanism, MIT simulated controlled electrochemical conditions on reference cells having ASM electrodes coated with LSC, on both sides of the SSZ electrolyte, without any Cr-containing layers on the LSC bond layer. The cell operated in air, under a constant current density of $400 \mathrm{~mA} / \mathrm{cm}^{2}$. The cell potential doubled (from $0.23 \mathrm{~V}$ to $0.43 \mathrm{~V}$ ) within $125 \mathrm{hrs}$ before eventually stabilizing (Figure 47). The time-dependent history of the cell is shown in Figure 47, including the electrochemical impedance of the anode before and at the end of the test shown as inset. Significant degradation observed in this experiment suggests that there exists at least one other mechanism that contributes to the degradation even in the absence of $\mathrm{Cr}$ poisoning.

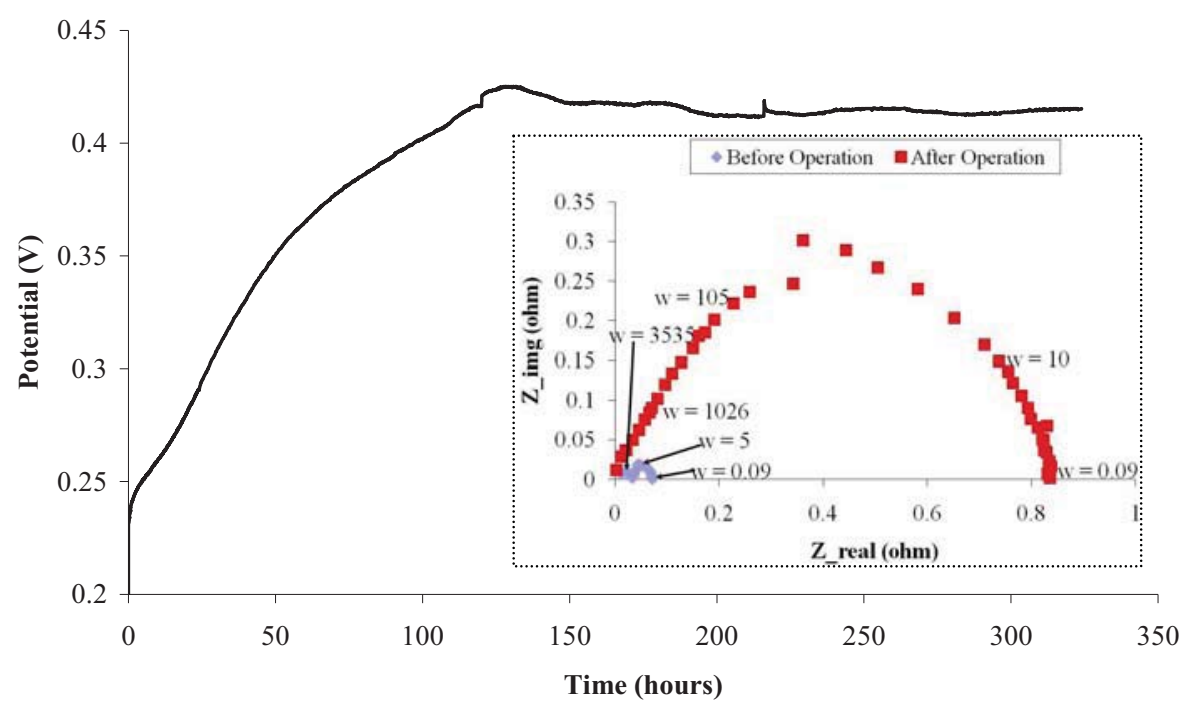

Figure 47. Performance for the reference half cell at $0.4 \mathrm{~A} / \mathrm{cm}^{2}$ in air at $820^{\circ} \mathrm{C}$ degraded significantly during the first $125 \mathrm{hrs}$, and the anode + LSC resistance increased (inset). 
To determine whether the degradation in the absence of $\mathrm{Cr}$ is due to cation segregation driven by electronic/ionic current, MIT compared the microstructure and microchemistry of the reference cell in the electrochemical treatment (shown in Figure 47) to those in an equivalent reference cell that was annealed in air at $820^{\circ} \mathrm{C}$ for 5 days. AES results showed that the microstructure and surface composition of the reference cells remained stable and uniform upon the electrochemical and thermal treatments, in spite of the degradation shown in Figure 47.

Thus, MIT concluded that the Cr-related thermodynamics could be the dominant mechanism driving the uneven dissociation and segregation of cations in LSC as observed in the stack cells (Figure 44). However, the exact mechanism by which $\mathrm{Cr}$ causes the long-range transport of cations leading to LSC dissociation, and the relation of $\mathrm{Cr}$ effects to the electrochemical conditions is not yet understood. MIT proposes that controlled-environment experiments, ideally under in situ conditions, coupled with material development can enable the solution of this challenge for the long-term success of the SOEC. 


\section{POSSIBLE CAUSES OF DEGRADATION IN SOEC}

At present, a complete understanding and reasonable agreement on the causes of degradation and the electrochemical mechanisms behind them does not exist. Therefore, the following discussion only represents some of the phenomena relevant to SOEC degradation and is based on discussion presented in another report (Sohal 2009).

This information adds to the ILS degradation information presented in Sections 4 and 5. From a theoretical point of view, experimental information on degradation presented in Sections 4 and 5 can be classified as (a) baseline progressive constant-rate degradation, (b) degradation corresponding to transients caused by thermal or redox (reduction and oxidation) cycling phenomena occurring in a cell, and (c) degradation resulting from a sudden incident or a failure/malfunction of a component or a control in a stack system. However, there is no clear evidence whether different events lead to similar or drastically different electrochemical degradation mechanisms within a cell.

\subsection{SOEC versus SOFC Stacks}

Sections 4 and 5 present research information on various scenarios of degradation in SOECs and SOFCs; data were taken in single cells as well as in stacks. The degradation mechanisms in a stack are not identical to that in a single cell (Virkar 2007). Also, degradation in a SOEC is not identical to that in a SOFC. Long-term, single-cell tests show that SOEC operation has greater degradation rates than that in SOFC mode. SOFC degradation can therefore be used for background information and guidance. But for SOEC stack development, all studies have to be done on SOEC stacks. Some researchers observed that a higher operating temperature increases degradation in SOECs, but higher current density does not increase degradation. However, ANL observed higher degradation in higher current flow regions of $\mathrm{O}_{2}$ electrodes. Future research needs to resolve such unconfirmed and conflicting findings.

\subsection{Air/Oxygen Electrode}

It is understood that degradation of the $\mathrm{O}_{2}$ electrode is more severe than that of the $\mathrm{H}_{2}$ electrode. Therefore, it was proposed to focus initially on the degradation of the $\mathrm{O}_{2}$ electrodes in a stack. ANL's examination of a SOEC operated by INL for $\sim 1,500$ hours showed that the $\mathrm{O}_{2}$ electrode delaminated from the bond layer/electrolyte. However, the causes of the delamination are speculative because confirmative tests proving the fundamental cause(s) have not been performed. It is thought that high oxygen evolution in an over-sintered region can build up high pressure at that location. In SOEC mode, $\mathrm{O}_{2}$ has to be pushed out; hence, chances of delamination increase. Therefore, the high porosity of the $\mathrm{O}_{2}$ electrode is very important. This opinion was expressed by many participants and deserves further examination. Per ANL observations, delamination occurs in cell areas with high current flows. It was also suggested that chromium poisoning originating from the interconnects or the balance-of-plant pipes may get located at the interface or TPB. This can result in the bond layer getting separated from the $\mathrm{O}_{2}$ electrode. Deposition of impurities at the TPB and delamination can adversely impact the electrochemical reactions and ionic conductivity in the cell. It was also mentioned that at the electrode-electrolyte interface, forced electron transfer can form defects. No detailed discussion took place on the specifics of the phenomenon.

\subsection{Air $/ \mathrm{O}_{2}$-Electrode Side Bond Layer}

An $\mathrm{O}_{2}$-electrode side protective bond layer is shown in Figure 8. Because it was next to the $\mathrm{O}_{2}$ electrode, it encountered similar electrochemical phenomena that lead to cell degradation. However, besides ANL's observations (Carter et al. 2008), no other studies or data were presented that can demonstrate the bond layer's significance relative to the $\mathrm{O}_{2}$-electrode in terms of overall cell degradation. ANL found an average of $1-8 \%(\sim 30 \%$ maximum $)$ Cr-contamination in the bond layer, probably 
originating from interconnects. Cr contaminants were found in association with lanthanum strontium chromite (LSC). In the $\mathrm{O}_{2}$ bond layer, a secondary phase may form. However, there are conflicting opinions about the severity of $\mathrm{Cr}$ contamination. ANL observed delamination and weak interface between the $\mathrm{O}_{2}$-electrode and LSC bond layer, which can prevent solid-state $\mathrm{Cr}$ from diffusing into the $\mathrm{O}_{2}$ electrode. For this reason, the $\mathrm{O}_{2}$-electrode can remain stable, but a weak interface is not desirable from the point of view of an electrical conductivity.

\subsection{Electrolyte}

In electrolytes, the main cause of degradation is loss of electrical/ionic conductivity. Müller et al. (2003) showed that during the first 1,000 hours of testing, yttria- and scandia-doped zirconia (8 mol\% $\mathrm{Y}_{2} \mathrm{O}_{3} \mathrm{Sc}-\mathrm{ZrO}_{2} / 8 \mathrm{YSZ}$ ) electrolytes showed $\sim 23 \%$ of degradation. For the next 1,700 hours of testing, the decrease in conductivity was as high as $38 \%$. An increase in the tetragonal phase during annealing at the expense of cubic and monoclinic phases was detected for the 3 YSZ samples. However, 3YSZ and 4YSZ samples showed a much smaller decrease in conductivity after 2,000 hours of testing. Both SteinbergerWilckens (2008) and Hauch (2007a) reported the formation of impurities at the TPBs. A substantial amount of $\mathrm{SiO}_{2}$ was detected at the $\mathrm{Ni} / \mathrm{YSZ} \mathrm{H}_{2}$-electrode-electrolyte interface during electrolysis, while no $\mathrm{Si}$ was detected in other reference cells. These Si-containing impurities were probably from albite glass sealing. ANL observed that cubic, tetragonal, and monoclinic phases of $\mathrm{ZrO}_{2}$ remained stable at the present scandia doping level.

\subsection{Steam $/ \mathrm{H}_{2}$-Electrode}

Overall, many researchers reported that the contribution of a steam $/ \mathrm{H}_{2}$-electrode to SOEC degradation is much less than that of other cell components. ANL also observed $\mathrm{Si}$ as a capping layer on the steam $/ \mathrm{H}_{2}$ electrode. It probably was carried by steam from the seals, which contain $\mathrm{Si} \mathrm{SiO}_{\mathrm{x}}$ also emanates from interconnect plates. Mn diffuses from interconnects as well, but the significance of Mn diffusion is unknown. Hauch (2007a) observed contaminants containing Si to segregate to the innermost few microns of the $\mathrm{H}_{2}$-electrode near the electrolyte. The impurities that diffused to and accumulated at the TPBs of the $\mathrm{H}_{2}$-electrode are believed to be the main cause of performance degradation in SOECs (Hauch 2007a). In the literature, it has been noted that steam content greater than $30 \%$ shows conductivity loss. Therefore, an optimum ratio of steam- $\mathrm{H}_{2}$ mixture and steam utilization percentage needs to be determined.

\subsection{Interconnect}

Interconnects can be a source of serious degradation. $\mathrm{Sr}, \mathrm{Ti}$, and $\mathrm{Si}$ segregate and build-up at interfaces. Sr segregates to the interconnect-bond layer interface. Mn segregates to the interconnect surface. Si and Ti segregate to the interconnect-passivation layer interface. $\mathrm{Cr}$ contamination can originate from interconnects and it can interact with the $\mathrm{O}_{2}$-electrode surface or even diffuse into the $\mathrm{O}_{2}$-electrode. Chromium reduction $\left(\mathrm{Cr}^{6+}\right.$ to $\left.\mathrm{Cr}^{3+}\right)$ can take place at the electrode-electrolyte interface (Singh et al. 2008). Coatings for the interconnects are being developed under the sponsorship of the US-DOE Solid State Energy Conversion Alliance (SECA) program. Coated stainless steel interconnects have shown reduced degradation rates. GE observed higher degradation with stainless steel current collectors than with $\mathrm{Au}$ current collectors (Gaun et al. 2006).

\subsection{Contaminants and Impurities}

A hydrogen electrolysis plant or a laboratory-scale experiment is always connected to the pipes, gas storage tanks/cylinders, or other such equipment. These components can be a source of undesirable particles/chemicals, which can get deposited at different locations in solid oxide electrolysis cells. It has been shown in previous sections that any foreign particles deposited at the triple-phase boundary can lead 
to degradation in cell performance. The reactant gases can also have undesirable impurities. It is understood that the balance of plant and gases are merely sources of impurities. The phenomenological causes of degradation depend on other electrochemical reasons.

Severe corrosion was encountered when glass seals were used but appeared to be reasonably under control when the glass seals were replaced. Nickel from nickel mesh can volatize in high water content environments, move into the steel and make it austenitic, which will eventually corrode. Silica poisoning is a potential problem. Impure water can contain Si. Therefore, in SOEC, it is likely that high temperature steam interacting with balance-of-plant piping picks up Si and transports it elsewhere to form a nonconductive scale. One solution to this problem can be to add certain materials into YSZ electrolyte, which may attract the Si and reduce degradation. Iron can also diffuse into glass seals and cause electrical shorting. Mn diffuses from interconnects, but its effect on degradation is unknown. Phosphorus and arsenic can react at the TPB levels and interact with the electrode containing Ni. They can form eutectics and enhance Ni mobility. This is a very low-level effect and demands appropriate detection techniques.

\subsection{Summary of Stack Degradation}

Main sources of degradation come from several cell components. Details about the following list of general observations and main sources of SOEC stack degradation have been discussed in earlier sections:

- Delamination occurs at the $\mathrm{O}_{2}$-electrode side bond layer from the $\mathrm{O}_{2}$-electrode

- Bond layer on steam $/ \mathrm{H}_{2}$-electrode side is not degrading

- Air and steam $/ \mathrm{H}_{2}$ flow channels are not degrading

- Five cell components are suspect:

- Bond layer on $\mathrm{O}_{2}$-electrode-Cr poisoning and dissociation

- $\quad \mathrm{O}_{2}$-electrode-microstructural changes and delamination

- Loss of electrical/ionic conductivity of electrolyte

- Interconnect-generation of contaminants

- Steam $/ \mathrm{H}_{2}$ - electrode

This list is not all inclusive but represents a majority opinion expressed at a workshop conducted in 2008 (Sohal 2009). Main sources of degradation come from several cell components. 


\section{SUMMARY OF RESEARCH NEEDS TO MITIGATE SOEC DEGRADATION}

The ILS post-test examination and conclusions from the 2008 Degradation Workshop (Sohal 2009) point to possible reasons for the degradation of the SOEC stacks. These reasons are listed in Section 6.

To achieve some SOEC performance targets in terms of current density, tolerable degradation rate, and desired lifetime ( $>20,000$ hours) of the SOEC stacks, a focused research approach has to be conducted. Some of these research needs are listed below.

\subsection{Electrochemical Phenomena in SOEC Cells and Stacks}

Addressing the problem of degradation in a SOEC stack will require an understanding of all the electrochemical phenomena at a single-cell level. The same phenomena should then be scaled up to a stack level. However, it is generally accepted that a single cell's performance cannot predict the performance of a stack made from the same cell. Therefore, the differences between the electrochemical behavior of a single cell and a stack should be clearly identified. Electrochemical similarities and differences between operations of SOEC and SOFC stack operations should also be clearly identified. Understanding the electrochemical phenomena during normal operation of a SOEC stack will lead to an understanding of off-normal operation resulting from a degraded stack. Many of the phenomena require the cells to behave in a nonequilibrium thermodynamic manner. This approach is being promoted by Virkar (2007). Such fundamental understanding can help identify and resolve the causes of degradation.

\subsection{Electrochemical Phenomena in SOEC Stacks and Cell Material Composition}

The electrochemical behavior of a SOEC stack in relation to the material composition of all cell components needs to be understood. Many electrochemical events responsible for normal and off-normal cell operation occur at the interface between various components - for example, the $\mathrm{O}_{2}$-electrode-bond layer and TPB. Different material compositions of various components impact a cell's electrochemical behavior differently. Thus the relationship between various materials and their corresponding degradation in a SOEC stack needs to be established. If successful, this could lead to cell composition that results in lower degradation rates. This knowledge can be very useful for a SOEC manufacturer.

\subsection{Modeling Electrochemical Phenomena and Stack Degradation}

Understanding electrochemical phenomena is essential for developing a model of a SOEC stack. With a suitable model, various stack characteristics and operating parameters, such as materials of composition, operational transients, thermal cycling, redox cycling, etc., can be modeled to determine the impact of a single or several parameters on stack degradation. It can also help determine the relative importance of various cell/stack parameters. A functioning model could thus be used to improve the material composition of cell components. As a general rule, any process model is used to plan for experimental testing and improve operation. If the couplings of various electrochemical phenomena are too complex, as a minimum, single phenomenon models should be developed that can also be verified by experimentation 


\subsection{Delamination of $\mathrm{O}_{2}$-Electrode and Bond-Layer}

The delamination of an $\mathrm{O}_{2}$ electrode and its role in causing cell degradation was previously discussed. Workshop attendees agreed that $\mathrm{O}_{2}$ electrode delamination is a major problem to address. Therefore, understanding the causes of $\mathrm{O}_{2}$ electrode delamination and its mitigation should be considered a high priority.

\subsection{Contaminant Transport and Deposition}

Researchers actively involved in SOFC research emphasize that the deposition of contaminants (chromium, nickel, silica, etc.) at reaction sites (for example, triple phase boundary) leads to degradation of SOFC performance. However, their relative contributions to degradation in SOECs are not well known. Some groups (for example, Risø National Laboratory, Denmark) strongly believe that even in SOECs, contaminants have significant impact on degradation. Others, such as Virkar (2007), believe that other phenomena are the primary causes of cell degradation/failure. The sources of these contaminants could be balance-of-plant, interconnects, seals, and external sources. In view of these differing opinions, the source of contaminants and their transport mechanism, poisoning and deactivation of reaction sites, and build-up of scales and layers and their relative impact on degradation should be resolved.

\subsection{Redox Cycling and its Impact on Degradation}

Reduction and oxidation (redox) cycling is a common issue in $\mathrm{H}_{2}$ electrode (anode in SOFC) supported cells. Redox cycling leads to electrode instability. $\mathrm{H}_{2}$ electrodes must exhibit a high performance in terms of high electrochemical activity and high redox stability. Ni-YSZ $\mathrm{H}_{2}$-electrodes often above $80^{\circ} \mathrm{C}$ are normally not redox stable. Volume changes in Ni-YSZ electrodes due to reduction and oxidation of $\mathrm{Ni}$ results in mechanical stresses in the electrode material, which degrades cell performance. For SOFCs, researchers are looking for an electrode material (usually ceramic-based) that will have a minimal impact on the redox problem. The relative impact of redox on SOEC cell degradation is not well understood.

\subsection{Interconnects and Seals Related Problems}

Chromium evaporation/condensation from interconnects, seal leakage, and the origination of contaminants from interconnects and seals also contribute to the degradation of SOEC performance. Seal leakage, $\mathrm{SiO}_{\mathrm{X}}, \mathrm{Mn}$ poisoning, etc., are considered second order effects. Hence, their relative impact on degradation needs to be quantified and acceptable solutions need to be developed.

\subsection{Other Related Issues}

Several researchers, especially with SOFC experience, have pointed out other issues, some of which have not been examined in the SOEC scenario and hence may not have the same degree of impact in a SOEC as they do in a SOFC. Corrosion is a common issue and can increase resistivity and change dimensions because of cell component swelling. SOEC electrode material may require improvement in order to increase mechanical strength and improve gaseous transport, reaction sites, and conductivity. Overall, these improvements should decrease the degradation rate. 


\section{REFERENCES}

Akkaya, A. V., 2007, "Electrochemical Model for Performance Analysis of a Tubular SOFC," Int. J. Energy Research, 31, 79-98.

Carter, D. J. et al. 2008, "Determining Causes of Degradation in High Temperature Electrolysis Stacks," Workshop on Degradation in Solid Oxide Electrolysis Cells and Strategies for its Mitigation, Fuel Cell Seminar \& Exposition, Phoenix, AZ, October 27, 2008.

Gazzarri, J. I., 2007, “Impedance Model of a Solid Oxide Fuel Cell for Degradation Diagnosis,” Ph. D. Thesis, University of British Columbia, Vancouver, Canada.

Gemmen, R. S., Williams, M. C., and Gerdes, K., 2008, "Degradation Measurement and Analysis for Cells and Stacks," J. Power Sources, 184, 251-259.

Guan, J. et al., 2006, "High Performance Flexible Reversible Solid Oxide Fuel Cell," GE Global Research Center Final Report for DOE Cooperative Agreement DE-FC36-04GO-14351.

Haering, C., Roosen, A., Schichl, H., and Schnoller, M., 2005, "Degradation of the electrical conductivity in stabilized zirconia system Part II: Scandia-stabilised zirconia," Solid Sate Ionics, 176, 3-4, 261268.

Hartvigsen, J. J., Larson, D., and Elangovan, S., 2009, "Post Test Stack Disassembly of Stacks A and B from Module \#3 from the Full Scale ILS Test in the $4^{\text {th }}$ Quarter 2008," Ceramartec Progress Report to INL for Subcontract 83664.

Hauch, A., Jensen, S. H., Menon, M., and Mogensen, M., 2005, "Stability of Solid Oxide Electrolyser Cells," Risø International Energy Conference, Roskilde, Denmark, May 23-25, 2005, Edited by Petersen, L. S. and Larsen, H.

Hauch, A., 2007a, "Solid Oxide Electrolysis Cells - Performance and Durability," Ph.D. Thesis, Technical University of Denmark, Risø National Laboratory, Roskilde, Denmark.

Hauch, A., Jensen, S. H., Ebbesen, S. D., and Mogensen, M., 2007b, "Durability of Solid Oxide Electrolysis Cells for Hydrogen Production,” Risø International Energy Conference, 2007, Roskilde, Denmark, Edited by Petersen, L. S. and Larsen, H.

Hauch, A., Ebbesen, S. D., Jensen, S. H., and Mogensen, M., 2008, "Solid Oxide Electrolysis Cells: Microstructure and Degradation of the Ni/Yttria-Stabilized Zirconia Electrode," J. Electrochemical Society, 155, 11, B1184-B1193.

Herring, J. S., Stoots, C. M., O'Brien, J. E., Hartvigsen, J. J., and Housley, G., 2007, "Recent Progress in High Temperature Electrolysis," AIChE Meeting, Salt Lake City, UT, November 5-9, 2007.

Housley, G. K., O’Brien, J. E., and Hawkes, G. L., 2008, "Design of a Compact Heat Exchanger for Heat Recuperation from a High Temperature Electrolysis System," 2008 ASME International Congress and Exposition, Boston, MA, Paper \# IMECE2008-68917.

Ivers-Tiffée, E. and Virkar, A. V., 2003, "Electrode Polarisation," Chapter 9 in High Temperature Solid Oxide Fuel Cells: Fundamentals, Design and Applications, Edited by Singhal, S. C. and Kendall, K., Elsvier, Oxford, U.K.

Mawdsley, et al., 2007, "Post-Test Evaluation of the Oxygen Electrode from a Solid Oxide Electrolysis Stack and Electrode Materials Development," AIChE Meeting, Salt Lake City, UT, November 5-9, 2007. 
Müller, A.C., Weber, A., Herbstritt, D., and Ivers-Tiffée, E., 2003, "Long Term Stability of Yttria and Scandia doped Zirconia Electrolytes," Proceedings $8^{\text {th }}$ International Symposium on SOFC, Edited by Singhal, S. C., Dokiya, M., PV 2003-07, The Electrochemical Society, 196-199.

Ni, M., Leung, M. K. H., and Leung, D. Y. C., 2006, “A Modeling Study on Concentration Overpotentials of a Reversible Solid Oxide Fuel Cell,” J. Power Sources, 163, 460-466.

O’Brien, J. E., Stoots, C. M., Herring, J. S., and Hartvigsen, J. J., 2007, "Performance of Planar HighTemperature Electrolysis Stacks for Hydrogen Production from Nuclear Energy," Nuclear Technology, 158, 118-131.

O’Brien, J. E., Stoots, C. M., Herring, J. S., Condie, K. G., and Housley, G. K., 2009, “The HighTemperature Electrolysis Program at the Idaho National Laboratory: Observations on Performance Degradation," High Temperature Water Electrolysis Limiting Factors, Eifer, Karlsruhe, Germany, June 9-10.

Sohal, M. S., 2009, “Degradation in Solid Oxide Cells during High Temperature Electrolysis," Idaho National Laboratory Report INL/EXT-09-15617.

Singh, P., Pederson, L. R., Stevenson, J. W., King, D. L., and McVay, G. L., 2008, "Understanding Degradation Processes in Solid Oxide Fuel Cell Systems," Presented at the Workshop on Degradation in Solid Oxide Electrolysis Cells and Strategies for its Mitigation, Fuel Cell Seminar \& Exposition, Phoenix, AZ, October 27, 2008.

Steinberger-Wilckens, R. (2008). "Degradation Issues in SOFCs," Presented at the Workshop on Degradation in Solid Oxide Electrolysis Cells and Strategies for its Mitigation, Fuel Cell Seminar \& Exposition, Phoenix, AZ, October 27, 2008.

Stoots, C. M., Condie, K. G., O’Brien, J. E., and Housley, G., 2009, "Integrated Laboratory Scale Test Report," Idaho National Laboratory Report INL/EXT-09-15283.

Virkar, A. V., 2007, “A Model for Solid Oxide Fuel Cell (SOFC) Stack Degradation,” J. Power Sources, $172,713-724$.

Windisch, C.F., Stevenson, J. W., Simner, S. P., Williford, R. E., and Chick, L. A., 2002, "Experimentally-Calibrated Spreadsheet-based SOFC Unit-Cell Performance Model," Pacific Northwest National Laboratory, PNNL-SA-37014, presented at 2002 Fuel Cell Seminar: Fuel CellsReliable, Clean Energy for the World, Palm Springs, CA, November 21, 2002. 